University of Louisville

ThinkIR: The University of Louisville's Institutional Repository

Electronic Theses and Dissertations

$5-2018$

\title{
A qualitative case study examination of athlete ally using social movement theory.
}

Samuel H. Schmidt

University of Louisville

Follow this and additional works at: https://ir.library.louisville.edu/etd

Part of the Sports Studies Commons

\section{Recommended Citation}

Schmidt, Samuel H., "A qualitative case study examination of athlete ally using social movement theory." (2018). Electronic Theses and Dissertations. Paper 2967.

https://doi.org/10.18297/etd/2967

This Doctoral Dissertation is brought to you for free and open access by ThinkIR: The University of Louisville's Institutional Repository. It has been accepted for inclusion in Electronic Theses and Dissertations by an authorized administrator of ThinkIR: The University of Louisville's Institutional Repository. This title appears here courtesy of the author, who has retained all other copyrights. For more information, please contact thinkir@louisville.edu. 


\title{
A QUALITATIVE CASE STUDY EXAMINATION OF ATHLETE ALLY USING SOCIAL MOVEMENT THEORY
}

\author{
By \\ Samuel H. Schmidt \\ B.A. University of Wisconsin-La Crosse, 2013 \\ M.S. University of Louisville, 2014
}

\begin{abstract}
A Dissertation
Submitted to the Faculty of the

College of Education of the University of Louisville

in Partial Fulfillment of the Requirements

for the Degree of
\end{abstract}

Doctor of Philosophy in Educational Leadership and Organizational Development

Department of Leadership, Foundations, and Human Resource Education University of Louisville

Louisville, Kentucky

May 2018 
Copyright 2018 by Samuel Harold Schmidt

All rights reserved 

A QUALITATIVE CASE STUDY EXAMINATION OF ATHLETE ALLY USING SOCIAL MOVEMENT THEORY

\section{By}

Samuel H. Schmidt

B.A. University of Wisconsin-La Crosse, 2009

M.S. University of Louisville, 2014

A Dissertation Approved on

April 20, 2018

By the following Dissertation Committee:

\begin{tabular}{c}
\hline Meg G. Hancock, Chair \\
Mary A. Hums \\
\hline Evan Frederick \\
\hline Meera Alagaraja
\end{tabular}




\section{DEDICATION}

To my family: Christine, Paul, Ryan, Kate, Kellie, Muriel, (Little) Harold, Ruth,

(Grandpa) Harold, Anthony, and Geraldine 


\section{ACKNOWLEDGMENTS}

I want to express my deepest gratitude to all those around me who have guided me throughout my doctoral process.

Dr. Meg Hancock - You have been a great mentor and even better friend over the past five years. Your leadership and mentorship have helped me grow as a person and a professional immensely. Words cannot express my appreciation for everything you have provided me.

Dr. Mary Hums - You have always been a great mentor to me, ever since I entered the Master's program. The number of times I visited you in your office and we engaged in a lengthy conversation about politics, sport's platform, and our Midwest background are too many to count.

Dr. Meera Alagaraja - You helped open the world of qualitative inquiry to me. It was in your class that I was allowed to explore my positionality in research and understand that research can be used to empower. Truly, that is a welcomed gift.

Dr. Evan Frederick - Your guidance over the past two years are invaluable. You've helped me with tremendous mentorship in all aspects of my professional career.

Dr. Megan Shreffler - Your role in my career/life has been invaluable. You provided me with a chance, encouraged me to engage in research, and sent me down a path that I find great joy and purpose in. "Choose a job you love, and you will never work a day in your 
life" is a cliché quote that I believe in. You provided that opportunity in my life and I cannot say thank you enough.

Dr. Hambrick - You are someone that everyone should look up to. Your work habits inspire all around you, while simultaneously having some of the work-life balance of anyone I know. Engaging in the community and with my passions are two lessons that I have learned from witnessing you.

Dr. Chris Greenwell - Thank you for everything over the past few years. You provide a strong mentor to all doctoral students. The WWE events, trivia, and movie nights show us the passion and love you have for the doctoral students.

Dr. Anita Moorman - You once said, "Hope is a terrible strategy." This is a quote that I use more often than you imagine. I always stop myself when I "hope" something will work out and enact change to ensure something will work out. Ms. Gin Presley - Without a doubt the best teacher in our department. You have served as a great mentor as I have learned to navigate the classroom. The dedication to your students is bar none at this university. I want to thank you a thousand times for your mentorship, but that would truly not be enough.

Linh - Someone who has been by me throughout my entire doctoral process. I cannot be more in awe of the love and support you provide me every day. You push and inspire me to be a better person, something I hold very dear to my heart. Thank you so much.

I would also like to thank the other mentors in my life. Dr. Brian Gordon provided my initial interest sport's impact on society. Had it not been for his Sport and Sociology class, I do not believe I would be where I am today. Dr. Matt Huml has served as a tremendous mentor and friend over the past few years. He provides a bright light for all 
of the doctoral students to follow. In addition, my family members have provided me with all the love in the world. They have guided me and molded me every day of my life. I carry the lessons and teachings you have provided me so that I can help make this world a better place.

Finally, I wanted to acknowledge Athlete Ally. The organization helped me achieve a dream project for my dissertation. The organizational staff is comprised of amazing people who work endlessly to actually create social change in and out of sport. The work you do is inspiring and immensely underappreciated. Thank you. 


\section{ABSTRACT \\ A QUALITATIVE CASE STUDY EXAMINATION OF ATHLETE ALLY USING SOCIAL MOVEMENT THEORY \\ Samuel H. Schmidt}

April 25, 2018

The following study answered the call for more social movement related studies in sport (Davis-Delano \& Crosset, 2008) and lessened the paucity of literature on athlete activism. The purpose of this study was to examine a sport specific social movement organization, Athlete Ally, using Social Movement Theory. Social Movement Theory is guided by three tenets: Resource Mobilization Theory (Edwards \& McCarthy, 2004), Political Process Theory (Kriesi, 2004), and Cultural Theory/Frame Analysis (Williams, 2004). Each of these tenets was used to examine the resources exchanged between Athlete Ally and their athlete constituents, determine the strategies for engaging with various sport (i.e. NCAA and NBA) and non-sport governing bodies (i.e. U.S. Government), and understand the tactics for ensuring frame resonance by Athlete Ally. The following qualitative case study was conducted through seven employee or board member interviews with Athlete Ally and an examination of salient organizational documents.

Findings indicate that a SMO can provide resources to minimize the impact of negative consequences for engaging in activism. For instance, providing a safe space and 
access to other athlete activists can allow an athlete to engage in activism knowing a SMO is supporting the athlete. On the other side, athletes also provide SMOs with resources, most notably a vast social-network of other constituents. From recruitment of other athlete ambassadors, like teammates, or raising awareness for the organization, athletes can be proficient resources that few other celebrities can match. Those resources can then be utilized to engage with various governing bodies. Typically, when Athlete Ally engages with a protagonist entity, they employ strategies of collaboration. Conversely, Athlete Ally utilizes combative strategies when faced with an antagonistic entity. Despite these strategies, Athlete Ally has to ensure their frames resonate with the intended audience to actually enact change. Athlete Ally accomplishes this by utilizing athletes' stories, objective statistics, and a diverse staff to increase the salience of their messages. Further findings and results are discussed. Overall, the study's findings speak to the mutually beneficial relationships sport specific SMOs and athletes can develop to further the goals of a social movement organization 


\section{TABLE OF CONTENTS}

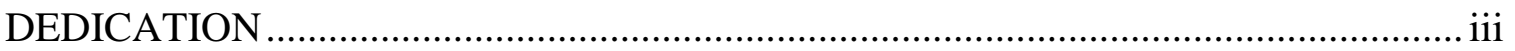

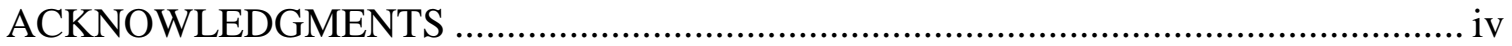

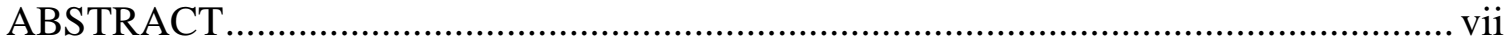

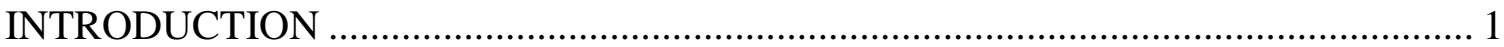

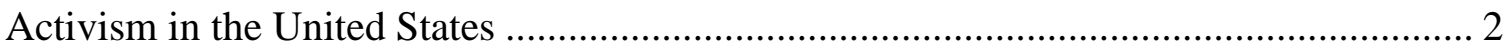

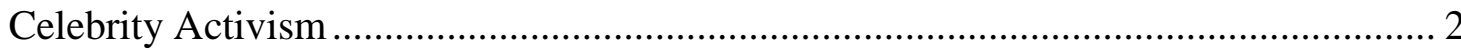

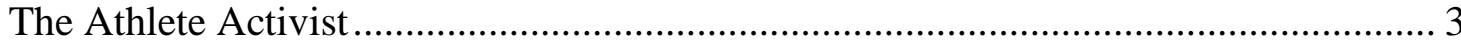

Silence of the 1990-2000s Athlete Activist ............................................................. 5

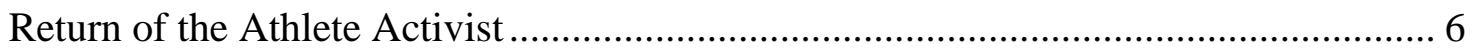

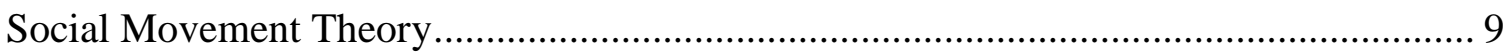

Resource Mobilization Theory (RMT) ……………......................................... 10

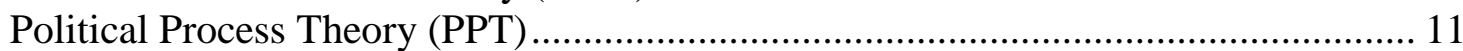

Cultural Theory/Frame Analysis....................................................................... 12

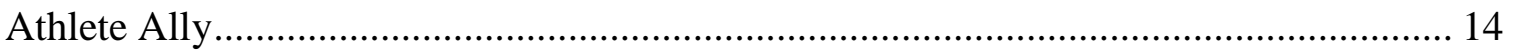

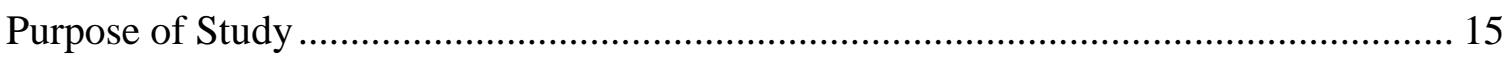

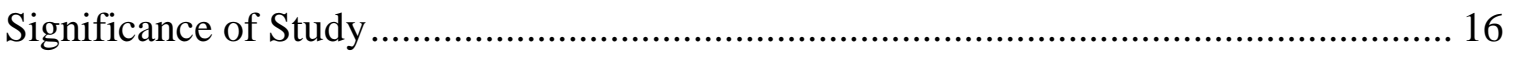

Research Questions ............................................................................................. 17

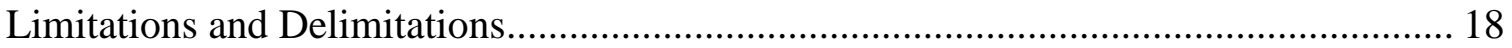

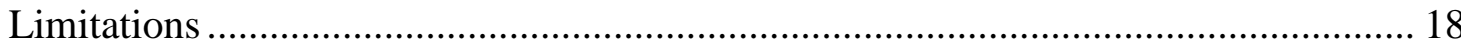

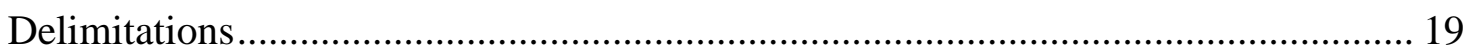

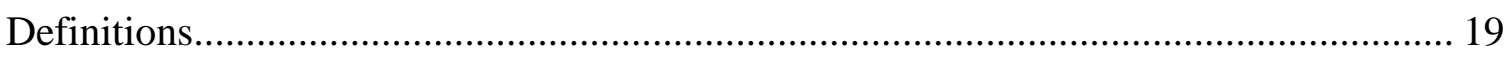

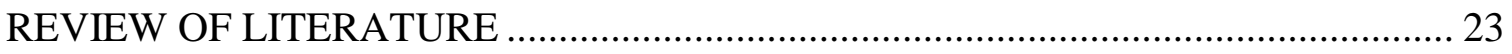

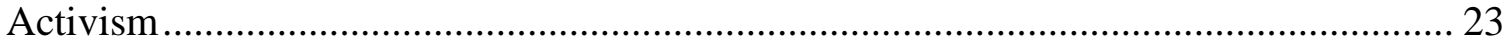

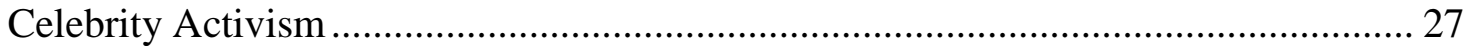

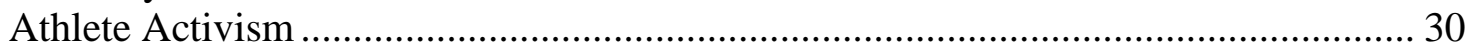

Social Movements and Social Movement Theory …………........................................ 36

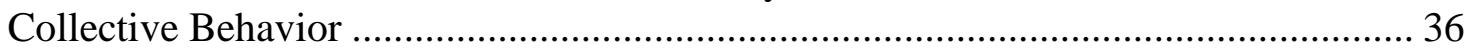

Social Movements and Social Movement Organizations ........................................... 40

Social Movement Theory....................................................................................... 44

Resource Mobilization Theory …………………….......................................... 45

Political Process Theory ..................................................................................... 53

Cultural Theory/Frame Analysis.......................................................................... 60

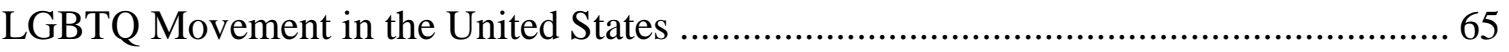

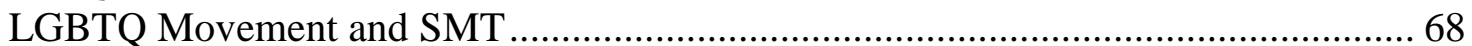

LGBTQ Movement and Sport .................................................................................... 72

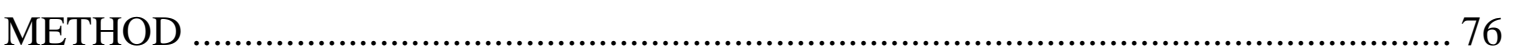


Purpose

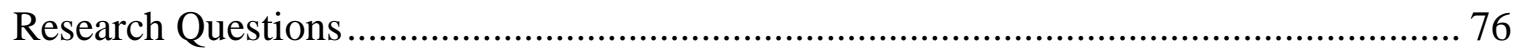

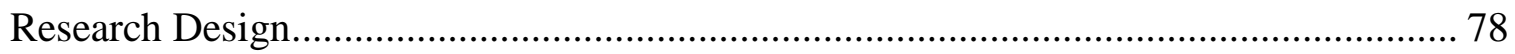

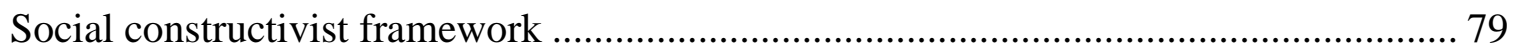

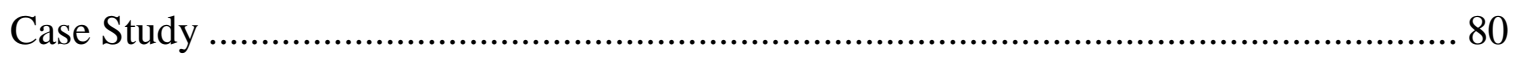

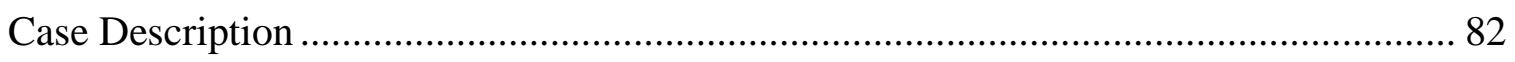

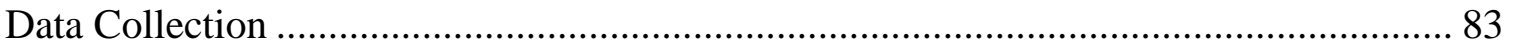

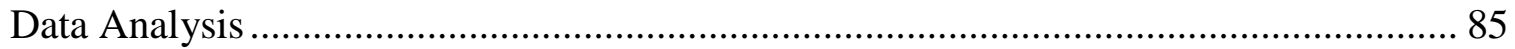

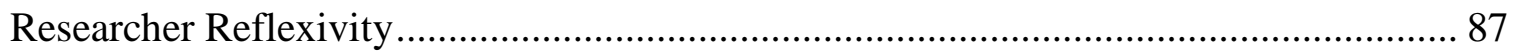

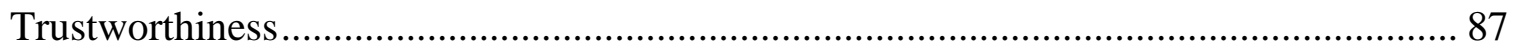

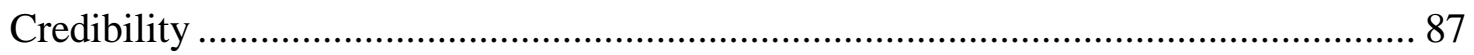

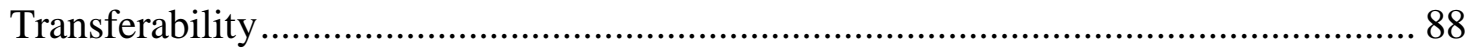

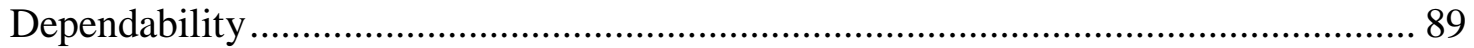

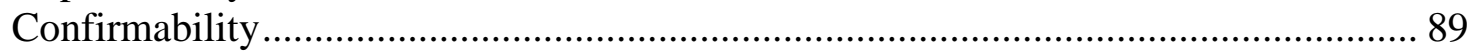

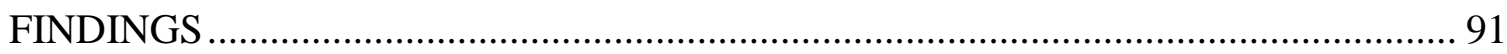

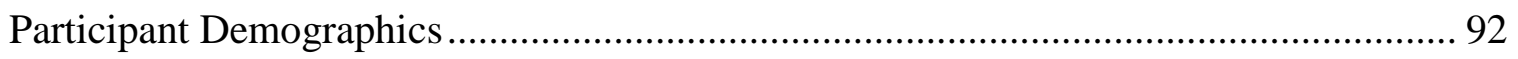

RQ1a: What resources does Athlete Ally provide its athlete constituents?...................... 93

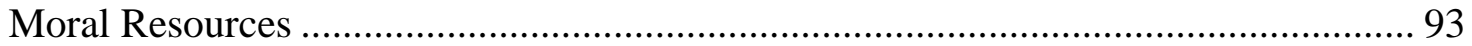

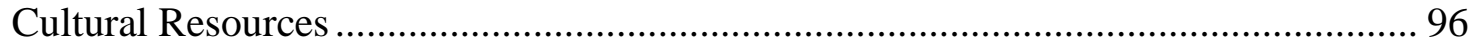

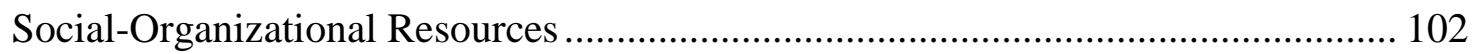

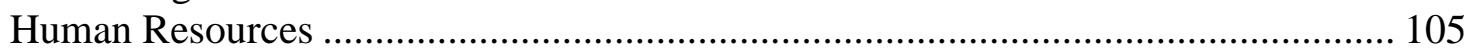

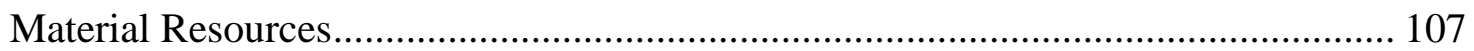

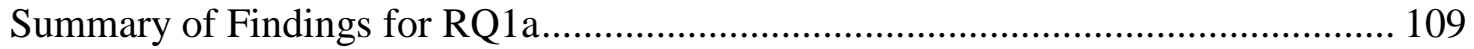

RQ1b: What are the perceived resources athletes provide Athlete Ally?....................... 111

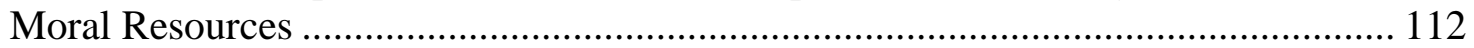

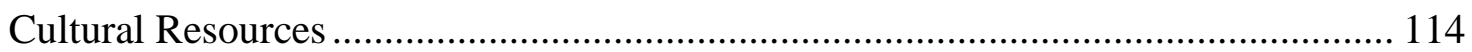

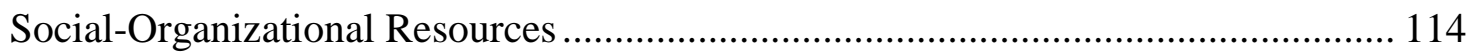

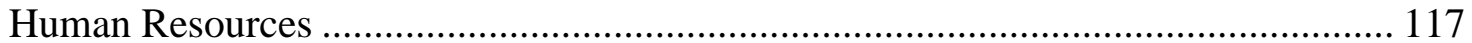

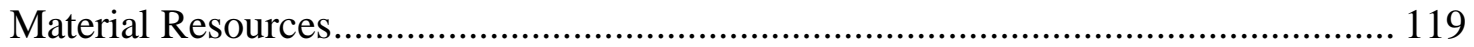

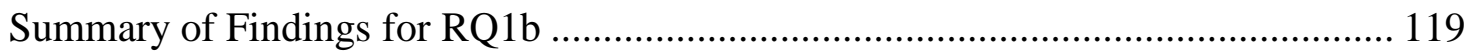

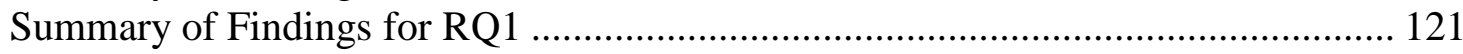

RQ2: What strategies does Athlete Ally utilize to engage with various governing bodies?

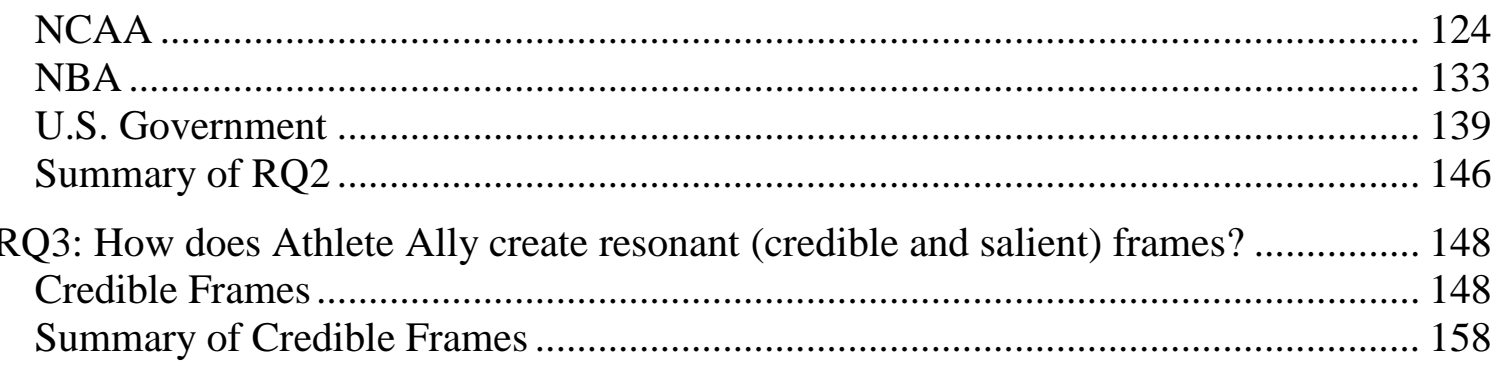




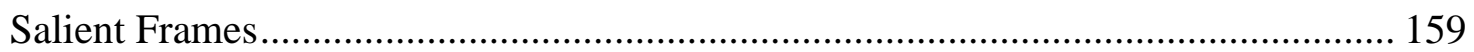

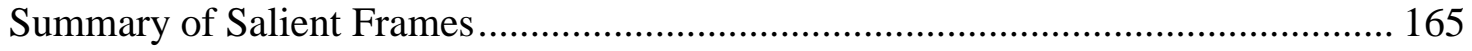

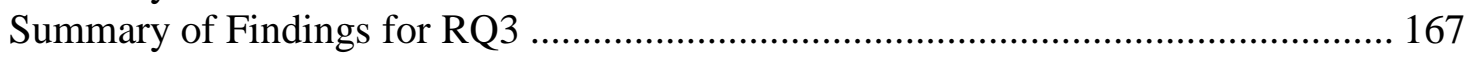

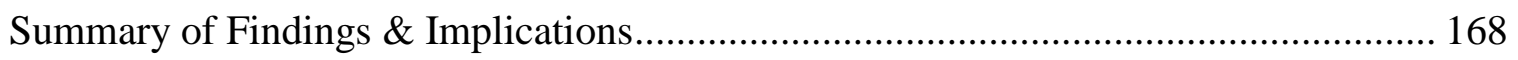

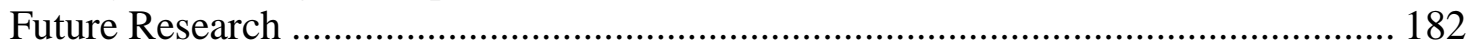

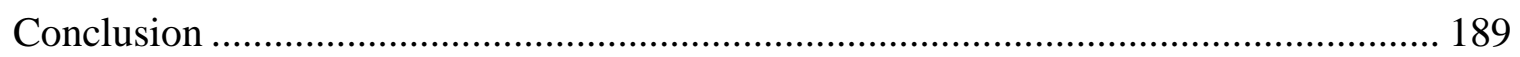

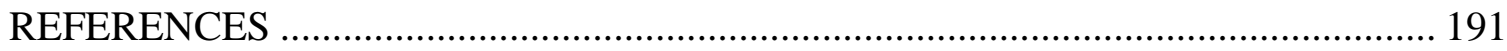

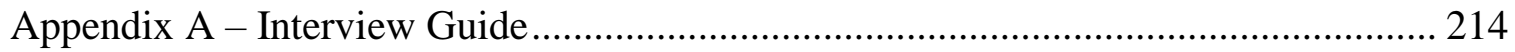

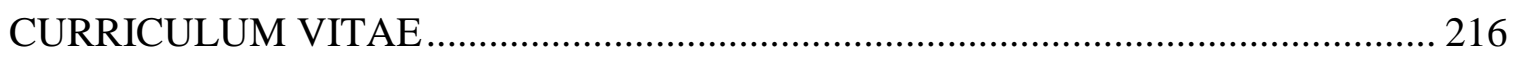




\section{CHAPTER I}

\section{INTRODUCTION}

In 2014, Travis Waldron of ThinkProgress questioned where and why the athlete activist had disappeared (Waldron, 2014). Waldron argued the days of social justice oriented athletes like Muhammad Ali, Billie Jean King, Tommie Smith, and John Carlos were gone, replaced by a generation of athletes unconcerned with the plights of the world (Candaele \& Dreier, 2015). Just two years later, the Ross Initiative in Sports for Equality, a non-profit organization concerned with unifying the power of sport to improve race relations and encourage social progress, released the From Protest to Progress: Athlete Activism in 2016 (Ross Initiative in Sports for Equality, 2017). The report listed 225 examples of athlete and team activism from July 8, 2016, to October 29, 2016. The sharp increase in athlete activism was attributed to the culmination of several major social events: the deaths of Trayvon Martin, Eric Garner, and Michael Brown at the hands of law enforcement officers and subsequent release of the officers without being charged in the deaths; the pay and field condition disparity between men and women soccer players; North Carolina's HB2 law, which legislated individuals must use the restroom of their birth sex; and, the Orlando shootings at a gay nightclub. These events and many others were catalysts for the return of the athlete activist. 


\section{Activism in the United States}

Since the 1960s, during the time of tremendous civil unrest in the United States, research on social movements and activism flourished. Activists were more likely to be affluent, which meant they were more likely to have the necessary resources (time, money, and skills) to engage in activism (Brady, Scholzman, \& Verba, 1999). Moreover, these young activists often did not have children, had freedom from work, and the ability to structure their own schedules (Wiltfang \& McAdam, 1991). Activists were drawn into their work through their social networks (Louis, Amiot, Thomas, \& Backwood, 2016) and ideological commitment to social issues (Fendrich, 1977). Activists often entered full-time employment later, changed jobs more frequently, and earned less than their nonactivist counterparts (McAdam, 1989). Still, activists reported high levels of life satisfaction, personal growth, and social well-being. One group receiving a considerable amount of scholarly attention was celebrity activists, as they could provide a greater impact using their resources and social networks to advocate for social injustices.

\section{Celebrity Activism}

Celebrity activists bring a number of benefits to a social cause or organization. They design products to sell in support of charitable organizations; facilitate access to people with social, political, and economic power; promote general awareness; and campaign, fundraise, and reward existing supporters (Brockington, 2014). The greatest benefit celebrities offer an organization is the ability to communicate the issue to the public through the broad platform given to them by their status (Kogen, 2015; Thrall et al., 2008). In short, celebrity activists are popular and have access to influential means of communication. The celebrity activist, however, can struggle to garner public support if 
s/he seems disingenuous toward the issue (Panis \& van Den Bulck, 2012) or fails to effectively articulate what non-celebrity individuals can do to help the humanitarian efforts (Kogen, 2015). Despite these criticisms, actors, musicians, writers, and other nonathlete celebrity activists are viewed more positively for their social justice when compared to another group of celebrity activists - athletes (Kaufman, 2008; Kaufman \& Wolff, 2010).

\section{The Athlete Activist}

The history of prominent athlete activism in the United States often begins in the 1960s and 1970s. Tommie Smith and John Carlos' activism at the 1968 Summer Olympic Games showed the platform prominent athletes could have in society (Smith \& Steel, 2008). Their actions were a part of a greater era of athlete activism. Muhammad Ali's activism, just a few years prior to Smith and Carlos, is widely recognized in sport, politics, and popular culture. In 1967, Ali famously refused induction into the U.S. Army citing religious beliefs and an opposition to the Vietnam War. He was stripped of his title, banned from boxing, and convicted of draft evasion (Gonyea, 2016; Orkand, 2017). Another activist, Billie Jean King, used her prominence for equal pay for female athletes; gender equality; lesbian, gay, bisexual, and transgender (LGBT) rights; and women's reproductive health (Shuster, 2013; Sanchez, 2017). In 1973, the same year she beat Bobby Riggs in the "Battle of the Sexes" (Smith, 2010), King founded the Women's Tennis Association (WTA), a league specifically for female tennis players. Later she was instrumental in the formation of the Women's Sports Foundation.

The activism by the aforementioned athletes, and many others not mentioned here, created the golden age of athlete activists (Hodges \& Fanning, 2017). Individually, 
athlete activists steadily engaged with social justice and activism. Yet, each of these athletes was not alone in their beliefs and work. For example, the Olympic Project for Human Rights (OPHR) supported Smith and Carlos. The OPHR, established by sociologist and activist Harry Edwards, was a project aimed at: (a) staging international protests of the violation of Black people's human's rights in the US, (b) exposing exploitation of the Black athlete in the US, (c) establishing an agenda of social responsibility by the Black athlete for the Black community, and (d) educating the Black community of the consequences of their sport involvement (Edwards, 1979). To raise awareness, the OPHR created pins for their athletes to wear. The OPHR pins can be seen on Smith, Carlos, and Australian silver medalist Peter Norman's jackets on the 1968 podium when Smith and Carlos raised their fists. The OPHR was a main driving force supporting the athletes as they stood on the platform. Tommie Smith, in his autobiography, noted that he was obligated to win the 1968 Olympic 200-meter race because of the OPHR (Smith \& Steele, 2008). Muhammad Ali's racial and anti-war activism was built upon the foundation of the Islamic faith. He found support for his stance from other Muslims. His strong belief in his faith provided unwavering inspiration as he lost millions of dollars, his title, and his prime athletic years (Czech, 2016). King's self-started organization, the Women's Tennis Association, provided her with motivation when Bobby Riggs challenged her in the Battle of the Sexes. King knew she had to beat Riggs for women everywhere and to ensure the success of the Women's Tennis Association (Chapin, 2017). It is evident that the persistence of these athlete activists was in part due to the organizations supporting them. Whether the support came in the form of tangible materials, like the OPHR pins (Edwards, 1979), or intangible sources like faith 
(Czech, 2016) or the need to succeed to further advance the women's movement (Chapin, 2017), athletes benefited from having that organizational support.

\section{Silence of the 1990-2000s Athlete Activist}

The golden era of athlete activism did not persist into the 1990s and 2000s. Money, fame, and respect overrode the desire to speak out against injustices in society (Candaele \& Dreier, 2015; Powell, 2008;). During the 1960s, when boxing and baseball were prominent sports in the United States, athletes were earning little more than the urban working class (Candaele \& Dreier, 2015). The earning potential from the 1990s/2000s television contracts and commercial endorsements vastly outpaced the earning potential in the 1960s. Thus, the financial implications were greater in the 1990s/2000s than in the 1960s/1970s.

Michael Jordan most embodies the notion that financial implications lead to the decrease in activism (Agyemang, 2011; Powell, 2008). Despite his popularity and global influence, Jordan refused to address issues of race in his home state or sweat shops and child labor issues with Nike (Agyemang, 2011). Additionally, Agyemang postulates that the "Be Like Mike" commercial from Nike served as a reminder to young Black athletes to remain silent like Mike. Some notable athletes became activists during this time period, however. Craig Hodges, teammate of Jordan during the late 1980s and early 1990s Chicago Bulls teams, was outspoken about discrimination against Native Americans, the poor and homeless, and the Black community in the United States (Hodges \& Fanning, 2017). Brandi Chastain, of the 1999 Women's National Soccer Team, became an advocate for Title IX and gender equality (Macur, 2014). Despite 
Hodges' and Chastain's individual activism, many athletes during this time remained silent.

Athlete activism research helps explain why the silence occurred. Research shows athletes may experience verbal retaliation from fans, media, coaches, and administrators (Agyemang, Singer, \& DeLorme, 2010; Frederick, Sanderson, \& Schlereth, 2017; Kaufman, 2008; Sanderson, Frederick, \& Stocz, 2016) if they are vocal about a social or political issue. Perhaps, it is because there is a belief that sport is neutral and exists outside of the political realms (Sage, 1998). In addition, the value of a sponsor's brand image decreases when an athlete activist endorses the organization (Schmidt, Shreffler, Hambrick, \& Gordon, 2018), resulting in potential negative financial consequences for the athlete and his/her associated sponsors. The overall negative consequences for a modern-day athlete seemed too grand to overcome for Jordan and other prominent athletes during this time frame.

\section{Return of the Athlete Activist}

Today's athletes are an integral part of various and diverse social movements. Whether it is Black Lives Matter, the Women's Movement, or the LGBT Movement, high profile athletes are returning to activism (Washburn, 2016). Prompted by the Trayvon Martin's death in 2012, prominent athletes like LeBron James and Dwyane Wade, along with the rest of the Miami Heat players, began to speak out against social injustices (Schmittel \& Sanderson, 2015). The world, unfamiliar with prominent athletes using their platform to highlight the plights of the oppressed, was witnessing the return of the athlete activists. Athletes from multiple leagues have recently utilized their platforms for activism spanning multiple issues. Over 50 Olympic athletes joined the Principle 6 
campaign to protest the "anti-gay" Russian laws at the 2014 Winter Olympic Games in Sochi, Russia (Principle 6, n.d.). The protests took to the field as five St. Louis Rams players raised their arms in a "hands up, don't shoot" manner during player introductions to honor the death of Michael Brown (Sanderson, Frederick, \& Stocz, 2016) and LeBron James and several National Basketball Association (NBA) players wore "I Can't Breathe" T-shirts during pregame warm-ups, breaking the NBA dress code to bring awareness to the death of Eric Garner (Adande, 2014). College athletic teams, like the University of Missouri football team, threatened to boycott the rest of their season if the social climate towards minority populations did not change on Missouri's campus (Maese \& Babb, 2015). In women's international and professional sport, the USWNT protested pay discrimination (Das, 2016) and, in the Women's National Basketball Association (WNBA), players stood up for Orlando Pride and the Dallas police officer shootings (Dator, 2016; Kennedy, 2016), In a strong act, Carmelo Anthony, LeBron James, and Chris Paul's speech highlighted social injustices in the US during ESPN's ESPY Award show (Grossman, 2016), only to be followed up by Colin Kaepernick's kneeling during the anthem of a National Football League (NFL) game to protest the oppression of Black and marginalized voices in the US (Wyche, 2016). Kaepernick's protest, specifically, was viewed as culminating moment for athlete activism as over 100 NFL players, Megan Rapinoe of the USWNT, and individuals in at least 52 high schools, 43 colleges, one middle school, and two youth leagues in 35 states joined in Kaepernick's protest (Gibbs, 2016). The aforementioned cases of athlete activism show the diversity and prominence of athlete activism in the mid to late 2010s in the United States. Whether it was the Black Lives Matter movement, Women's movement, LGBTQ movement, student's rights 
movement, or any other movement, athletes using their platform joined in protest to help advance social movements in the United States.

Every one of the activism efforts mentioned above was either supported by several athletes or a formal organization. Just like the activists of the 1960s and 1970s, today's athletes work with informal and formal groups to spread their message. The NFL players kneeling during the anthem to bring awareness to racial injustices in the US are an example of an informal group supporting each other as teammates. Formally, athletes like Colin Kaepernick (Know Your Rights Campaign) and Megan Rapinoe (Athlete Ally) perform activism with support from social movement organizations (SMOs). Just as they do for activists from a variety of backgrounds, SMOs can provide support for athletes, while working with political entities and the public. Further, SMOs may help mitigate the negative consequences athletes experience for their social and political advocacy.

Athlete activists, and their collaborative SMOs, are important to study as they can provide a major influence in social movements. Athlete activists are celebrity activists with the ability to reach large numbers of people given their profession. When given a chance, athletes like Tommie Smith, John Carlos, Billie Jean King, Colin Kaepernick, and Megan Rapinoe use their platform to influence the public on issues like racial oppression in the U.S. and LGBTQ rights. Each of these athletes was supported by a formal organization, in most cases a SMO, to assist in their political and social activism. For Smith and Carlos, the OPHR was a crucial resource, Billie Jean King was given confidence from the Women's Tennis Association, Colin Kaepernick has partnered with the Know Your Rights Campaign, a campaign to help youths be education on law enforcement interactions, and Megan Rapinoe became an athlete ambassador for the 
LGBTQ SMO Athlete Ally. Through the study of sport specific SMOs we can begin to try and understand how athletes, in conjunction with SMOs, impact modern day social movements.

\section{Social Movement Theory}

After witnessing the social movements of the 1960s and 1970s, the call for a specific theory on social movements was answered in the 1980s (della Porta \& Diani, 2006). Prior to the 1960s and 1970s, social movements were not viewed as deliberate and organized collective action, but spontaneous riots and crazes (Buechler, 2004). In the 1960s and 1970s, however, a group of movements broadly known as the New Left movements, occurred in the United States. The New Left movements included such movements as the Civil-Rights movement, women's right movement, LGBT movement, and the anti-Vietnam War movement, among others (Broadhurst, 2014). The wave of New Left movements led social movement researchers to question the spontaneous and random nature of new social movements based on cultural and identity issues (della Porta \& Diani, 2006; Williams, 2004). Through the constant discourse on newer social movements, Social Movement Theory (SMT), the theoretical foundation for studying social movements, was established. Three main theoretical tenets of SMT emerged: Resource Mobilization Theory (RMT), Political Process Theory (PPT), and Cultural Theory/Frame Analysis. While Davis-Delano and Crosset (2008) noted two additional theoretical tenets of SMT, Collective Behavior Theory and New Social Movement Theory, their findings revealed RMT, PPT, and Cultural Theory/Frame Analysis were present in sport specific social movements. The three theoretical tenets of SMT (i.e., 
RMT, PPT, and Cultural Theory/Frame Analysis) provide a holistic lens to view a social movement theory and its components.

\section{Resource Mobilization Theory (RMT)}

The RMT approach investigates how groups overcome prevailing patterns of resource inequality in their pursuit of social change (Edwards \& McCarthy, 2004; McCarthy \& Zald, 1977). RMT targets meso-level analysis, focusing on the organization as a whole (Buechler, 1993). Specifically, RMT provides a lens for investigating what resources SMOs utilize for advocacy and/or for their members, the attributes of those resources, and how resources are acquired. For example, Cress and Snow (1996) investigated 15 SMOs that worked with homelessness in the United States. In their investigation into the types of resources gathered by the SMOs, Cress and Snow noted that having a single benefactor (one main donor) increases the chances of survival by the SMO. Within sport, Wilson, van Luijk, and Boit (2015) utilized RMT to investigate Kenyan Olympic runners' influence on a Run-For-Peace in Africa. The Run-For-Peace events were a series of running events organized by elite Kenyan runners intended to promote reconciliation between the Kikuyu and the Kalenjin, two prominent Kenyan ethnic groups. The Kenya runners provided phenomenal resources for the eace movement, including, but not limited to: event promotion, transportation, volunteer recruitment, legitimacy for the event, sponsorships and money, and other resources through their athlete connections. The study showed the resources athletes could provide support to an advocacy event, but not necessarily how the SMO might support the athlete. 


\section{Political Process Theory (PPT)}

Political Process Theory investigates political entities (i.e. the United States government, Russian government) and their influence on social movements. Expanding to a macro-level analysis, PPT focuses on the factors external to movements that can determine the movement's ability to succeed (Caniglia \& Carmin, 2005). The framework splits into three variables: political opportunity structures (POS), configurations of actors/power, and interaction contexts (Kriesi, 2004). At its base, the POS analyzes the dominant political entity of a country as open or closed, centralized or decentralized, and weak or strong. The United States, being a decentralized government, is both weak and open, allowing for easy access into the political system (Kriesi, 2004). Once the POS is identified, the configuration and power of the actors can be examined.

Actors are categorized as protagonists, antagonists, and bystanders (Hunt, Benford, \& Snow, 1994). Protagonists are ally policy makers, public authorities, media members, and related movements. For instance, President John F. Kennedy was a protagonist to the civil rights campaign. Antagonists are adversarial to social movements including counter-movements, repressive agents, and other public authorities. An example of an antagonist are Republican senators to the Green movement (McAdam, 2017). Bystanders are not directly involved with the social movement, but attentive to the social climate (Kriesi, 2004). The general public, not associated with a social movement one way or the other, is the most obvious example of a bystander. The interaction context, influenced by the Political Opportunity Structure and configuration/power of actors, constitutes the last level of PPT. This level is concerned with strategies utilized by social movements, SMOs, and their opponents by linking structures and configuration to 
agency and action (Kriesi, 2004). For example, Bernstein (1997) noted the different strategies LGBT SMOs utilized with various political entities in the 1970s. In New York, LGBT SMOs relied on antagonist and grass roots mobilization strategies as the political actors were antagonist to the LGBT SMOs missions. Conversely, in Oregon, LGBT SMOs worked behind closed doors to create policy and influence legislation as the political actors were protagonists to LGBT SMOs. In sport, Pelak (2005) noted the postapartheid peace movement through netball. During apartheid, the African government instituted separate sport federations for Africans, Whites, Coloreds, and Asians (Booth, 1998). Once apartheid ended and the political opportunities were opened up, allies of the peace movement desegregated netball leagues to bolster peace efforts in Africa. Pelak's study only investigated national political structures and not local or sport-specific governance structures.

\section{Cultural Theory/Frame Analysis}

The final theoretical tenet of SMT is Cultural Theory/Frame Analysis (Williams, 2004). Post-World War II, social movements focused on the cultural understandings, norms, and identities (i.e., LGBT equality, race relations, etc.) instead of economic distribution and material differences (i.e., working class and elites). The result was a focus on affirmation of expressive needs (della Porta \& Diani, 2006) through symbols, language, discourse, identity, and other cultural artifacts influencing members to join, mobilize, and sustain membeship (della Porta \& Diani, 2006; Williams, 2004).

One of the main forms of SMT analysis uses an advocacy organization or actor's frame. Frames (Goffman, 1974) are the interpretive schemas that enable individuals to "to locate, perceive, identify, and label occurrences within their life space and the world 
at large" (Snow, Rochford, Worden, \& Benford, 1986, p. 464). Frames allow SMOs and advocacy organizations to mobilize activists around certain messages or symbols (della Porta \& Diani, 2006). For instance, the LGBT movement uses a rainbow flag to mobilize activists and symbolize LGBT sexuality (Alimahomed, 2010).

Social movements frames can differ in several ways: problem identification and direction/locus of attribution, flexibility and rigidity, inclusivity and exclusivity, interpretive scope and influence, and resonance (Benford \& Snow, 2000). While each frame can be used to interpret social movements, resonance is important to understanding the success of frames. For instance, one major criticism of celebrity activism is that celebrities fail to effectively articulate the frames of the organization to the non-celebrity public (Kogen, 2015). Thus, the celebrity (in this case athlete) who is unable to articulate the frames fails to clearly articulate the importance of the message to the public. Two sets of factors describe frame resonance: credibility and salience (Benford \& Snow, 2000; della Porta \& Diani, 2006; Williams, 2004). Schwirian, Curry, and Woldoff (2001) noted the importance of frame resonance in a movement aimed at preventing public fundraising for an arena and stadium in Columbus, Ohio. The arena opposition framed the issue of public funding as corporate welfare, class privilege, fiscal irresponsibility, and the righteous citizen. The frames resonated with voters as they captured their values, beliefs, and priorities. The result was victory for the anti-public funding movement as voters opted not to fund the stadium and arena (Schwirian, Curry, \& Woldoff, 2001). The frame analysis did not include the use of professional athletes as frame articulators, however.

Resource Mobilization Theory, Political Process Theory, and Cultural Theory/Frame Analysis provide a holistic lens to view a social movement and its 
components. These three tenets allow the researcher to investigate the organizational, political, and cultural landscape of a social movement organization in the context of society. In the study at hand, these three areas of SMT will be applied to the social movement organization Athlete Ally to better understand the resources provided to and from athlete activists, influence of various political structures, and frames of resonance (credibility and salience).

\section{Athlete Ally}

Athlete Ally is a pro-LGBTQ, 501c-3 nonprofit organization that provides public awareness campaigns, pro-ally programming, and other tools to foster inclusive sport environments (Athlete Ally, n.d-a). Hudson Taylor, a straight ally to the LGBTQ movement, created Athlete Ally in 2011. An ally is defined as "a person who is a member of the dominant or majority group who works to end oppression in his or her personal and professional life through support of, and as an advocate with and for, the oppressed population" (Washington \& Evans, 1991, p. 195). Throughout high school and college, Taylor recognized the homophobic language utilized in sport. He befriended LGBTQ students as a student-athlete at the University of Maryland, when he recognized the negative effects of homophobic behavior. While wrestling, Taylor wore an LGBTQ equality sticker from the Human Rights Campaign on his headgear to stand in solidarity with the LGBTQ community. As expected, he received criticism from his peers. Taylor, however, received positive attention from parents and closeted athletes. His experience encouraged him to start Athlete Ally (Athlete Ally, n.d.-a).

The governing structure of Athlete Ally consists of a 20-member board of directors, four directors and two coordinator positions, and 22 advisory board members. 
Despite the large number of board members, Athlete Ally only employs 5 full-time staff. The employees work with and offer support to athletes, sport organizations, and government actors on a personal level to bring about social change. In addition to employees and the advisory board, Athlete Ally has formal partnerships with professional, Olympic, and collegiate athletes, called athlete ambassadors (professional and Olympic) and campus ambassadors (college). Athlete ambassadors are professional and Olympic athletes from all over the world: Kenneth Faried of the NBA, Sue Bird of the WNBA, Mollie Lensig of Major League Quidditch, and Imke Duplitzer of the German Olympic fencing team, to name a few. Athlete Ally currently has a relationship with over 150 athlete ambassadors. Athlete ambassadors help promote the mission of Athlete Ally to peers in their sport and their fan bases (Athlete Ally, n.d.-d). Campus ambassadors are primarily athletes who represent, recruit, and mobilize resources for Athlete Ally.

Athlete Ally can be considered a SMO because it "carries movement strategies, resources, goals, and collective identities" (Minkoff, 2002, p. 263). The organization goes beyond the classification of an interest group as SMOs are more focused on collective good compared to interest groups (Andrews \& Edwards, 2004). The organization is one of many SMOs in the gay and lesbian movement, but unique to sport. By examining the structure and dynamics of Athlete Ally, we can learn about activism in sport at a SMO level.

\section{Purpose of Study}

After decades of silence on social issues, (Agyemang, 2011; Candaele \& Dreier, 2015; Powell, 2008), the athlete activist has triumphantly returned with the assistance of 
other athletes and formal organizations (Coombs \& Cassilo, 2017; Gibbs, 2016; Ross Initiative in Sports for Equality, 2017). Formal SMOs, like Athlete Ally, can provide numerous benefits for athletes engaging in activism as they provide the basis of mobilization for social movements (Caniglia \& Carmen, 2005). Athlete Ally is one specific SMO dedicated to lesbian, gay, bisexual, and transsexual acceptance in sport. Other organizations have mobilized or may begin to mobilize for other social injustices, like racism, gender inequality, poverty, and other societal plights reflected in society and sport. The use of athlete activists, akin to celebrity activists by magnitude of star power, may provide a boon to these organizations as athletes can provide unique resources (e.g., legitimacy, event promotion, broad communication platform; Brockington, 2014) and ability to access political entities (Wilson et al., 2015). Therefore, the purpose of this study was to investigate the resources exchanged between Athlete Ally and their athlete constituents, tactics for engaging with various governing bodies, and tactics for ensuring frame resonance by Athlete Ally using Social Movement Theory.

\section{Significance of Study}

The study's significance impacts SMT, SMT research within sport, and athlete activism. From a theoretical standpoint, the present study investigates resources exchanged between SMOs and activists. Prior studies have investigated the resources SMOs provide activists (i.e. Cress \& Snow, 1996), but not how activists provide the SMO with resources. Further, the study attempted to investigate how a SMO interacts with a sport governing body (i.e. NCAA and NBA), not just non-sport governing bodies (i.e. U.S. Government; Kriesi, 2004). Finally, the study examined the use of celebrity through an investigation of frames. Additionally, the study attempted to bring more 
knowledge of a sport SMO into SMT literature. Social Movement Theory's application to sport and social movements has been limited (Benford, 2007; Davis-Delano \& Crosset, 2008; Harvey, Horne, \& Safai, 2009; McDonogh, 2011; Schwirian, Curry, \& Woldoff, 2001; Wilson et al., 2015). Only three known sport-based studies have utilized RMT, PPT, and Cultural Theory/Frame Analysis (Davis-Delano \& Crosset, 2008; McDonogh, 2011; Wilson et al., 2015). This study is distinguished from previous studies as it focused on a sport specific SMO, instead of a sport event or temporary sport league. From a social movement perspective, this study answered the call from Davis-Delano and Crosset (2008) who encouraged social movement research in sport to "serve social movements that they value by doing research that may help the activists to understand how their movements succeed and fail" (p. 131). Finally, the study may offer insight into a prominent SMO's use of resources, political context, and frames. Other social movement and advocacy organizations can use the findings from this study to provide similar mechanisms of support to recruit and retain athletes, understand the political context of US society, and ensure their frames are credible and salient to their audience.

Additionally, athlete activists can understand potential mechanisms of support to help lessen the burden of athlete activism and encourage athletes to stand up against the social inequalities in society.

\section{Research Questions}

Therefore, the purpose of this study investigates the resources exchanged between Athlete Ally and their athlete constituents, tactics for engaging with various governing bodies, and tactics for ensuring frame resonance by Athlete Ally using Social Movement Theory. 
The above purpose will be achieved by answering the following research questions:

RQ1a: What resources are provided from Athlete Ally to athlete constituents?

RQ1b: What are the perceived resources athlete constituents provide Athlete Ally?

RQ2: What strategies does Athlete Ally utilize to engage with various governing bodies?

RQ3: How does Athlete Ally create resonant (credible and salient) frames?

\section{Limitations and Delimitations}

As with any study, the current study is not without its limitations and delimitations. The following section outlines the limitations and delimitations for the study. According to Hancock and Algozzine (2006), limitations are the factors beyond the researcher's control, but that still impact the effect of the results of the study. Delimitations are the choices the researcher makes that impact the study, often the boundaries of the case study.

\section{Limitations}

One limitation related to a case study methodology is the lack of generalizability (Flyvjerg, 2011; Snow \& Trom, 2002; Yin, 2009). Per critiques of a case study methodology, the ability of a single case to generalize information to larger populations is impossible. As noted by the researchers listed here, however, this limitation is often overblown. Flvjerg (2011) argued knowledge may be transferrable, even if it is not formally generalizable. Snow and Trom (2002) claimed statistical generalization is not the only kind of generalization. Analytic or theoretical generalization, the type of generalization that could emanate from case studies, can provide an additional benefit. 
Finally, Yin (2009) believed case studies are generalizable to theoretical propositions, not populations or universes. Another limitation to the study was a concern outlined by della Porta (2014a) in that social movement researchers often study social movements to which they are sympathetic. As a self-identified advocate and ally to the lesbian and gay movement, the researcher understands bias may influence the study's results. As noted by many researchers (Creswell, 2013; Denzin \& Lincoln, 2011; Hays \& Singh, 2011), the effects of personal bias can be limited using peer debriefing.

\section{Delimitations}

One delimitation of the current case is the boundary of the case to one case, instead of multiple cases. The specific use of Athlete Ally narrows the transferability of the results to sport advocacy organizations in the United States. Another delimitation of the study was the interviews of individuals who worked for Athlete Ally or athlete ambassadors. Other constituents, like organization followers or bystanders, were not interviewed for the current study. This delimitation "privileges" the structure and organization of the social movement, instead of investigating the entire movement (Mueller, 1992).

\section{Definitions}

Activism - "extra-ordinary, extra-usual practices which aim, collectively or individually, institutionally or informally, to cause social change" (Bayat, 2005, p. 893-894).

Adherents - "those individuals and organizations that believe in the goals of the movement" (McCarthy \& Zald, 1977, p. 1221). 
Ally - "a person who is a member of the dominant or majority group who works to end oppression in his or her personal and professional lift through support of, and as an advocate with and for, the oppressed population" (Washington \& Evans, 1991, p. 195). Athlete Activism - "an amateur or professional athlete's practices which aim, collectively or individually, institutionally or informally, to promote progressive social change" (Schmidt et al., 2018, p. 5).

Bystander publics - Individuals who do not actively support or oppose the social change sought by the SMO (McCarthy \& Zald, 1977).

Beneficiaries - Individuals that directly benefit from the social movement's proposed or enacted social change (McCarthy \& Zald, 1977)

Cadre - "the individuals who are involved in the decision-making process of the organization" (McCarthy \& Zald, 1977, p. 1227).

Celebrity Activism - "any work by famous people in service of some cause other than themselves" (Brockington, 2014, p. xxii).

Collective Behavior - "behavior of individuals under the influence of an impulse that is common and collective, an impulse, in other words, that is a result of social interaction (Park \& Burgess, 1921, p. 865).

Conscience constituents - "direct supports of a SMO who do not stand to benefit directly from its success in goal accomplishment” (McCarthy \& Zald, 1977, p. 1222). Constituents - Individuals providing resources for a SMO (McCarthy \& Zald, 1977). Countermovement - A movement that seeks to preserve the status quo or repeal recent changes to the status quo (Dorf \& Tarrow, 2014). 
Frames - Interpretive schemas that enable individuals "to locate, perceive, identify, and label occurrences within their life space and the world at large" (Snow, Rochford, Woden, \& Benford, 1986, p. 464).

Political Opportunity Structure (POS) - the core of the political process framework as it influences protest strategies and the impact of SM on the environment (Kriesi, 2004). Potential beneficiaries - Those who directly benefit from a SMO goal (McCarthy \& Zald, 1977).

Professional Cadre - Individuals who devote full-time to a SMO and receive compensation (McCarthy \& Zald, 1977).

Professional Staff - Individuals who devote full-time to a SMO, but are not involved in central decision making processes (McCarthy \& Zald, 1977).

Resource Mobilization - A SMT approach investigating how groups overcome prevailing patterns of resource inequality in their pursuit of social change (Edwards \& McCarthy, 2004)

Social Movement - "collectivities acting with some degree of organization and continuity outside of institutional or organizational channels for the purpose of challenging or defending extant authority, whether it is institutionally or culturally based, in the group, organization, society, culture, or world they are a part" (Snow, Soule, \& Kriesi, 2004, p. 11).

Social Movement Organization - "complex, or formal, organization, which identifies its goals with the preferences of a social movement or a countermovement and attempts to implement those goals" (McCarthy \& Zald, 1977, p. 1218). 
Workers - Individuals who intermittently give time to a SMO, but not at the cadre level (McCarthy \& Zald, 1977). 


\section{CHAPTER II}

\section{REVIEW OF LITERATURE}

The purpose of the current study was two-fold. First, this study seeks to identify the resources provided to and from athlete activists for Athlete Ally. Second, this study examines tactics for engaging with the political structure and frames utilized by Athlete Ally. One avenue for athletes to engage in activism is with a social movement organization, like Athlete Ally. The proposed study aims to serve social movements and social movement organizations, an area of sport research that experiences a paucity of research (Delano \& Crosset, 2008), by investigating how a prominent advocacy organization operates with athletes and within the political and cultural landscape.

The following literature review is divided into three sections: activism, social movements and social movement theory, and the LGBT movement. Activism, the first content area covered consists literature on general activism, celebrity activism, and athlete activism. The social movements and SMT section covers literature on the history of social movements and the three theoretical tenets of SMT (RMT, PPT, and the Cultural Theory/Frame Analysis). Finally, the last section summarizes the LGBT movement in the United States since World War II, provides an overview of research involved LGBT and SMT studies, and finally investigates LGBT and sport studies.

\section{Activism}

The following section begins with the definition of activism for the current study. The author then explains general activism literature, including history, characteristics, 
motivations, and consequences for activism. Celebrity activism is described in brief, followed by literature on athlete activism. A brief overview of athlete activism in the United States from the 1960s until today is provided before the author explores why activism in sport is a natural partnership. Finally, a review of the negative consequences for engaging in activism and tactics utilized by athlete activists are discussed.

Per Bayat (2005), activism is defined as "extra-ordinary, extra-usual practices which aim, collectively or individually, institutionally or informally, to cause social change" (p. 893-894). Bayat equates activism to religion. True believers of the faith not only passively worship their gods, but also preach their religion. For one to truly be an activist, one must actively, not passively, support a cause.

Activism is a rich part of US history. In fact, activists were the foundation of the formation of the United States. For example, college-age students were some of the first activists, dumping tea into the Boston Harbor and rebelling against British rule in the late $18^{\text {th }}$ century (Broadhurst, 2014). Despite a history of activism, like student rebellions against classical curriculum, poor food, and lodging conditions by students in the $17^{\text {th }}$ and $18^{\text {th }}$ century (Broadhurst, 2014), social movements in the US did not receive significant scholarly attention until the 1960s (della Porta \& Diani, 2006; Flacks, 1967; Kerpelman, 1969) nearly 200 years after the Boston Tea Party. Since the 1960s, however, a tremendous amount of research has investigated the biographical characteristics of activists, the reasons for engaging in activism, and consequences of activism. Activists were originally from upper-status families in which parents had higher levels of education and family income (Flacks, 1967). Activists were likely to be college students, intelligent and engaged in campus activities (Kerpelman, 1969). Thus, affluent 
individuals were more likely to have the necessary resources (time, money, and skills) to engage in activism (Brady, Scholzman, \& Verba, 1999). Moreover, these young activists often did not have children, enjoyed freedom from work, and had the ability to structure their own schedule (Wiltfang \& McAdam, 1991).

After identifying the prototypical "activist," research turned to understanding why people engaged in activism. A prior history of activism, like participation in a sit-in or monetary contributions to a civil rights organization, was an overwhelming factor encouraging future activism efforts (McAdam, 1986; 1992; Wiltfang \& McAdam, 1991). Fendrich (1977) noted individuals were more motivated to continue their activism if they had strong ideological commitment to the social issue, like an ally in the lesbian and gay movement. Extrinsic rewards, like money, prestige, and security, did not lead to further commitment (Fendrich, 1977).

Social networks, however, are also an important facilitator of activism. Louis et al. (2016) noted the importance of groups in mobilizing activists. Louis et al. (2006) hypothesized that being part of a community group, whether it is an activist group or not, would be a predictor of activism. Simply put, an individual is more likely to be an activist if they are part of a social group, like an athletic team. Additionally, Louis et al. (2006) tested the social network size as an indicator of activism across different social injustices (e.g. LGBTQ activist also being an activist for women's rights). The bigger the social network of the activist, the more likely they will be an activist for different rights, highlighting the importance of groups and networks for activists. This is further compounded by della Porta \& Diani (2006), who note that a larger social network increases an individual's likelihood of being involved in activism, but also shapes the 
participant's own network. By engaging in activism with a movement or a particular SMO, one grows their own network and affects subsequent development in activism efforts. Further, an activist's affiliation with a group, in combination with other groups, can create linkage between them (Breiger, 1974; Simmel, 1955). For example, an athlete working with Athlete Ally has access to the rest of his/her teammates, thus possibly expanding Athlete Ally's social network. This is a probable hypothesis, as the majority of activists in two separate studies (between 60-90\%) were recruited from their social network (Diani \& Lodi, 1988; Snow, Zurcher, \& Olson-Ekland, 1980). Additionally, other than recruitment, activists are more likely to remain committed to organizations when they have social ties to most members of the organization (McPherson, Popielarz, \& Drobnic, 1992). Within the LGBT movement, specifically, the use of networks has created many advancements for the LGBT movement for equality and LGBT-related legislation. The leadership of the LGBT Equality Caucasus, founded by Senator Tammy Baldwin and Barney Frank, were able to unify around inequality found in the LGBT community and transfer those issues into political spaces (Smitton, 2017). Thus, social networks are a crucial aspect for social movement organizations.

Finally, consequences of activism have received prominent scholarly attention. McAdam (1989), in his examination of the 1964 Mississippi Freedom Summer activists, noted activists entered full-time employment later, changed jobs more frequently, earned less, and worked fewer years during the 1960s than their non-activist counterparts. Additionally, women experienced discrimination more than the male activists. Women were also more often rejected for participation in the 1964 Mississippi Freedom movement, despite being more qualified. Women also experienced discriminatory 
questions during the interview process, were asked to do clerical work, experienced a sexual double standard, and had less political roles than males. Despite the negative consequences of activism, there are positive consequences (Fendrich \& Turner, 1989; Klar \& Kasser, 2009). Fendrich and Turner (1979) noted activists in college were more likely to be politically involved in adulthood than non-activist college students. Klar and Kasser (2009) concluded activists experienced higher levels of life satisfaction, personal growth, purpose in their life, and social well-being, as well as basic psychological needs.

In sum, previous research has shown the characteristics, motivations, and consequences for activism. Despite the various demographics, motivations, and consequences, two important factors stood out among activists: plentiful resources and social networks. Having more resources, like time and money, allowed activists the opportunity to devote time to activism (Brady, Scholzman, \& Verba, 1999). Additionally, having large social networks allowed activists to rely on that network for multiple benefits (i.e. streamline information about other activism efforts; Louis et al., 2016). One group that specifically has access to resources and a large social network are celebrities (Brockington, 2014).

\section{Celebrity Activism}

Celebrity activism is defined as "any work by famous people in service of some cause other than themselves" (Brockington, 2014, p. xxii). The United Nations was one of the first major organizations to employ celebrity activists (Kogen, 2015). In 1953, American actor, singer, and dancer Danny Kaye was appointed as the United Nations Children's Fund's (UNICEF) first Goodwill Ambassador (Wheeler, 2011). Kaye utilized his fame and notorious humor to speak on the behalf UNICEF to advocate for a better 
world for children. Since then, celebrity activists and advocates have publicized field trips; designed products to sell in support of charitable organizations; facilitated access to people with social, political, and economic power; promoted general awareness; and campaigned, fundraised, and rewarded existing supporters (Brockington, 2014). Most of all, literature supports the idea that a celebrity activist's largest impact stems from being able to communicate proficiently with the public (Kogen, 2015). Moreover, celebrities garner more media attention thus giving the celebrity activist a broader platform from which to advocate (Thrall et al., 2008). If the celebrity activist is authentically and genuinely committed to the cause, the credibility of the celebrity increases (Ellcessor, 2016; Huliaras \& Tzifakis, 2012). For example, Marlee Matlin’s activism for closed captioning on television shows was effective because the actress was deaf. She was personally connected to the cause, thus was seen as more authentic in her activism (Ellcessor, 2016). Credibility is important as it directly affects non-celebrities intentions to volunteer time and donate money (Wheeler, 2009).

From the media perspective, celebrity advocates, individuals who plead the causes of others or defend a cause or proposition (Keck, \& Sikkink, 2014), and star power (i.e., how famous a celebrity is) are related (Thrall, et al., 2008). Thrall and colleagues noted activist groups with more celebrity advocates would provide greater news coverage and help with agenda setting and persuasion. Star power advocacy does provide a benefit for activist groups in the form of mobilization of constituents (Simonson, 2001) and building infrastructure, like raising millions of dollars or providing access to the celebrities' network (Thrall, et al., 2008). Thus, organizations founded on social change, or SMOs 
(discussed at greater length later in this chapter), could benefit from a famous celebrity activist who can provide star power and media draw.

Despite the benefits of celebrity activism, there is heavy criticism toward celebrity activists (Brockington \& Hensen, 2015; Davis, 2010; Dieter \& Kumar, 2008; Huliaras \& Tzifakis, 2012; Kogen, 2015; Panis \& van Den Bulck, 2012; Winge, 2008). Generally speaking, celebrity activism can lead to de-politicizing the conflict, distorting its real causes, leading one sided campaigns, and painting a simplistic good against bad picture (Huliaras \& Tzifakis, 2012; Winge, 2008). This leads to some claiming celebrities are unqualified, over simplify issues, and offer only shortsighted solutions (Dieter \& Kumar, 2008). Additionally, the use of celebrity activism for large scale events, such as the 1985 rock concert Live Aid, can financially benefit organizers, celebrity participants, corporate sponsors, event places, providers of event equipment, and the host cities, while providing only short-term marginal benefits for the intended recipients (Davis, 2010). Focusing specifically on celebrity activists, non-celebrity individuals often believe celebrities are just seeking to increase their fame when engaging in advocacy (Panis \& van Den Bulck, 2012). Additionally, celebrities, though used for their ability to communicate with the masses, struggle to articulate what non-celebrity individuals can do to help the humanitarian efforts (Kogen, 2015) and detract from the efforts by focusing on their celebrity status (Brockington \& Hensen, 2015).

Despite the criticisms mentioned above, Kaufman (2008) and Kaufman and Wolff (2010) noted actors, musicians, writers, and other non-athlete celebrity activists are viewed positively compared to another group of celebrity activist, athletes. One reason for this phenomenon is that celebrities do not often bring politically oriented advocacy 
into the celebrity news mix (Thrall et al., 2008). Athlete activists are known to infuse their advocacy within their sporting event, as they know the news mix will highlight their persons to a mass audience (Kaufman \& Wolff, 2010). Due to the line between athlete (celebrity) self and advocate self being blurred, activist athletes are viewed as social deviants for engaging in activism and are less likely to engage their political views compared to non-athlete celebrity activists (Kaufman, 2008).

\section{Athlete Activism}

Activism in the athletic realm can be defined as "an amateur or professional athlete's practices which aim, collectively or individually, institutionally or informally, to promote progressive social change" (Schmidt et al., 2018, p. 5). Athlete activism deserves its own definition due to the inherent qualities that provide a natural link between activism and sport (Kaufman \& Wolff, 2010).

Athlete activism in the 1960s and 1970s was prominent. Notable Black athletes like Tommie Smith, John Carlos, Muhammad Ali, and Bill Russell, to name a few, used their platform as sport stars to advocate for a better world. Smith and Carlos famously raised their fists in a Black Power salute on the podium of the 1968 Summer Olympics in Mexico City (Agyemang, Singer, \& DeLorme, 2010) setting the landscape for further athlete activism. Outside of race, Billie Jean King used her platform as Wimbledon champion for activism on many fronts. Her LGBT activism is perhaps the most wellknown activism as her efforts, along with Martina Navratilova's, helped pave the way for present day LGBT athletes (Carrol, 2016). As mentioned, athlete activism was prominent and relevant during the 1960s and 1970s. During the 1990s and 2000s, however, athlete activists remained silent. 
Money, fame, and Michael Jordan are a few of the reasons cited for the decline in athlete activism (Agyemang, 2011, Powell, 2008). As Powell (2008) states, the 1990s/2000s athlete “...has a comfortable standard of living, a fair degree of fame, a healthy amount of respect from the public, and because he does not want to jeopardize any of that, he also has a severe case of laryngitis" (p. 26-27). Additionally, Michael Jordan could shoulder some of the blame for the decrease in particularly Black male activism. Jordan was viewed with global fame, equal to Ali's, to the point of being a hero. Thus, when individuals, particularly adolescents, look up to the hero, they try to emulate his/her actions. Such is the case with Michael Jordan. Those who looked up to him and attempted to emulate his actions saw a man who refused to comment on the 1990 North Carolina Senate race with a race baiting-segregationist. Jordan also refused to comment on the racial tension and violence in Los Angeles in 1992. He also and failed to condemn his own sponsor, Nike, for poor treatment of Southeast Asia factory workers (Agyemang, 2011). Instead Jordan remained silent, opting for financial gains instead of roughly $\$ 110$ million from shoes, for a total net worth of $\$ 1.3$ billion (Badenhausen, 2017). This silence, reinforced by Nike commercials to "be like Mike" commercials may have had a large hand in ensuring silence among the next generation of athletes. For example, LeBron James (7-year, \$100 million contract with Nike; Badenhausen, 2017) and Kobe Bryant (\$10 million per year; Lynch, 2016) echoed the sport and politics “do not mix" during the 2008 Summer Olympics (Agyemang, 2011).

Today's athlete, however, is more inclined to participate in activism. Starting with NFL players' responses via Twitter to the George Zimmerman verdict in 2013, Schmittel and Sanderson (2015) noted the ability of social media an even greater platform for 
athletes to engage in social justice. The St. Louis Rams players increased the steaks by moving the activism onto the field (Sanderson, Frederick, \& Stocz, 2016). Shortly after, the University of Missouri football team threatened to sit out their remaining football games if the racial climate was not improved on campus (Frederick, Sanderson, \& Schlereth, 2017). Colin Kaepernick and Megan Rapinoe joined in the activism efforts by kneeling during the national anthem during NFL games and National Women's Soccer League/United States Women's' National Team matches respectively (Schmidt, Frederick, Pegoraro, \& Spencer, in review). The actions of aforementioned prominent athletes, along with the activism of the WNBA, NFL players, NBA players, collegiate athletes, and many others have solidified the notion that the athlete activism has returned.

Even today, athlete activists receive harsh backlash for their engagements with social justice. In one of the seminal studies on athlete activism, Kaufman (2008) noted the sources of backlash for athlete activists. Coaches, players, fans, opponents, teammates, prominent media members, politicians, and others were all the source of negative pushback, like verbal abuse from national personalities, coaches, and crowds, suspensions, stripped of sport accolades, to name a few. While there were positive comments towards the athlete activist, the loudest and most frequent voices were the negative. The push back, especially from fans and organizations, has been confirmed several times through literature (Agyemang, Singer, \& DeLorme, 2010; Sanderson, Frederick, \& Stocz, 2016; Schmidt et al., in review).

Sanderson, Frederick, and Stocz (2016) noted the intense racial backlash the Rams' organization received directed towards four athletes who held up their hands in a "Hands up, don't shoot" motion. The gesture was about the shooting of Michael Brown. 
Fans hurled racial slurs and statements of abandoning fanship on the Rams' page for the players' actions. Similar findings appear in an examination of the Missouri football team's Facebook page when the football team threatened to boycott the football season (Frederick, Sanderson, \& Schlereth, 2017). Fans believed the athletes were manufacturing the issue of racial tensions to deviate from expected behavior. Schmidt, Frederick, Spencer, and Pegoraro (in review) noted fan's use of social media to condemn athlete activism occurring on the field. Colin Kaepernick knelt during the national anthem to symbolically stand with those oppressed. Despite being inactive with his Facebook account, Kaepernick's Facebook page was flooded with negative comments questioning his patriotism and masculinity and telling him to leave the United States.

Not only are personal attacks a concern for athlete activists, financial backlash looms for athlete activists (Agyemang, Singer, \& DeLorme, 2010; Cunningham \& Regan, 2012). In an interview with Black male collegiate athletes, the athletes were hesitant to engage in activism against racial inequality for fear of backlash in the form of a professional contract being taken away. While the athletes in the study were aware of the deeds of Muhammad Ali, Tommie Smith, John Carlos, they explained the difference in today's athletes. With money being so prominent in athletics, the chance of losing income was too much to overcome. Their fears, however, were largely based on anecdotal evidence, until Cunningham and Regan (2012) and Schmidt et al. (2018) studied the marketing implications of athlete activism.

Cunningham and Regan (2012) studied White students' attitudes towards Black male athletes engaging in activism based on fit between athlete and product the athlete was going to endorse. The activism was split into risky activism (anti-war) and safe 
activism (anti-obesity). Results indicated that activism (risky or safe) did not impact the perceived fit between the athlete and the product. Their conclusions indicated the type of activism did not have a negative impact on consumer perceptions of fit. The results certainly hold true for someone with a Black male athlete with a strong brand. Take, for instance, LeBron James, who situated his brand around his activism (Coombs \& Cassilo, 2017). James positioned his brand as a socially conscious athlete, but through a cautious and deliberate approach by emphasizing attention, not aggression in his messages and focusing on the community and not protest. Websites like ESPN, Deadspin, and Sports Illustrated were comparing the athlete's social justice to Ali, Brown, and Bill Russell. James expertly navigated his brand to be social justice focused and was mainly praised for his activism (Coombs \& Cassilo, 2017). The results conflict somewhat with Schmidt et al.'s (2018) study of brand image of an athlete activist engaging in risky activism (antiracial inequality) and safe activism (anti-obesity). The results of their study concluded there was a statistically significant difference in risky and safe activism on brand image of the organization. Engaging in risky activism meant a decrease in brand image of the organization, compared to safe activism. Thus, an organization might be hesitant to partner with an athlete that hurts their brand (Cunningham \& Regan, 2012). The decrease in brand image of the athlete can lower the evaluation of the endorsed product by consumers (White, Goddard, \& Wilbur, 2009). Therefore, inconsistent evidence supports and refutes the notion that activism has a negative impact on consumer perceptions.

Literature has also investigated the tactics in which athletic activism persists. Bundon and Clarke (2014) investigated the messages by individual Paralympic athletes towards their activism. The activists either used methods of advocating for the 
Paralympic movement by being metaphorically described as "honey," "vinegar," and "sweet and tangy." The honey method involved indicating ways organizations and people could be more inclusive towards persons with disabilities. The vinegar tactic involved showcasing or explaining ways organizations are being exclusive towards persons with disabilities through their practices. Finally, the sweet and tangy method involved a little bit of both. Activism, however, does not have to be an individual act. Schmittel and Sanderson (2014) reviewed social media accounts of prominent NFL athletes after the George Zimmerman trial. Their results indicated most of the tweets surrounding the case were commenting on the social climate of America, rather than disbelief, anticipation, or critiques of the American Justice System. The researchers also contended social media may be a tactic a prominent athlete could use to engage in activism as it arms the athlete with many followers.

The notion of an athlete utilizing their platform and followers to engage in social justice is noted in a study by Kaufman and Wolff (2010). Kaufman and Wolff interviewed 21 athletes about their activism and their findings revealed that one of the major links between athletics and activism was interdependence. The athletes understood their athletic and personal successes were a result of collaboration among many individuals. Through the work and support of coaches, trainers, fans, family, or other supporters, the athletes were able to earn significant achievements. Athletes needed a team to achieve their goals. Through this realization, the athlete activists recognized the importance of collaborative efforts to achieve social change. The Missouri football team is a prime example of this notion as all of them threatened a boycott of their season if social issues were not addressed on campus. The interdependence of each of them, along 
with the head coach pressured administration to resign (Frederick, Sanderson, \& Schlereth, 2017). It is through this collaboration between athletes, the public, advocacy organizations and others, that a social movement is born.

\section{Social Movements and Social Movement Theory}

The following section will provide an overview of the theoretical foundation for the proposed study: Social Movement Theory. First, the author will provide an overview of collective behavior and social movements before reviewing SMT. The SMT section is further divided into the three tenets: Resource Mobilization Theory, Political Process Theory, and Cultural Theory/Frame Analysis.

\section{Collective Behavior}

In the $20^{\text {th }}$ century, social movements were viewed as nothing more than a subtype of collective behavior with "panics, crazes, crowds, rumor, and riots" (Buechler, 2004, p. 47; Turner \& Killian, 1972). The combined sub-types all fell under the umbrella of collective behavior. Collective behavior is defined as the "behavior of individuals under the influence of an impulse that is common and collective, an impulse, in other words, that is a result of social interaction" (Park \& Burgess, 1921, p. 865). Gustave Le Bon first introduced the concept of collective behavior in the late $19^{\text {th }}$ century. Le Bon (1897) studied crowds, which he defined as a gathering of individuals of whatever characteristics by whatever has brought them together. Although Le Bon did not mention the term collective behavior, his description of crowds served as a prototype for collective behavior: "the sentiments and ideas of all the persons in the gathering take one and the same direction, and their conscious personality vanishes" (p. 2). To further this notion, Le Bon claimed, "when the structure of a civilization is rotten, it is always the 
masses that bring about its downfall" (p. 19). Le Bon's statements seem harsh, but echo the negative connotation associated with social umbrella under the umbrella of collective behavior. Le Bon's work clearly identified the behavior of a mass amount of people, despite focusing on specifically one portion of collective behavior (crowd). His approach to group behavior was more psychological, rather than sociological in nature.

In the early $20^{\text {th }}$ century, Park and Burgess (1921) introduced the term collective behavior and gave it a formalized definition (see above). Park and Burgess approached collective behavior from a sociologic lens, noting that every individual in a collective was influenced by the action of every other individual. At this point, collective behavior was viewed in a negative light. Contextually, in the 1930s, The United States witnessed mass movements like the Wall Street crash and ensuing Great Depression and global recession, European fascism, and World War II created a climate where "populist expressions of dissent were approached with suspicion" (Chester \& Welsh, 2011, p. 5). Instead of movements dedicated for rights and social change, spontaneous eruptions from deviant behavior were more common. Thus, researchers and sociologists viewed collective behavior as a negative action.

In 1934, Harold Blumer provided the catalyst collective behavior needed to shake its negative connotation and solidified collective behavior study in the sociological field (Chester \& Welsh, 2011). Instead of viewing collective behavior as spontaneous and reckless, Blumer (1951) argued for collective behavior to be viewed as purposive, meaningful, and potentially creative. He believed collective behavior could introduce new norms, behaviors, and ideas to the larger society. Blumer's approach was coined the symbolic interactionist approach. Turner and Killian (1972) furthered the symbolic 
interactionist by focusing on the individual unit of analysis for collective action. For example, their viewpoint questioned why individuals joined movements. Their investigations of collective behavior, primarily focused on social movements, became the foundation for social movement studies.

Another approach, the structural functionalism approach, expanded the view of collective behavior. Instead of the individual being the central focus of collective behavior studies, structural functionalists focused on the broader picture. In the 1962's edition of Theory of Collective Behavior, Smelser (2011) articulated the focus of structural functionalism on the macro-unit of analysis. Instead of focusing on motivations for involvement in collective behavior, Smelser was more concerned with the political, social context, and economic changes that stemmed from a mass movement. Further, this approach believed “... societies tended toward equilibrium, collective action by social movements could be understood as a natural mechanism reacting to structural strains or changes in society" (Chester \& Welsh, 2011, p. 6). In other words, collective behavior was framed in ways of strain and breakdown, due to the impulsive nature of collective behaviors (Smelser, 2011). When social order remained intact, strain and breakdown on society did not exist and collective behavior was avoided. When societal controls and morals started to strain and then breakdown, collective behavior thrived (Buechler, 2004). For instance, before the Stonewall Riots, the gay and lesbian movement was hardly organized and often employed passive tactics focused on assimilation. On June $28^{\text {th }}$, 1969, when police raided the Stonewall Inn, the strain of the relationship between the gay and lesbian community and law enforcement lead to the breakdown of social order 
(Engel, 2001). A multi-day violent raid between police and gay and lesbian members incurred sparking the official gay and lesbian movement.

While the two views of collective behavior provided a path for future studies of collective behavior in the 1960s, the 1970s brought criticisms of the approach. Turner and Killian (1972) noted two reoccurring issues in collective behavior theory: The group mind issue and the narrative of irrationality and emotionality toward collective behavior studies. The first concern, the group mind issue, was concerned with whether "there is a group mind, whether the group is something other than the sum of individual response, and similar questions" (Turner \& Killian, 1972, p. 16). The major concern was the lens through which collective behavior was viewed and subsequently described by researchers. Is a group of people separate members or are they all one? By viewing the group as one entity (e.g. the mob attacked the man), researchers oversimplify the action and ignore the diversity of individual behavior within the group. However, if researchers believe only the behavior of individuals can be described, researchers tend to attribute the individual member's motives and attitudes to explain the action of the group.

Another reoccurring issue with collective behavior was the emotionality and irrationality narrative surrounding the study. Turner and Killian (1972) critiqued the negative views of collective behavior, noting, "destructive mobs, panics, and revolutionary or totalitarian social movements is reflected in this tendency" (p. 19). The authors believed emotion and reason were not mutually exclusive, as a well-thought out plan may be filled with emotion and an inadequate plan may be void of any emotion. Additionally, other researchers viewed social movements actors as acting rational. Their image of rational assumed the individual weighed the costs and rewards for collective 
behavior. This cost and reward approach, coined Resource Mobilization Theory, viewed costs and risks in an economic sense (discussed later in this chapter). Turner and Killian's concern with Resource Mobilization Theory approach stemmed from the belief that an individual's sense of reward and success was different than other individuals within the crowd. Thus, the crowd cannot be viewed as one as the reward to one individual, may be not be a reward to another individual. Similarly, what may be rational to one activist may not be rational to another. The two concerns rose by Turner and Killian (1972), among other researchers, signified major flaws in collective behavior literature as social movements were simply not in the same vein as craze, panics and riots. Slowly the two separated and by 1980, collective behavior and social movements became a major body of literature within the American Sociological Association (Smelser, 2011).

\section{Social Movements and Social Movement Organizations}

The term social movement was first scholarly discussed by Lorenz von Stein in 1850. He narrowly viewed social movements as a continuous, unitary process by which the working class gained power (Tilly \& Wood, 2013). During this time, Marx and Engel's Communist Manifesto (2002) in 1848 noted that past movements were based through minorities or in the interests of minorities. The widespread European movements in the 1848 were self-conscious movements by the majority, in the interests of the majority (Marx \& Engel, 2002). As social movement studies entered the $19^{\text {th }}$ century, scholars differential them by program, organization, and setting. Indeed, political analysts extended social movements beyond the working class to farmers, women, and other varieties of groups (Heberle, 1971; Tilly \& Wood, 2013). As mentioned, during the early and mid- $20^{\text {th }}$ century, social movements were subsumed within collective behavior 
literature in the early to mid- $20^{\text {th }}$ century. This echoes the sentiment from Tilly and Wood (2013) who argued the term social movement lost value as it was used loosely to include all relevant popular protest, often confused with the collective actions of organizations and networks that supported the movement, and was viewed as a single unitary actor (anyone associated with the social movement in any context; e.g., adversaries, media, countermovements, cadres) during this time.

It was about the mid- $20^{\text {th }}$ century, during the Civil Rights, feminist, and gay and lesbian movements of the United States, which changed the studies of social movements. As mentioned briefly before, the rise of the Resource Mobilization Theory approach in the mid- $20^{\text {th }}$ century contested the assumption that social movements belonged under collective behavior (Buechler, 2004). First, the Resource Mobilization Theory approach challenged the nature of social movements being a subtype of collective behavior and postulated that social movements deserved their own framework for analysis. Social movements were not random outburst of unstructured public behavior like collective behavior (Blumer, 1951). Instead, social movements were organized and deliberate. Second, social movements were viewed as having enduring, patterned, and institutionalized elements. This challenged the former belief that social movements as a subtype of collective behavior were non-institutionalized. Third, social movement actors were seen as rationale actors, unlike those in crazes, panics, or riots. Finally, the newer approaches highlighted the political dimension of movements by conceptualizing them as group interests. From this point on, social movements were viewed in their own light and given their own analysis (Buechler, 2004). 
An abundance of definitions for social movements are available. Most definitions, however, include the three or more of the following characteristics: "collective or joint action; change-orientated goals or claims; some extra- or non-institutional collective action; some degree of organization; and some degree of temporal community" (Snow, Soule, \& Kriesi, 2004, p. 6). One of the earliest modern iterations of the definition is "a set of opinions and beliefs in a population which represents preferences for changing some elements of the social structure and/or reward distribution in society" (McCarthy \& Zald, 1977, p. 1217-1218). Snow et al. (2004) offer a more moderated definition that was used in this study:

collectivities acting with some degree of organization and continuity outside of institutional or organizational channels for the purpose of challenging or defending extant authority, whether it is institutionally or culturally based, in the group, organization, society, culture, or world they are a part. (11)

Today, social movements are viewed by many as a counterweight to oppressive power through popular action against a wide range of ill-devised intentions (Tilly \& Wood, 2013). Social movements are viewed as normal behavior and often observed as political struggles, rational, actor-center, and goal-orientated in academic literature.

One of the important parts of social movements are the SMOs and advocacy organizations inside the social movement. The earliest definition described SMOs as "complex, or formal, organization, which identifies its goals with the preferences of a social movement or a countermovement and attempts to implement those goals" (McCarthy \& Zald, 1977, p. 1218). SMOs are an important area of study as they serve as the central point for social movement studies (Edwards \& McCarthy, 2004). SMOs 
provide the basis for mobilization of a social movement (Caniglia \& Carmin, 2005) by pooling resources, coordinating action, and facilitating later resurgence of activism (McCarthy \& Zald, 1977).

According to McCarthy and Zald (1977), a SMO is comprised of cadres, professional cadres, professional staff, workers, and constituents. Cadres are individual members who make decisions, but do not get paid. Professional cadres are decision makers who receive compensation, like the board of directors or director of communications. Professional staff devote significant time to the organization, but do not make decisions. An example may be the administrative workers and interns. Workers are those who intermediately assist the organization. An individual outside of the organization who periodically volunteers their time might fall under this category. Constituents, like donors or celebrities, provide resources (generally time or money) to a SMO. Those that do not stand to benefit from the social change, but directly support the organization are conscious constituents. In the case of the gay and lesbian movement, allies are conscious constituents. Those that benefit directly from the social change are called beneficiaries. In the feminist movement, one would consider women to be the beneficiaries of the movement's goals. Bystander publics are individuals who do not actively support or oppose the social change sought by the SMO; adherents do not actively support the SMO, but support the cause. For example, someone may believe in the Black Lives Matter movement, but not engage in an advocacy or activism to benefit the movement. Ideally, SMOs attempt to turn Bystander publics into adherents, and finally into conscious constituents or working members of the SMO (McCarthy \& Zald, 1977). 
As mentioned before, Athlete Ally, as a SMO, was the focal point for this study. One such SMO, Athlete Ally is the focal case for this study. Athlete Ally represents a unique intersection of the LGBTQ movement and the recent wave of athlete activism in sport. The organization utilizes both waves of movements to end homophobia and transphobia in sport. The appropriate theoretical framework for studying Athlete Ally is Social Movement Theory.

\section{Social Movement Theory}

Social Movement Theory is an umbrella theory for different bodies of theories. For example, Davis-Delano and Crosset (2008) in their systematic review of the explanatory power of social movement theories, utilized five theories to examine sport related social movements: Collective Behavior, Resource Mobilization Theory, Political Process Theory, New Social Movements, and Cultural Theories/Frame Analysis. Their analysis found support for RMT, PPT, and Cultural Theories/Frame Analysis, but not full support for Collective Behavior nor New Social Movements. Further, other scholars have utilized those three specific theories to investigate the Women's United Soccer Association movement (McDonough, 2011) and the Kenyan peace movement in 2008 (Wilson et al., 2015). Thus, the current study will utilize Resource Mobilization Theory, Political Process Theory, and Cultural Theories/Frame Analysis.

The call for a specific social movement theoretical foundation came as early as the 1940s, but was only fully respected until the 1960s (della Porta \& Diani, 2006). Olson (1965) provided a boon for Social Movement Theory when he challenged the previous assumption that deprivations and grievances lead to social movements. In theory, social movements only arose when unrest or grievances were at its peak. Olson (an economist) 
challenged the assumption based on his "free-rider" theory that states a rational actor would not bear the costs of a social movement to bring about the collective goods (Giugni, 2008; McCarthy \& Zald, 1977). Thus, how could collective behavior materialize if all actors were acting rationally and in their self-interest? Explaining collective behavior required attention to the selection of incentives, cost-reducing mechanisms, and career benefits leading to collective behavior (Oberschall, 1973). This shift in thinking allowed social movement researchers to develop and provide an explosion of theoretical and empirical writings on social movements in the mid-1970s. By the 1980s, both Europe and the United States had formalized approaches to study social movements. America focused on RMT (how organizations within a social movement mobilize resources) and the PPT (focusing on the political structures interactions with the social movement). Europe, conversely, empathized the conflict between lifestyles and identities, known as the Cultural Theory/Frame Analysis approach (van Stekelenburg, \& Roggeband, 2013). In 1985 and 1986, social movement researchers gathered together in New York and Amsterdam, respectively, to bridge the theoretical connection between the structural and cultural components of social movements. In 1999, social movement researchers concluded on the political opportunities, mobilizing structures, and framing processes as the core tenants of SMT (McAdam, 1999). While critics of the triad approaches of SMT claimed the theory lost its luster (see McAdam, Tarrow, \& Tilly, 2001), the paradigm has yet to be replaced. Still, the major approaches of RMT, PPT, and Cultural Theory/Frame Analysis persist within Social Movement Theory.

Resource Mobilization Theory. The RMT approach investigates how social movement groups overcome prevailing patterns of resource inequality in their pursuit of 
social change (Edwards \& McCarthy, 2004). The perspective adopts prior literature suggesting social movements should decentralize deprivation and grievances in favor of a cost and benefit analysis (Olson, 1965; McCarthy \& Zald, 1977; Mueller, 1992). McCarthy and Zald (1977) noted grievances and discontent could be created and manipulated by issue entrepreneurs and organizations. However, RMT seeks to expand on the notion that social movements deliver collective benefits, but only a select few individuals will bear the cost to obtain the benefits. From a rational-choice framework, Olson's (1965) stated the self-interested individual will seek to minimize the costs, as the benefits will be distributed equally to the group. This paradox creates a "free-rider" dilemma: if a rational individual does not want to shoulder costs, but will wait for collective benefit, no collective action can be formed. While Edwards and McCarthy (2004) believed the Olson (1965) paradox could be minimized by the formation of permanent SMOs, other theorists discussed the out-datedness of the rational-choice theory (Ferree, 1992; Schwartz \& Paul, 1992). The theory believes people will always make rational and logical choices. An individual bearing the risks of activism to change society and benefit others is not a logical choice. Ferree (1992) criticized the rationalchoice theoretical approach as it: was a one-dimensional view of rationality, insists on the outdated theoretical significance of the free-rider, and decontextualizes the individual. Additionally, other social movement scholars attempted to reconceptualization the actor to eliminate the free-rider paradox for a new shared-fate model (Mueller, 1992). A shared-fate model presumes group logic will supersede individual logic, and eliminate the free-rider problem, based on two criteria: the belief that no one will benefit unless large 
numbers of people come together and the "inability of individuals to distinguish among themselves in terms of their capacity to contribute" (Mueller, 1992, p. 9).

Types of resources. Resource mobilization theories are concerned with how social movements and SMOs gain and utilize the resources available to them. While resource mobilization has been a popular approach to SMT, researchers noted the frustration of discussing resources without conceptualizing important resources for social movements (Cress \& Snow, 1996). Cress and Snow investigated the salient resources to SMOs in their study of 15 SMOs combatting homelessness. The authors developed four major categories of resources: moral (endorsements by external organizations; sympathetic and solidarity), material (tangible goods and services; supplies, meeting spaces, office space, transportation, employment, and money), informational (knowledge capital; strategic, technical, and referrals), and human (people; captive audiences, leaders, and cadre). However, Edwards and McCarthy (2004) theorize resources from an economic viewpoint and synthesizing past work conceptual literature on resource types (Cress \& Snow, 1996, Lahuasen, 1996; Oliver \& Marwell, 1992). The authors believe the different resources available to SMOs are moral, cultural, social-organizational, human, and material resources (Edwards \& McCarthy, 2004). Per the authors, moral resources are the legitimacy and support from external organizations (Cress \& Snow, 1996), with legitimacy receiving the most attention (Edwards \& McCarthy, 2004). The key notion is that an outside entity can give and retract legitimacy to a SMO, causing an image transfer or shift for the SMO. Just as an external organization or individual can give a SMO legitimacy through verbal or tangible support, the external organization or individual can take it away. For example, starting in the 1980s, People for the Ethical Treatment of 
Animals (PETA) utilized celebrity support as a moral resource. Gaining the support from Rue McClanahan, Betty White, Ted Danson, k.d. lang, the B-52's, and other celebrities to earn legitimacy. The resources helped the organization as media calls, membership, and volunteers all increased during the period of enlisting celebrity support (Simonson, 2001).

Cultural resources are the conceptual tools and specialized knowledge that a SMO uses to achieve its goal. For instance, a cultural resource could be the knowledge of enacting a protest event or contacting the media. Social-organizational resources are the resources utilized to further organizational goals through other organizations, social networks, and infrastructures. For example, the post office is a social-organizational resource utilized by SMOs to deliver marketing material or the recruitment of volunteers. Human resources are the labor, experience, skills, and expertise individuals bring to the SMO. Not to be confused with cultural resources, human resources provide a "valueadded" approach to a SMO (Edwards \& McCarthy, 2004, p. 128). Finally, material resources are the money and tangible materials SMOs utilize. All the above listed resources are what SMOs use to mobilize and accomplish organizational goals. The resource types offer an explanation as to what SMOs are trying to mobilize and different useful properties of the different resources as well.

Attributes of resources. The above-mentioned resources have differing attributes: how transferable they are and how proprietary they are to the SMO. Understanding the attributes of SMO resources is important as they dictate how useful or valuable the resource is to the SMO (Edwards \& McCarthy, 2004). The first attribute, transferability, touches on the context specificity of the resource to the SMO. A greater exchangeable 
resource is less context-specific compared to a lesser exchangeable resource. For instance, money is one of the most exchangeable of resources as it can be easily transferred into different resources. However, human-made signs for a specific protest may offer only a one-time use, thus being entirely context-specific. The value for the SMO in a less exchangeable resource is more context-specific, but offers less transferability. In addition to being transferable, resources also vary based their level of proprietary. If a resource is completely proprietary, access to the resource is tightly controlled. Money, human labor, and moral resources, like formal endorsements, are all completely proprietary. Those that head the SMO cannot dictate freely the amount of money, human labor, and moral resources that flows into the organization. However, resources that are less proprietary exists within the public domain and are accessible to a wider range of individuals and SMOs. Organizational templates and other culturally available tools are seen as less proprietary as they are easily accessible. The transferability and proprietary level of resources are important for understanding the role of a resource provider (Edwards \& McCarthy, 2004). A more transferrable and more proprietary resource, like money, is extremely valuable to the SMO as merchantability is high and access to the resource is difficult to attain. Thus, resource providers can attach strings to a SMO dictating its direction and outcomes and makes the discussion around how SMOs gain resources vital.

Acquisition of resources. While understanding the different resources and attributes to those resources is important, SMO's ability to gain access to those resources are vital to any social movement. The above-mentioned resources have different access points: Aggregation from constituents, self-production, co-option/appropriation, and 
patronage (Edwards \& McCarthy, 2004). Aggregation from constituents is the collection of resources from a dispersed set of individuals. SMOs often solicit donations from individual donors or encourage individuals to sign a petition or letter of support to the organization, which all constitute aggregation from constituents. Next, self-production is internal resources the SMO creates. The signs, logos, music, literature, and organizational templates created by the SMO are all prime examples of self-produced resources. Of note, the self-produced resources could be improvements or changes that add value to resources gained through aggregation from constituents, co-option/appropriation or patronage. Third, co-optation/appropriation refers to the borrowing or exploitation of resources from another SMO. Per Edwards and McCarthy (2004), SMOs develop and exploit relationships with other SMOs in both formal and non-formal instances. Cooptation is the transparent and permitted use of resources from one SMO to another, while appropriation is the "surreptitious exploitation of the previously aggregated resources of other groups" (Edwards \& McCarthy, 2004, p. 134). To illustrate, the New Left was a broad movement encapsulating the student movement, anti-war movement, Black power movement, and feminist movement, to name a few (Engel, 2001). Organizations often utilized protestors (human resources) from other movements to bolster their own presence (for example, the Black power movement lent protestors for the feminist movement during a rally). Finally, patronage is the gain of resources by an SMO from an individual or an organization that specializes in giving or sponsorship. Government contracts, grants, and large private foundation donations all fall within this category. With any donation of funds, especially large foundation donations, a concern of influence from the foundation or individual materializes. However, Cress and Snow 
(1996), in their study of 15 homeless SMOs across the United States, noted that most had a single facilitative organization that donated over $50 \%$ of resources. The single benefactor increased the chances of survival by the SMO, while simultaneously not modifying the tactics for those specific SMOs. Edwards and McCarthy (2004), in direct response to Cress and Snow, note the vast number of avenues SMOs use to gain access to resources makes studying one specific avenue folly.

While SMO resource types, attributes, and how they are mobilized have been well established, research has yet to appropriately explore how SMOs serve to benefit their constituents. From a broad perspective, SMOs act as an important point of continuity for identity and collective action for their constituents (della Porta \& Diani, 2006). More tangibly, SMOs define organizational goals, manage and coordinate contributions, collect resources, select, train, and replace members and introduce participants to their services (Scott, 1981). Their services vary from SMO to SMO, but their services can help the needs of the social movement constituencies or assist with cultural and symbolic challenges of a new lifestyle. For instance, rape crisis centers, therapy groups, and communes were created from feminist SMOs. Student movement SMOs offered used books and advice centers, allowing for the protest action in the right to education to be both theoretical and practical in nature (della Porta \& Diani, 2006). The SMOs mentioned above served to provide extrinsic logistical support to their constituencies. Intrinsically, SMOs often claim the personal rewards for engaging in activism. For instance, research supports activists oftentimes achieve higher levels of well-being (i.e. life satisfaction, personal growth, and purpose) and social well-being (social integration; McAdam, 1989) than their non-activist counterparts (Klar \& Kasser, 2009). 
Focusing on sport, Wilson et al. (2015) investigated how athletes were able to provide resources for the Kenyan event Run-For-Peace. The event utilized famous Olympic Kenyan runners promote African peace and end civil war in Kenya. The Kenya runners provided phenomenal resources for the movement, including, but not limited to: event promotion, transportation, volunteer recruitment, legitimacy for the event, sponsorships and money, and other resources through their athlete connections. Other sport and social movement studies focused on how organizations can support their constituents. Antunovic and Hardin (2012) investigated posts on the Women Talk Sports blog network. The blog allowed users to talk about their fandom of sport, social issues within sport, and hegemonic masculinity. By advocating for women's sport, the users were able to promote the feminist movement. The Women Talk Sports blog network provided the resource of an area to discuss fandom and concerns with women's sport and helped provide forward momentum for the movement. Carty (2002) noted how SMOs provided resources for their constituents in a movement against Nike's worker conditions via the Internet. Anti-Nike SMOs provided virtual training sessions for big protests, online handbooks, chants, campaign starter kit, petitions, sample letter to university officials and Phil Knight, strategies, advice on planning rallies and demonstrations at sports events, fact sheets, sample press releases, fliers, educational anti-sweatshop workshops, contact list of college presidents, to name a few. Additionally, one SMO created a listerserv to update constituents on the changing conditions, lend support in real time, give information on how to contact Nike directly, and organize "National Days of Action". The above mentioned were important resources for non-athlete activists and not created specifically for Olympic and professional athletes. 
While RMT was the dominant approach to SMT until the late 1990s, major critiques of the approach dampened the importance of the approach. The RMT approach, focusing on the motivation, recruitment, strategy, tactics, and the like (Buechler, 1993), leaves out the "contingency, emotionality, plasticity, and interactive character of movement politics" (McAdam, Tarrow, \& Tilly, 2001, p. 15). Additionally, the RMT approach failed to investigate movement diversity, which can lead to different resources, analyzing collective identity, and bringing culture into social movement outcomes. Most importantly, perhaps, the RMT approach investigates the meso-level of analysis (organizational component), while failing to investigate the micro-level (individual) and marco-level (greater societal structure) levels of analyses (Buechler, 1993).

Political Process Theory. The PPT is another approach to SMT focusing on the physical political entities and how the entities hinder or permit social movements. Following the emergence of RMT, theorists of the political context approach focused more on movement successes and failures as opposed to SMO infrastructure (as with RMT). In other words, the PPT focuses on the factors external to movements that can determine the outcome's ability to succeed (Caniglia \& Carmin, 2005). Meyer (2004) noted that the point of the PPT "was that activists do not choose goals, strategies, and tactics in a vacuum" (p. 127). Instead, the political context helps set the grievances around which activists mobilize. The framework is broken into three variables in order: political opportunity structure (POS), configurations of actors/power, and interaction contexts (Kriesi, 2004).

Political opportunity structure. The POS is the core of the political process framework as it influences protest strategies and the impact of social movement on the 
environment (Kriesi, 2004). At its basis, POS is split into political institutions and cultural modes. Political institutions include open and closed structures of the dominant political entity (Eisinger, 1973). The degree of openness is determined on its territorial centralization and its degree of separation of power. Open structures allow for easy access into the political system, as opposed to closed systems, which limit political access. This was further compounded by Kitschelt (1986) who linked open and closed systems to inputs and outputs. An open system, while allows for more access, has a limited capacity to output policy as external sources can easily input frames. Conversely, a closed system has a greater capacity to act and produce output due to the lack of input from external sources. The nature determining open and closed POS is derived from the structure's degree of decentralization. A decentralized structure, implied by multiple state actors, allow for more openness and greater significance at the national, regional, and local level. A prime example of this is the United States with strong government presence at the local, state, and national levels. On the other end, a centralized structure, like that of France, places less significance at the national, regional, and local level thus closing the political structure and generating a stronger output potential. The structures closed and centralized are more likely to be strong states (e.g. North Korea), as oppose to weak states (e.g. United States). As one can imagine, the type of system, open or closed, can determine the strategy a political entity uses when being challenged. Closed systems will utilize exclusive strategies of repression, confrontation, and polarization to interact with challengers. Whereas, open systems will be more integrative with their strategies and facilitate, cooperate, and assimilate with challengers (Kriesi, 2004). Kriesi argues that the reason for a political system being open or closed is in part due to the history and culture 
of the nation. However, open and closed systems are just one model to view the institutional opportunities social movements have to challenge the political elite.

The other is a cultural model emphasizing on social movement frames called discursive opportunity structure (Koopmans \& Statham, 1999). Koopmans and Statham argue the mobilization and success of a social movement is the social movement's ability to be visible to the public, resonate with public opinion, and be considered legitimate by the audience. The authors argue success and mobilization will be more successful if "(1) the more dominant discourse on national identity and citizenship corresponds to and legitimates the ethnic-cultural ideal-type of national identity, and (2) the less the dominant conception of the nation is grounded in and legitimized by civic-political elements" (p. 72). Koopmans and Statham combine their discursive opportunity with more structured institutional opportunities. When neither discursive nor institutional opportunities are available, the challenger (social movement) will find no support for their thoughts or actions, nor will they have access to a political entity. When discursive opportunities area available, but not institutional opportunities (closed political structure), the challenger will be stifled by the political elite. The political elite will discard any of the frames and claims that conflict the dominant ideas. Third, there are no discursive opportunities, but access to the political structure is open, the challenger is likely to be co-opted without real gain. Finally, the challenger will find success when the discursive and institutional opportunities are both available. The political institutions and culture offer variables within the POS and serve as the first step in the political opportunity model. The configuration and power of the actors provides the next step in the model. 
Configurations of actors/power. Once the POSs are identified, investigation into the actors and power of the actors is a logical next step. From the viewpoint of a social movement, the configuration of actors is split into: protagonists, antagonists, and bystanders (Hunt, Benford, \& Snow, 1994). Protagonists are the allies, including policymakers, public authorities, the media, related movements, etc. Antagonists represent those in an adversarial position to the social movement, including countermovements, repressive agents, and other public authorities. Finally, bystanders are those not directly involved with the social movement, but are attentive to the social climate surrounding the social movement. Actor configurations include the knowledge of the set of actors at a given time (capabilities, perceptions, and evaluations of outcomes, and comparability with other sets of actors). The configuration of political actors is somewhat determined by the structures of the political context (Kriesi, 2004). Kriesi noted the importance of an ally and conflict structures between a political actor and the social movements. The configuration of political actors is much less stable than the structure of political context. For instance, a social movement has an easier time modifying the configuration of political actors than the structural political context. A political elite looking to advance his/her own agenda might provide a social movement with a natural ally in the political structural political context. This serves as a bridge from the formalized structures of POS, to the third component the interaction context.

Interaction context. The last level of the framework for studying the political context is the interaction context, which is influenced by the structural context and configuration of actors. This level is concerned with strategies utilized by social movements and their opponents by linking structures and configuration to agency and 
action (Kriesi, 2004). Social movements focus their attention on the context-specific opportunities social movement actors take to challenge the social norms. Kriesi noted the internal struggle of social movements to determine factors influencing the benefits and costs of collective action (means) and the factors related to the desired outcomes of action (ends). From a political environment lens, the movement's actors should determine the risks and gains from each strategic option for action for both their means and ends. Focusing on the action (means), political authorities may impose sanctions to make collective action more difficult (repression) or provide resources or moral support for a favorable movement (facilitation). Switching to the outcomes, after action takes place, the political authorities may reform, or respond favorably by changing policy. Conversely, political authorities could provide a threat by responding unfavorably and changing policies in the opposite direction of the movement's goals. Of course, there is always the chance neither reform or threat happens if the authority does not respond. Movement actors are expected to basis their strategic decisions on the chances of reform or threat, and the risks of repression or reward of facilitation. Once the action between the social movement and its adversaries begins, the impact will be felt back on the political context and the configuration of actors (Kriesi, 2004).

Institutional assets (e.g. open, weak) do not explain: emergence of movements, levels of mobilization, or existence of protests (della Porta \& Diani, 2006). For example, an open institution will have more access points for the social movement, but also provides more opportunities for rejection from the polity or access points for countermovements. Similarly, a closed institution can provide quick social movement victories as few channels are needed to go through, but those victories can easily be 
stopped if the few channels are antagonistic to the social movement ideals. The institutional context can help explain which strategies are more effective (della Porta \& Diani, 2006). In the 1970s, the New York City LGBT movement faced a closed and hostile polity. Opposition, in the form of police beatings and discrimination, was routine (Bernstein, 1997). LGBT SMOs relied on more theatrical tactics (i.e. marches, rallies, kiss-ins) to gain societal support in hopes of enacted change. In Oregon, conversely, access to the polity was available. Thus, Oregon SMOs discouraged mass participation and favored closed-door meetings with council members (Bernstein, 1997). Therefore, there is an expectation that an open polity will yield different approaches and tactics than a closed polity.

The political context has played an important role in sport social movements. Pelak (2002) noted the benefit Title IX legislation had in providing a collegiate women's ice hockey team an opportunity to be a varsity sport. Due to Title IX, the college's gender equity record was under intense examination. The opportunity provided one of the hockey players with an opportunity to request varsity status for the women's hockey team. In anticipation, the athletic department agreed to the request and pledged $\$ 50,000$ for travel, equipment, lodging, and tournament fees over the next three years. Pelak (2005) also noted the importance of the abolition of apartheid for netball players. The apartheid government instituted separate sport federations for Africans, Whites, Coloreds, and Asians (Booth, 1998). Once apartheid ended and an opportunity to mobilize was present, formal discussions started on desegregation of the four leagues. The ending of apartheid opened up the political context structure and many seized the moment to reinstituted de-segregated leagues. Outside of the strictly legal political opportunities, two 
other political opportunities provided an opportunity for the African peace movement (Wilson et al., 2015). Kenyan runners, in their organization of the Run-For-Peace event, utilized the upcoming Olympic Games and Kofi Annan (former Secretary-General of the United Nations) as an opportunity for peace. The approaching Games served as a beacon for unifying a Kenyan nation amidst civil war. Additionally, athletes were able to claim they were unable to train in a country at war. The Games provided the mechanism for the movement to occur and a successful Run-For-Peace event. The other opportunity was a Kenyan visit from Kofi Annan. Annan mobilized people to come together, talk, and discuss peace. The aforementioned studies examined how federal legislation and major sport governance provided opportunities for movement successes within and using sport. However, the studies failed to provide an in-depth understanding of how to work with both federal legislation (i.e. U.S. Government) and a major sport governance entity (e.g. NCAA) concurrently.

Critiques of the political approach to examining social movement success are plentiful (Goodwin \& Jasper, 1999). First, the political opportunity approach does not properly examine social movements that specifically avoid changing the polity in favor of changing societal norms, such as the religious, utopian, or self-help movements. Second, Goodwin and Jasper build on a critique often utilized to combat resource mobilization: anything that helps a social movement is seen as a political opportunity. While political opportunity approach theorists attempted to ensure the political opportunity was specific to structures, fixed, stable and mechanisms outside of a movement's control, strategies and cultural messages were subsumed into the political approach. In summation, the 
political opportunity approach fails to recognize the cultural factors that influence social movements (della Porta \& Diani, 2006; Goodwin \& Jasper, 1999).

Cultural Theory/Frame Analysis. The latest approach to gain steam in SMT research comes in the form of the Cultural Theory/Frame Analysis, a framework emerging in the United States around the 1980s (Williams, 2004). This newer theory derived from two claims: 1) new social movements indicated a shift to a postindustrial economy and 2) new social movements are unique from older, working class movements (Pichardo, 1997). Post-World War II, the new social movements focused on the cultural understandings, norms, and identities (i.e. LGBT equality, race relations, etc.) instead of economic distribution and material differences (i.e. working class and elites; Williams, 2004). Adults, post-1960, experienced unprecedented access to education, reduced exposure from war, and high levels of affluence. The result was a focus on affirmation of expressive needs (della Porta \& Diani, 2006). The theory calls for scholars to focus on the affirmation of expressive needs through symbols, language, discourse, identity, and other cultural artifacts influencing members to join, mobilize, and retain members (della Porta \& Diani, 2006; Williams, 2004). The symbols and cultural artifacts are the major way social movements can organize their grievances and desires for actions towards bystanders and opponents. Unlike the PPT framework, the cultural context focuses on the movement, meaning the social movement, its activists, and the meanings associated with the movement. The cultural context brings about the focus of movement-centric, instead of context-centric. Despite its close nature to RMT, the cultural context investigates the demand side of collective action (grievances or shared identity), instead of the structural factors of a SMO (money, membership, organization, etc.). 
The paradigm is often derived from Goffman's (1974) discussion on frames.

Frames are defined as interpretive schemas that enable individuals "to locate, perceive, identify, and label occurrences within their life space and the world at large" (Snow, Rochford, Worden, \& Benford, 1986, p. 464). As della Porta and Diani (2006) noted, the symbolic production of frames allows individuals to attribute events and behaviors, of individuals or groups to facilitate the activation of mobilization. Social movement frames can differ in several ways: problem identification and direction/locus of attribution, flexibility and rigidity, inclusivity and exclusivity, interpretive scope and influence, and resonance (Benford \& Snow, 2000). The last variation, resonance, is important as it attempts to understand the success of frames. In other terms, why do frames resonate (or not resonate) with individuals? Two sets of factors attempt to describe frame resonance: credibility and salience (Benford \& Snow, 2000; della Porta \& Diani, 2006; Williams, 2004).

Credibility of frames. The first major function of frame resonance is credibility. Frame credibility is a function of three factors: frame consistency, empirical credibility, and credibility of the frame articulators (Benford \& Snow, 2000; Snow \& Benford, 1988). Frame consistency is the ability of a social movement or SMO to articulate consistent beliefs, claims, and actions. In other words, are the frames portrayed by the organization and its constituents contain a unified message? Empirical credibility is the fit between the frames and the events of the world. In other words, are the frames empirically verified? Finally, the credibility of the frame articulators is related to credibility. The individual articulating the frame must have a certain height of status or perceived expertise to appeal, and ultimately mobilize, adherents or constituents. Benford 
and Snow (2000) claimed, theoretically speaking, the more consistent the frames, the higher the empirical credibility, and the greater the credibility of the frame articulators will lead to a more credible frame. From a celebrity activist stand point, the green movement (Winge, 2008), animal rights movement (Simonson, 2001), Live 8 movement (Davis, 2010), and LGBT movement (Engel, 2001) to name a few movements, used celebrities as perceived credible frame articulators. Celebrities with a good fit to the social issue will be more credible and a better spokesperson (Wheeler, 2009). However, most celebrity activism research agrees that celebrity activists struggle with inconsistency among their frames (Brockington \& Hensen, 2015; Davis, 2010; Dieter \& Kumar, 2008; Huliaras \& Tzifakis, 2012; Kogen, 2015; Winge, 2008).

Salience of frames. Another major function of frame resonance is salience (Benford \& Snow, 2000; Snow \& Benford, 1988). Salience is also a function of three factors: centrality, experiential commensurability, and narrative fidelity. Frame centrality is how essential the values, beliefs, and ideas of the movement frames to the lives of the targets for mobilization. For instance, a pro-LGBTQ individual might find pro-LGBTQ frames salient, but they may not find pro-choice as salient to their beliefs and ideas. Thus, the individual may reject parts or entire frames from social movement organizations as the frames do not align with the individual's beliefs. Experiential commensurability investigates the movement's frames and their relation to the everyday lives of the targets of mobilization. Are the frames congruent or too abstract and distant from the lives and experiences of the targets? Finally, narrative fidelity investigates the cultural relevance of the frames. The frames have to be relevant and legitimatized to society (Snow \& Benford, 1988), fitting within the stories, myths, and folk tales that are part of the society's cultural 
heritage (Gamson \& Modigliani, 1989). Once again, Benford and Snow (2000) theorize the more central, experientially commensurate, and greater the narrative fidelity of the proffered framings, the more salient the movement's frames are to targets. As experienced by the LGBT movement, legal victories and the creation of more LGBT SMOs seldom occurred for LGBT population without the development of salient frames to ensure a cultural backing from society (Bernstein, 1997; Bernstein, 2003; Kane, 2010). Celebrity activists experience difficulties in creating salient frames to their audience. Kogen (2015) postured UN celebrities struggled to provide advice as to how regular citizens can help in Darfur and the fight against AIDS and HIV, missing out on the centrality of the frames. Winge (2008) noted Vanity Fair's special issue, "Green is the New Black", which highlighted celebrities and models donning green friendly garments, known as ecofashion. Ecofashion represented a luxurious style and cultivated taste, which created a disconnection of salience between celebrities and the regular individual. The movement frame missed the experiential commensurability of the targets. Research has yet to examine the celebrity activist and narrative fidelity. Additionally, research has yet to examine salience in respect to athlete activists.

Investigating credibility and salience of frames within sport, few studies have investigated how frames are used within sport. Focusing on credibility, Wilson et al. (2015) noted elite athletes could be perceived as skilled and appropriate leaders and peaceful people for short-term peacebuilding efforts. Thus, athletes have the ability to be perceived as credible in their activism. However, the study investigated elite runners for an initial event, Run-For-Peace in Kenya. The investigation of a formalized organization that employs hundreds of athletes not surrounded by a particular event, has yet to be 
investigated. Specifically, concerns over the consistency of the frames with so many athletes arise for the credibility of the frames. Shifting towards salience, Schwirian, Curry, and Woldoff (2001) noted the importance of salient frames in a movement to prevent public fundraising for an arena and stadium in Columbus, Ohio. The anti-public funding movement framed the issue of public funding as corporate welfare, class privilege, fiscal irresponsibility, and the righteous citizen. The frames were salient to the voters as they captured their values, beliefs, and priorities. The result was victory for the anti-public funding movement, despite being economically and politically inferior to the opposing movement. The study from Schwirian, Curry, and Woldoff (2001) investigated how an ad hoc organization framed their cause, but the organization did not have celebrity athletes articulating their frames to non-celebrity individuals.

Like the other two tenets of SMT, the cultural context/NSMT/framing approach has critiques. An obvious critique is the notion that the cultural context is different to everyone. Therefore, frames can resonate with some individuals, but not others. One major critique is the explanatory capacity of frames towards collective actions and social movements towards the success of the movement. della Porta and Diani (2006) sum of this critique when they ask, "Is it more important, for the success of a social movement, to have good communicators, or to operate in favorable political conditions, such as divided elites?" (p. 85). Because of this critique, partnered with the critiques of resource mobilization and the political context, that the current study will examine all three approaches to SMT. The purpose of the study, then, was to investigate the resources provided to and from athlete activists, tactics for engaging with political structures, and frames utilized by Athlete Ally. 


\section{LGBTQ Movement in the United States}

The current section discusses the lesbian and gay movement (later LGBTQ movement) bounded by pre-World War II $20^{\text {th }}$ century to the early $21^{\text {st }}$ century in the United States. Before World War II, homosexuality was present, but invisible. In fact, many had not heard about what homosexuality was or did not meet others who expressed their non-heteronormative views. It was the catalyst of World War II that set the foundation of the lesbian and gay movement. World War II, for the first time in the postindustrial era, separated the nation into men in one area and women in another area. Men, once enlisted in the army, were thrust together in an environment promoting masculinity and athleticism. Additionally, the army was known for a) homoerotic language and b) encouraging men to buddy up with one another. Women, who replaced men in the work place, were also put into a situation of living in houses with other women. They were encouraged to make female friends their only companions. World War II did not cause people to identify as homosexual, but provided the opportunity, for the first time in America's history, for men and women who were attracted to members of the same sex (Engel, 2001).

The return of male troops to America brought the return of heteronormative ideology (Engel, 2001). Being gay or lesbian was not as accepted, especially as medically homosexuality was labeled a contagious disease (Renn, 2010). The one surviving piece of the foundation of the lesbian and gay movement was the networks built from the war of individuals who identified as lesbian and gay. Bars, which were viewed as safe places for gay and lesbian individuals, were appearing in New York and Los Angeles. During the period from the 1950s-1960s, the lesbian and gay movement started as the homophile 
(read: same love) movement. The homophile movement was a few gay and lesbian advocacy organizations advocating for homosexual acceptance. Two prominent ideologies spilt the homophile movement: 1) militarized condemning of heteronormative ideology, and 2) assimilative ideology of emphasizing the notion that the difference between a heterosexual and homosexual is one minor detail. The first ideology was the dominant ideology of the early part of the two decades, whereas the assimilative ideology gained increased traction towards the later ends of the 1960s until the Stonewall Inn riots (Engel, 2001).

On June $28^{\text {th }}, 1969$, a group of roughly 200 police officers raided the Stonewall Inn, a popular gay bar in Manhattan. While the act of police raiding a gay bar was not new or uncommon, the response was. For the first time, the individuals inside the gay bar rioted. The riots lasted two days pitting hundreds of police against thousands of protestors. Many point to this event as the spark of the lesbian and gay movements in the United States. Instead of promoting one as being "homophile" the emphasis was on one being "gay". Being gay was a process beyond coming out. One who was gay accepted their identity. SMOs dedicated towards homosexual equality quickly spread throughout the nation. Support was increasing for homosexual individuals. However, the rifts within the movement were ever present. The combined lesbian and gay movement started to break apart as the lesbian movement believed the gay movement was only in the fight for their own equality and were not concerned about the lesbian movement. Further, the oppression for lesbian individuals was twofold as 1) they were lesbian and 2) they were women. A second rift, a much more macro-intensive issue, also created struggles within the lesbian and gay movement. The lesbian and gay movement questioned its 
involvement with other "New Left" movements, such as race, feminist, and other movements. While some believed the lesbian and gay movement should concentrate its efforts on their movement and no other movements, some believed the lesbian and gay movement could help be benefitted by helping others. The end result was the end of the collective lesbian and gay movement, and the start of the LGBT movement. The LGBT movement found benefit in incorporating multiple identities and cultures. During the 1970s, the homosexual movement witnessed an explosion of pride, accompanied with risky behaviors including unprotected sex, drugs, alcohol, and partying (Engel, 2001). At the beginning of the 1980s, five men were diagnosed with a curious form of cancer. By the end of 1980s, 300,000 individuals would die from a disease known as AIDS, (210,000 being gay males; Engel, 2001). The 1980s saw increased support for gay and lesbian individuals at a terrible cost of hundreds of thousands of individuals within the community. When AIDS first hit, there was a tremendous amount of backlash towards the gay community because it seemingly focused on gay men. Support came to the now-LGBT movement when AIDS was not only found within gay and lesbian individuals. AIDS affected everyone; in turn causing support for the LGBT movement. The LGBT movement focused their efforts on showcasing how the disease was killing their friends, co-workers, individuals they knew. While the AIDS movement caused a tremendous amount of support for people with the lesbian and gay community, the movement detracted away from the lesbian and gay movement. Instead of focusing on the rights of lesbian and gay individuals, the movement was focused on safety. Lesbian and gay SMOs were committed to providing education on safe sex. 
The 1990s brought about unimaginable support and visibility to the LGBT movement. The LGBT movement found allies in presidential candidates (i.e. Bill Clinton) and celebrity activists (e.g. Courtney Love) fighting for the rights of LGBT individuals. Visibility was also skyrocketed as Hollywood was not only involving gay actors, but also creating entire shows or storylines about gay individuals (e.g. Big Daddy, Ellen, Darma and Greg, Will and Grace). The 1990s brought about another change in terms as the term gay was supplanted for queer (Kulick, 2000). Being queer was once again met with a sense of pride. It also was an umbrella term to capture the LGBT movement. Finally, a major rift began when being queer with synonymous with gay, young, middle to upper class, white male. Those who did not fall into that category were seen as outsiders and cast away (Engel, 2001).

\section{LGBTQ Movement and SMT}

Due to its time period, the LGBTQ movement has witnessed considerable scholarly attention from the viewpoint of Social Movement Theory. Scholars have utilized the three approaches separately and combined to create a picture of the social movement from different points. Just as the evolution of SMT emphasized resource mobilization in the earlier years of SMT, moving towards political context, and now incorporating the cultural factors/framing with their predecessors, so too did the study of the LGBTQ movement.

Utilizing a resource mobilization approach, scholars investigated the strategies of early gay and lesbian social movement organizations. The passive strategies used by the homophile movement in the 1960s were unsuccessful (Bernstein, 2003; Ghaziani, Taylor, \& Stone, 2016). Due to a lack of energy and resources and focused on preventing police 
brutality (Bernstein, 2003), few SMO goals were accomplished. Post Stonewall Riots (1969), however, witnessed a change in strategy for gay and lesbian SMOs (Bernstein; 1997; Bernstein, 2003; Ghaziani, Taylor, \& Stone, 2016). Social movement organizations were proactive, creating shirts, campaigns, flyers, a language to discuss sexuality and politics (Bernstein, 2003). Additionally, the use of aggressive tactics like a gay pride parade, "out of the closet, into the streets" activities, and demanding the removal of homosexuality from the mental disorder list, created positive outcomes for social movements (Ghaziani, Taylor, \& Stone, 2016). The use of protest-orientated tactics served to boost media attention for LGBT SMOs, but only for a short period of time. Well-resourced and inclusive identity SMOs incurred sustained media attention when positive change happened (Elliot, Amenta, \& Caren, 2016). This attention converted into significant political victories during the late 1970s and into the 1980s and 1990s.

The political opportunities for gay and lesbian and LGBT SMOs evolved over the later part of the $20^{\text {th }}$ century. In the 1970s, gay and lesbian SMOs faced a closed and hostile polity in New York. The closed polity strengthened the identity of the movement on the east coast. Oregon, on the other hand, had an open polity. The SMO elites had closed door meetings with the Oregon polity passing anti-discrimination legislation, but unsuccessfully managed to create a positive relationship with grassroots activists (Bernstein, 1997). Dorf and Tarrow (2014) noted the importance of an opening polity towards gay and lesbian social movement organizations. Three land mark cases in the 1990s and 2000s in the courts lead to an acceptance of gay rights. In 1993, court case Baeher v. Lewin was the first serious debate about same-sex marriage, as the Hawaii's Supreme Court believed gay and lesbian couples might have the right to marry. Romer $v$. 
Evans, in 1996, provided the United States Supreme Court's first pro-gay-rights ruling. Justice Anthony Kennedy's opinion was not ready to say discrimination about gays and lesbians were unconstitutional, but condemned Colorado's Amendment 2 as it specifically attempted to prevent protection for LGBT individuals. Seven years later, Lawrence v. Texas, the Court determined the Texas law forbidding sodomy (but only for same-sex partners) was unconstitutional. The Court's opinions were becoming increasingly pro-gay-rights, leading to the increase in the presence of a countermovement.

As LGBT rights started to widen in the 1990s and 2000s, anti-LGBT SMOs started to use specific frames to push back on LGBT movement (Dorf \& Tarrow, 2014; Ghaziani, Taylor, \& Stone, 2016; Miceli, 2005). In the 1990s, the LGBT movement suffered from an identity issue. Debates over bisexuality and trans people's inclusion into the gay and lesbian movement occurred in gay and lesbian publications. Individuals identifying as bisexual and transgendered blurred the "membership line" as membership of the group was unclear. This specific debate gave rise to the collective identity of the LGBT community, which is necessary and damning. While the collective identity gave the LGBT community a voice, it also allowed the community to be scrutinized. The LGBT movement was facing increasing scrutinizing from the Christian Rights groups. Dorf and Tarrow (2014) noted the rise of the pro-same-sex marriage platform by LGBT SMOs was a response from an anti-gay-rights countermovement. A countermovement seeks to preserve the status quo or repeal recent changes to the status quo (Dorf \& Tarrow, 2014). Christian Rights SMOs, part of the LGBT countermovement, witnessed the pro-gay-rights ruling by the Supreme Court and perceived same-sex marriage as an 
end goal for gay and lesbian social movement organizations. The Christian Rights SMOs employed the strategy of framing same-sex marriage as the destruction of the American family. The destruction of the American family was used as a morality frame, claiming social order would be ruined if same-sex couples were allowed to marry. Christian Rights SMOs utilized a similar strategy for anti-discriminatory practices in public education (Miceli, 2005). Their assumptions that same-sex was an end goal for the LGBT movement, as the LGBT movement had no initial intention on pursuing same-sex marriage legislative changes until the countermovement advocated banning same-sex marriage. It was not until grassroots activists witnessed the countermovement present their frames that LGBT SMOs were pressured by grassroots activists to mobilize.

While the use of all three approaches to SMT shifted in importance throughout the LGBTQ movement, the use of all three approaches paints a holistic picture of the movement. Bernstein (2003) noted the change in strategy by gay and lesbian SMOs postStone Wall riots to target the cultural climate, instead of just the political context. By creating languages to discuss sexuality, designing shirts and campaigns, gay and lesbian SMOs were able to gain significant allies in society through the normalization of samesex relationships. Television shows like Will and Grace and books publication discussing same-sex relations were becoming more popular and recruiting more allies. The allies helped advocate on the behalf of gay and lesbian SMOs to slowly start to open the political system for gay and lesbian rights (Dorf \& Tarrow, 2014). In response, a countermovement started to develop frames to prevent more legal victories for the LGBT movement (Dorf \& Tarrow, 2014; Ghaziani, Taylor, \& Stone, 2016;). The destruction of the American family and appealing to morality frames were unsuccessful as the frames 
never evolved as society increasingly believed gay and lesbian individuals deserved civil rights (Miceli, 2005). Without a doubt, the cultural support lends itself to significant legal victories in the United States (Bernstein, 1997; Bernstein, 2003; Kane, 2010) and abroad (Calvo \& Trujillo, 2011). The opening of the political system through anti-discrimination legislation and cultural support for the LGBT movement generated more gay and lesbian SMOs to further the movement towards the present (Kane, 2010). By utilizing all three approaches of SMT, one is open to seeing how the focus on the SMO strategies leads to significant cultural victories, which mediated the political victories.

\section{LGBTQ Movement and Sport}

The LGBTQ movement in sport has progressed through many years of exclusionary practice to lead to today's landscape of ever increasing inclusion. Sport was known, and is still known, to reinforce dominant heterosexual hegemony. As Sartore and Cunningham (2009) stated, LGBTQ athletes, coaches and players are often cast out as "other," face negative stereotypes, and experience status loss within sport for their sexual orientation or preference.

In an interview with renowned LGBTQ and sport researcher, Dr. Pat Griffin, the history of LGBTQ athletes in sport was discussed (Sartore-Baldwin, 2012). Prior to the 1950s, homosexuality in sport was rarely discussed, invisible to the athlete environment. Even as the world entered the mid and late $20^{\text {th }}$ century, homosexuality was stereotyped against men and women differently. Questions surrounding a male athlete being gay were

not even considered in the athletic environment until recently. Gay men were supposed to be weak and non-athletic, so it was inconceivable for society to accept a prominent athlete being gay. For female athletes, homosexuality was used a tool to attempt to 
discriminate women or prevent their athletic success. When a woman started to dominate her sport, much like Billie Jean King and Martina Navratilova, their sexual orientation was questioned. Thus, homosexuality was used to limit participation or discriminate against women. If a woman were to come out as a lesbian, it would certainly destroy her image and career. Women had to remain quite about their sexual orientation during their career. As Dr. Griffin stated, it was not until the late 1990s that this mindset started to change towards a more inclusive today (Sartore-Baldwin, 2012).

The explosion of LGBTQ inclusivity in the athletic realm can be attributed to the likes of Bill Tilden, David Kopay, Billie Jean King, and Martina Navratilova (Carrol, 2016). The aforementioned individuals were some of the first athletes to come out as gay or lesbian. Per Carrol, the LGBTQ sports movement made significant progress on the backs of two complementing fronts: 1) LGBTQ coaches or administrators confronting their own sexuality or identity while maintaining careers and 2) efforts to ensure LGBTQ athletes and participants are comfortable with their sexuality or identity through finding support from their teammates. To the first point, coaches and administrators hold the power to dictate the culture on inclusivity (Sartore-Baldwin, 2012). If a player was gay or lesbian, but the coach was dismissive of LGBTQ individuals, the player would quietly transfer to another school or play for find another team. The culture, however, was available for inclusive change when LGBTQ individuals were in those positions of power. This point is never more evident than in the study performed by Krane and Barger (2006). The researchers interviewed lesbian college coaches about their experiences working in collegiate basketball. The coaches noted the negative stereotypes surrounding lesbian coaches, so much so, that only one of the 13 coaches were openly gay. The others 
felt the need to conceal their identity. When asked how to change their social climate, the coaches noted being an example of a successful lesbian coach, promoting inclusive dialogue in the team, and being accepting of all teammates, regardless of their lifestyle (Krane \& Barger, 2006). Through the strategies mentioned by the coaches, an inclusive environment can be created.

The first front coincided with the efforts to ensure LGBTQ individuals were comfortable participating in sport and had support for their teammates. The later front has been the subject of much scholarly attention (Anderson, 2011; Bush, Anderson, \& Carr, 2012; Cunningham, 2015). Anderson (2011), in a comparison of openly gay high school and university athletes between 2008 and 2010 and then 2000 and 2002, found that the 2010 cohort experienced less heterosexism and maintained better support from their teammates than the 2002 cohort. Instead of having their sexual identities silenced, teammates used their sexual identities as a source of pride and found it furthered the bond between gay and non-gay athletes. Bush, Anderson, and Carr (2012) examined the views of male athletes towards homosexuality throughout four years of college athletics when the individual shared a locker room with a gay player or coach. After being interviewed in their freshman year and their final week of college, the researchers revealed there were significantly more positive views of homosexuality by the straight athletes. When thrust into a situation with a gay teammate or coach, straight players tended to get rid of homonegativity over time in favor of support for their teammates. While athletes can ensure LGBTQ individuals feel comfortable participating in sport through their support, sport institutions can offer systematic support. Cunningham (2015) noted LGBTQ inclusive athletic departments can serve as agents of social change by calling out 
exclusionary practices, be an active model of inclusion and show a pragmatic alternative for other athletic departments. In summation, the two fronts helped provide today's more inclusive landscape. Despite the gains, there are still exclusionary practices by some institutions towards LGBTQ athletes, coaches and participants. 


\section{CHAPTER III}

\section{METHOD}

The following chapter outlines the methodology used for the proposed study. First, the researcher reviews the purpose and research questions. Then, the researcher provides an overview of the research design: a qualitative, social constructivist case study. The case, Athlete Ally, is described in detail in the following section. Finally, the data collection and data analysis are outlined, followed by the methods used for ensuring trustworthiness.

\section{Purpose}

The purpose of the study was to investigate the resources exchanged between Athlete Ally and their athlete constituents, tactics for engaging with various governing bodies, and tactics for ensuring frame resonance by Athlete Ally using Social Movement Theory. The case, Athlete Ally, was chosen as athlete activism in the United States continues to rise and Athlete Ally is one of the most prominent sport SMOs in the United States.

\section{Research Questions}

The following research questions were aimed at understanding the purpose:

RQ1a: What resources are provided from Athlete Ally to athlete constituents?

RQ1b: What are the perceived resources athlete constituents provide Athlete
Ally? 
RQ2: What strategies does Athlete Ally utilize to engage with various governing bodies?

RQ3: How does Athlete Ally create resonant (credible and salient) frames?

The research questions were derived from the organization's make up and interactions with various governing bodies and the public. The first research question was created because the organization under examination, Athlete Ally, frequently partners with athletes. These individuals are known as Athlete Ambassadors and are comprised of professional, Olympic, and international athletes. In addition, Athlete Ally forms partnerships with university clubs, known as College Chapters. Determining what resources exchanged between the athlete constituents and Athlete Ally allows the researcher to determine the benefit of the partnerships. Thus, research question one investigated the specific resources exchanged between the two entities.

The second research question, which investigated political interactions with various governing bodies, is derived from the recent movement activity. While Athlete Ally has partnerships with many leagues across the world, the NCAA and NBA are two of the most visible entities Athlete Ally interacts with. For instance, Athlete Ally worked with the NCAA and NBA in their decision to pull seven 2016-2017 NCAA championships and the 2017 NBA All-Star game, respectively, out of North Carolina due to the 'bathroom bill' (Ellis, 2017). The 'bathroom bill', known as House Bill 2 (or HB2), was discriminated against people who use public restrooms and locker-rooms based on their identified gender (Aschburner, 2016). The bill was not specifically related to sport or athletic facilities, but Athlete Ally still worked with the NCAA and NBA to pressure the North Carolina government into not passing the bill. House Bill 2, was not legislation 
derived from any sport league, but from a part of the U. S. Government. Thus, because of Athlete Ally's working relationship with the NCAA and NBA to enact change within these organizations and the U. S. Government, research question two investigated the interactions with those three entities.

The final research question examined how Athlete Ally ensures their frames resonate with the public or other athletes. Following the Cultural Theory/Frame Analysis, today's movements are more about identity and cultural acceptance and not economic differences (della Porta \& Diani, 2006). Understanding how Athlete Ally perceives and ensures their frames to resonate with a larger collective is important as without resonate frames, movements are less likely to succeed (Schwirian, Curry, \& Woldoff, 2001). Thus, the final research question aimed to understand how Athlete Ally creates resonant frames.

\section{Research Design}

A qualitative methodology was utilized to satisfy the purpose of the current study. Denzin and Lincoln (2011) offer a recent definition:

Qualitative research is a situated activity that locates the observer in the world. Qualitative research consists of a set of interpretive, material practices that make the world visible. These practices transform the world. They turn the world into a series of representations, including field notes, interviews, conversations, photographs, recordings, and memos to the self. At this level, qualitative research involves an interpretive, naturalistic approach to the world. This means that qualitative researches study things in their natural settings, attempting to make sense of, or interpret, phenomena in terms of the meanings people bring to them (p. 3). 
A qualitative methodology was appropriate for this specific study for several reasons. First, qualitative research is appropriate when a study seeks to examine complex problems (Creswell, 2013). Between investigating Athlete Ally and its athlete ambassadors through three different lenses, understanding the perceptions from both the SMO and its constituents, and the paucity of SMT research in sport settings, complex problems arise and deserve exploration through qualitative methods. Second, qualitative methodologies empower individuals to tell their story, offer a space to hear their voices, and minimize the power relationships between researcher and participant (Creswell, 2013). Through qualitative interviews, the researcher attempted to empower the participants to explain their perceptions of their activism and the SMO with which they associate. Third, qualitative methodologies gain a deep understanding of one or few participants (Creswell, 2013). The in-depth knowledge from a few participants provided the depth and detail needed to answer the research questions, a task unsuitable for quantitative methods. Finally, qualitative research is appropriate when quantitative does not fit (Creswell, 2013). Given the complexity of Social Movement Theory and the study research questions, a quantitative methodology would be lengthy and tiresome for participants. Quantitative methodologies are more structured than qualitative data, leading to a rigid and inflexible method. The qualitative approach allowed for a more fluid approach to research (Patton, 2015), an attribute needed for the proposed study.

\section{Social constructivist framework}

The current study utilized a social constructivist framework. A social constructivist framework assumes individuals try to make sense of the world they live in through socially constructed models, theories, symbols, and other representative entities 
(Creswel, 2013; Crotty, 1998). Each individual interprets and constructs the world in a different manner, therefore, it is important to gain a deep understanding of many points of view within the study (Creswell, 2013; Schwandt, 2000). The researcher gained a deeper understanding of the participants' views through multiple means. First, the researcher positioned himself as close to the subjects as possible to learn how the participants created and made sense of the activist world. As Crotty (1998) mentioned, researchers must recall that different people inhabit the world in different ways. Gaining a deeper understanding from each participant in the study helped the researcher make sense of those realities and the differences and similarities between them. In addition, the researcher positioned himself by acknowledging his own personal, cultural, and historical circumstances (Creswell, 2013). Second, the researcher utilized multiple data sources to get a better perspective of the issue. Qualitative methodologies attempt to take the reader into the setting observed (Patton, 2015). Thus, multiple sources of data yield multiple perspectives of the situation or issue from which the reader can create a holistic picture. Finally, the interview questions developed were broad to allow the participants to construct the meaning of the situation, typically formed by interactions with other individuals. The broad questions allowed the participants to construct meaning of the situation from the questions asked (Creswell, 2013).

\section{Case Study}

A case study is an empirical inquiry that investigates a contemporary phenomenon within its real-life context, especially when the boundaries between phenomenon and context are not clear (Yin, 2009). According to Yin, a case study approach is appropriate in three contexts. First, the research questions contain "what", 
"how", and "why" questions. While "what" questions are more appropriate for surveys or experiments, the questions may be appropriate when performing an exploratory study (Yin, 2009). Due to the paucity of research on social movements and sport-based advocacy organizations, the exploratory nature of the questions was appropriate for the study. Additionally, "how" and "why" questions are explanatory in nature and allow for analyses over time, instead of measuring point in time frequencies and incidences. Thus, "what", "how", and "why" questions were utilized in the research questions. Second, in a case study, the researcher does not have control over behavioral events during the study (Yin, 2009). All questions and interviews were conducted without influencing the behavior of the participants. Understanding the depth of the organization was more important than a direct comparison of behaviors between participants, like in an experimental study. Finally, Yin suggests case studies be utilized when investigating contemporary, as opposed to historic, events. The current study interviewed and observed Athlete Ally personnel at the time of the study, rarely investigating past behavior of the participants unless the participants brought up past events.

Most importantly, the choice of method depends on the specific study and its circumstances (Flyvjerg, 2011). Case studies allow investigators to understand real-life events and complex social phenomena (Yin, 2009). Athlete Ally is a contemporary SMO in the sport setting that utilizes athletes as prominent organizational spokespeople. The complexity of understanding how Athlete Ally operates through the lens of SMT deserves an in-depth examination. Further, case studies are often used in social movement studies. Snow and Trom (2002) state: 
Since most studies of social movements derive their data from research on a particular movement or a stretch in time in a movement's career, one could conclude that the case study method and the study of social movements are almost one and the same. (p.146)

\section{Case Description}

Athlete Ally is a pro-LGBTQ, 501c-3 nonprofit organization in the United States. The organization provides public awareness campaigns, pro-ally programming, and other tools to foster inclusive sport environments (Athlete Ally, n.d.-a). The mission of the organization is to foster ally-ship in the athletic environment through collaborations with collegiate, professional, and Olympic athletes. The organization carries out its mission through trainings and workshops for LGBTQ athletes and allies at colleges and high schools. Per their website, Athlete Ally also works with the WNBA, NFL, NBA, their respective players' associations, and the NCAA.

The researcher worked with Athlete Ally on a separate, unrelated project a year prior to the current study. To commence that study, the researcher contacted the organization through their Contact Us page. An email was sent to the organization, not a specific individual. A full-time employee of the organization agreed to participate in the previous study. This individual became the gatekeeper to the organization. The researcher, several months later, contacted the gatekeeper to inquire about participation in the current study. The researcher provided the gatekeeper with the purpose of the study via email. Shortly after, the gatekeeper and the researcher initiated a phone call to review the purpose of the material and consent to participating in the study. The gatekeeper, on behalf of Athlete Ally, agreed to take part in the study. 


\section{Data Collection}

A case study's strength lies in its ability to provide a variety of evidence (e.g. documents, artifacts, interviews, and observations; Creswell, 2013; Yin, 2009). Yin suggests six major forms of data available for case study researchers: documents, archival records, interviews, direct observations, participant observation, and physical artifacts. The current study relied primarily on documents and interviews for data collection. Documents, such as emails sent to the public that signed up for alerts were obtained, as were social media tweets by the organization and athletes, an educational tool kit for holding a fundraiser, an educational tool kit for starting a college chapter, a journal from the 2017 Athlete Ally Annual Action Awards, the Athletic Equality Index (AEI), a report between founder Hudson Taylor and the NCAA, and a financial statement from 2015 were collected and reviewed by the researcher. In addition, to determine the appropriate characteristics of the NCAA, NBA, and U.S. Government for RQ2, the research relied on constitutions, formal reports, and prior literature from the entities. The aforementioned data sources were used in combination with the final and primary source of data: in-depth interviews. The documents and information gathered from the website occurred before and during the in-depth interviews to provide the researcher with more context about the case when interviewing participants. Document analysis occurred in the months between November 2017 and March 2018.

Interviews are one of the most common methods of data collection in social movement research (della Porta, 2014b) and case study research (Yin, 2009) because interviews focus specifically on the case study topic and provide casual inferences (Yin, 2009). The researcher employed a semistructured interview method. Semistructured 
interviews are well-suited for case studies as the ability to ask follow-up questions after the initial protocol questions is important. Follow up questions allow the researcher to probe for more information and encourage the participants to define the world from their own perspectives, not solely from the perspective of the researcher (Hancock \& Algozzine, 2006).

The researcher relied on della Porta's (2014b) advice as to what to ask and whom to interview for social movement studies. Following della Porta's lead, an interview grid (McCracken, 1988) assists the researcher in determining what to ask. First, the researcher listed relevant themes toward which to orient the conversation (e.g. resources given from Athlete Ally to an athlete ambassador). Second, the researcher turned those relevant themes into questions (e.g. What resources does Athlete Ally provide it athlete ambassadors?). Finally, the researcher improved the phrasing of the questions for the participant's benefit (What tangible/intangible resources does Athlete Ally provide its athlete ambassadors?). The researcher used everyday language, avoided double negatives, avoided asking two questions at one time, and prepared for any potentially sensitive or difficult questions (della Porta, 2014b). The researcher carefully planned whom to interview. When deciding whom to interview, the researcher recruited participants based on knowledge of organization to answer questions related to SMT (della Porta, 2014b) and based on access to participants. The researcher began with the most easily accessible participants, identified by the gatekeeper, and slowly incorporated lesser accessible individuals into the study. Interviews were conducted from December 2017 until March 2018 and until saturation of knowledge was achieved (Creswell, 2013; della Porta, 2014b; Yin, 2009). Saturation was achieved when no additional themes were generated 
for the research questions. Simply put, when no additional resources, strategies for engaging with various governing bodies, and strategies for ensuring resonant frames were identified in three consecutive interviews, the authors concluded that saturation was achieved.

The interviews lasted between 30 and 75 minutes. Interviews were recorded using an audio recorder and transcribed verbatim. A complete breakdown of questions is listed in Appendix A. Following the interview demographic information was collected, including identified gender, sexual orientation, employment status, race/ethnicity, age, relationships status, and parental status.

\section{Data Analysis}

Yin (2009) acknowledged that the least developed, but most important, step in a case study is the analytical strategy utilized by researchers. A preferred strategy, and one employed for the current study, relied on theoretical propositions to shape the data collection and, by extension, the relevant analytical strategy. The strategy calls for the researcher to orient the analysis around the theoretical propositions of the case study. For the current study, the researcher positioned the study of Athlete Ally through the lens of social movement theory. Pattern-matching, comparing the collected empirical data and with data theorized from SMT, served as the dominant mode of analysis. Using this method allowed the researcher to use a strong theoretical lens to provide context for the data.

Data were analyzed using Creswell's (2013) data spiral. First, data were gathered and organized. Transcriptions were coded verbatim using a transcription service. Transcription files were stored on a single, password-protected computer. All obtained 
documents were stored on the computer, as well. Second, data were read multiple times and notes taken in using NVIVO, a qualitative software analysis. Reading and re-reading the documents allowed for the researcher to know the data intimately. The researcher used a hybrid method of a priori coding and coding based on text, as suggested by Crabtree and Miller (1992). The initial codes were developed with the guidance of SMT tenets and information, but the researcher allowed for new themes to emerge if the data did not fit a pre-arranged theme. For example, resources mentioned by Athlete Ally were placed into one of five typologies created by Edwards and McCarthy (2004). If a resource did not fit into one of the five typologies, it would constitute its own resource type. Finally, memoing provided the researcher with more intimate knowledge of the data. While reading the transcripts, the researcher simultaneously described, classified, and interpreted the data.

According to McCracken (1998), the first reading is for observations within the text. An observation is defined as a theoretical relevant utterance. The researcher interpreted the observations according to the evidence in the interview, meaning, the researcher separated the data into the three tenets of SMT: RMT, PPT, and Cultural Theory/Framing. Then, the researcher completed a second reading of the data after reviewing the theoretical framework and familiarizing himself with other relevant literature. This allowed the researcher to separate the broad codes from each of the three tenets into more specific themes in each tenet. For instance, in this step, the research would code the data in Cultural Theory/Framing, to either credible frames or salient frames, per the appropriateness of the statement to theory. The final reading connected the observations to one another (McCracken, 1998). Finally, the data were visualized for 
the reader. The visualization manifested itself through separating the information by research questions in the findings section of the manuscript (Baxter \& Jack, 2008).

\section{Researcher Reflexivity}

Researcher reflexivity is an important part of qualitative methodology. Reflexivity is defined as the manner in which the writer is conscious about the biases, values, and experiences that the researcher brought to the study (Creswell, 2013). Researchers bring multiple personalities into a study as an inquirer and respondent, teacher and learner, and must integrate those personalities before, during, and after the research process (Denzin \& Lincoln, 2011). One method to appropriately self-reflect is peer debriefing (Hays \& Singh, 2011). The researcher utilized three sport management scholars, Dr. Meg Hancock, Dr. Mary Hums, and Dr. Evan Frederick with knowledge of SMT and activism for peer debriefings throughout the current study.

\section{Trustworthiness}

Trustworthiness is one of the most important parts of qualitative research (Creswell, 2013). Trustworthiness is the confidence in one's research to deliver accurate results (Lincoln \& Guba, 1985). According to Guba and Lincoln (1989), there are four main areas of trustworthiness: credibility, transferability, dependability, and confirmability. The authors outlined the four criteria for trustworthiness as they paralleled with conventional paradigms for many years: internal validity, external validity, reliability, and objectivity. However, the latter speaks to a positivist paradigm while the former adheres to a constructivist's paradigm.

\section{Credibility}


Credibility refers to the internal validity or the accuracy of the results (Creswell, 2013). Strategies for proving credibility include prolonged engagement, persistent observation, peer debriefing, negative case analysis, and member checking (Guba \& Lincoln, 1989). The current study used prolonged engagement and peer debriefing to establish credibility. The researcher spent multiple months interacting with the organization before and after the study to gain an understanding of the culture. As mentioned before, peer debriefing was also used with scholars familiar with the subject area of the study. Finally, member checking, which Guba and Lincoln (1989) argued is the most crucial technique for establishing credibility was also be used. Member checking is the use of participants' views to review the findings, themes, and accuracy of the account (Creswell, 2013). The researcher utilized multiple participants after interviews to assist in this process. For instance, the researcher sent a fully transcribed copy of the interview to the participant and asked him/her to review the document and determine if the meaning behind the words is present.

\section{Transferability}

Next, transferability refers to external validity, or the ability to generalize the results of the study (Guba \& Lincoln, 1989). In a constructivist framework, transferability is the empirical process for "checking the degree of similarity between sending and receiving context” (Lincoln \& Guba, p. 241). The major technique for establishing transferability is thick description, which was utilized in this study. The researcher was careful to provide a detailed description of the organization Athlete Ally including mission, vision, and tactics utilized for social change in sport. Additionally, the 
researcher provided numerous quotes and supplemental documents for the reader to gain an understanding of the thick description of the data.

\section{Dependability}

Third, dependability, or reliability, refers to the consistency of results or the stability of data over time (Guba \& Lincoln, 1989). According to Guba and Lincoln, methodological changes and shifts are expected in an emergent design, in contrast to stricter quantitative methods. The changes and shifts indicated successful inquiry. Lincoln and Guba warned that the changes and shifts should be tracked and trackable in a public sense. Those authors claim the tracking process should be known as an inquiry audit, a metaphor for a fiscal audit (Guba \& Lincoln, 1989). The audit trail focuses on the description of the researcher's steps from the start of the project to the end. An external author should be able to understand the conclusions drawn by the researcher from the audit. The researcher in the present study kept a separate journal for the audit. Creswell (2013) offered several additional strategies for ensuring dependability. Enhancing reliability is possible if the researcher obtains detailed field notes by using a high-quality recording device and transcribing the interviews verbatim. The researcher utilized a new tape-recorded purchased for the current study. Additionally, Creswell (2013) also suggested multiple coders to assist in the data analysis. The researcher utilized qualitative specialty methodologists, Dr. Alagaraja and Dr. Hancock, to assist with data collection and analysis.

\section{Confirmability}

Finally, confirmability, or objectivity, is the notion that the researcher attempted to eliminate or make obvious their biases (Guba \& Lincoln, 1989). Per a constructivist 
paradigm, the integrity of the findings must be rooted in the data. Creswell (2013) pointed to the reflexivity journal as an important way for the researcher to establish their biases and reflect on the researcher and its potential impact. The researcher purchased a journal to detail his biases and assumptions before, during, and after data collection and analysis begins.

In summation, this study used a qualitative case study approach to investigate Athlete Ally through the frame of SMT. Interviews with members of the organization were the primary data source for the study, with accompanying information from the website and organization to help triangulate the information. The researcher relied on theoretical propositions to shape the data collection and the relevant analytical strategy (Yin, 2009). Data was analyzed using a hybrid method of mainly a priori coding using SMT, but also allowing the data that does not fit into those codes to emerge and constitute their own findings, when needed (Crabtree \& Miller, 1992). Trustworthiness was accomplished by a variety of strategies, most notably, triangulation of other data sources. Overall, the use of qualitative method was appropriate for this study as it investigated Athlete Ally in-depth to gain an intimate understanding of the organization. 


\section{CHAPTER IV}

\section{FINDINGS}

The purpose of the study was to investigate Athlete Ally's resources, political context, and cultural/framing techniques through the lens of Social Movement Theory. The study is significant in that it is an in-depth examination of a sport specific SMO that collaborates with athlete activists at various levels and leagues. By completing this study, the author wished to showcase effective strategies used by a prominent sport specific social movement organization. This information can be used by the SMO to refine practices or other sport specific SMOs to evolve strategies and resources. In addition, the researcher attempted to determine the major benefits for athletes having a formal relationship with a sport specific social movement organization. As athletes continue to engage in activism at an increasing rate, these sport specific SMOs can provide a space for athletes to effectively engage in activism.

The purpose of the following section is to outline the findings from the present study. The focus of this study investigated the resources exchanged between Athlete Ally and their athlete constituents, tactics for engaging with various governing bodies, and tactics for ensuring frame resonance by Athlete Ally using Social Movement Theory. The study utilized the following research questions:

RQ1a: What resources are provided from Athlete Ally to athlete constituents? RQ1b: What are the perceived resources athlete constituents provide Athlete Ally? 
RQ2: What strategies does Athlete Ally utilize to engage with various governing bodies?

RQ3: How does Athlete Ally create resonant (credible and salient) frames?

Four employees and three board members of Athlete Ally participated in the current study. Semi-structured interviews were the main form of data collection for the case study method. Each interview consisted of questions regarding (a) resources provided to and from Athlete Ally to athlete constituents, (b) interactions with various political entities, and (c) the creation of credible and salient frames. The following sections will outline the demographic information of the participants and the emergent themes from the research questions.

\section{Participant Demographics}

A total of seven participants agreed to take part in the study. To protect their anonymity as much as possible, pseudonyms were utilized. Demographic data was collected, but with a small organization, any demographic information given would reveal the identity of the individual. The participants represent a wide range of positions, some entrenched with day-to-day operations of the organization (Directors \& Coordinator, henceforth employee), while others establish the strategic plan, fundraise, and hire for the organization (Board Member).

Table 1.1

Participant Demographic Information

\begin{tabular}{ll}
\hline Name & Position with organization \\
\hline Dean & Director \\
Lane & Director \\
Logan & Director \\
Jess & Coordinator \\
Luke & Board Member \\
Kirk & Board Member \\
Richard & Board Member \\
\hline
\end{tabular}




\section{RQ1a: What resources does Athlete Ally provide its athlete constituents?}

Edwards and McCarthy (2004) created a fivefold typology of SMO resources based on previous literature (Cress \& Snow, 1996, Lahuasen, 1996; Oliver \& Marwell, 1992). The five resources include moral, cultural, social-organizational, human, and material. The following section outlines the resources that Athlete Ally provides its athlete constituents. The athlete constituents can be either a professional and Olympic athlete or an athlete who is part of Athlete Ally's college chapter. For a comprehensive list of resource types exchanged between Athlete Ally and its athlete constituents, see Figure 2. Table 2.1 provides a list of resources Athlete Ally provides its athlete constituents and Table 2.2 provides a list of resources the athlete constituents provide Athlete Ally.

Table 2.1

Summary of Resources Athlete Ally provides Athlete Constituents

\begin{tabular}{ll}
\hline Type of Resource & Specific Resource \\
\cline { 1 - 2 } Moral & $\begin{array}{l}\text { Credibility \& Legitimacy } \\
\text { Community/Safe Space }\end{array}$ \\
\hline Cultural & $\begin{array}{l}\text { Educational Tool Kits, One-page summary sheets } \\
\text { Collaborations on op-eds \& social media posts } \\
\end{array}$ \\
$\begin{array}{ll}\text { Availability or questions } \\
\text { Social-Organizational }\end{array}$ & $\begin{array}{l}\text { Network to athletes and activists } \\
\text { Platform }\end{array}$ \\
\hline Human & None \\
\hline Material & "SWAG", T-shirts, Stickers \\
\hline
\end{tabular}

\section{Moral Resources}

Moral resources include intangible, external resources like legitimacy, support, and celebrity provided to the SMO or activist. Interviews with employees of Athlete Ally consistently showed Athlete Ally provides its athlete constituents with a plethora of moral resources, including credibility and legitimacy and a community of individuals 
who support athlete activism. When speaking on credibility and legitimacy, Jess (employee) noted:

I often speak to a lot of athletes who are queer, who are on college campuses, who are like, 'I kind of do this work in some capacities, but I'm alone in it and now that I have this organization's name, and this organization's support, I can get other people to join me in this work under the umbrella of a club.' So, I think that credibility and that name is really helpful...

In other words, having the organization's name and support behind the athlete acts as an important point of continuity for identity and collective action for their constituents (della Porta \& Diani, 2006). By using the brand, image, philosophy, and shared values of Athlete Ally, according to Luke (board member), the athlete can more successfully engage in activism and or mobilize other allies.

Athlete Ally's support in the form of a community of athlete activists is another moral resource that Athlete Ally provides its athletes. Athlete Ally provides a space for athletes to engage in activism. Logan (employee) mentioned that an athlete may not be comfortable talking about LGBTQ issues whether s/he is LGBTQ or not. Per Logan (employee), Athlete Ally is “...that organization that creates a sense of inclusion a community where they can be involved.” Athlete Ally's website lists over 150 professional, Olympic, and international athletes engaging in activism to end homophobia and transphobia in sport, so athletes may be more willing to engage in activism once they see that community of athlete activists. Lane (employee) reiterated the importance of community as a resource for athletes: 
I think the other piece that we offer is this sense of community in terms of being a part of a larger social justice movement for human rights of LGBTQ athletes just being in the social justice space and have it be both expected, we like to say, and accepted, because as you know, athlete activism is on the rise, but as is criticism of athlete activism, especially in this country.

As noted, the community is an important resource. Just as important, is the last phrase about how activism is on the rise, but so are the critics of athlete activism. As Luke (board member) said:

More often than not, owners of sports professional franchises really don't want their athletes being political. You know, they don't like athlete activism, they want them to keep their heads down, play the sport, win the games, make money for them, and be quiet.

Luke offers evidence that certain actors do not want athletes engaging in activism. Fears of financial backlash from teams or sponsors (Agyemang, Singer, \& DeLorme, 2010; Cunningham \& Regan, 2012) and verbal backlash from coaches, fans, and media (Frederick, Sanderson, \& Schlereth, 2017; Kaufman, 2008; Sanderson, Frederick, \& Stocz, 2016) can prevent athletes from engaging in activism. However, Athlete Ally can provide their athletes with a space to openly engage in activism with a decreased fear of retaliation. Having a formal organization backing the athlete provides credibility, legitimacy, and a community of allies if/when backlash does occur. Furthermore, a major benefit of SMOs is providing a basis for mobilization of activists (Caniglia \& Carmin, 2005) and a safe space for sport activists (Antunovic \& Hardin, 2012). Being able to engage with a community that accepts activism would alleviate some of those issues. For 
instance, research has shown that athlete activists can be viewed as manufacturing issues like racial injustice when engaging in activism (Frederick, Sanderson, \& Schlereth, 2017). Being part of a SMO engaging in activism about the same social injustice can limit this perception. According to the study participants, an athlete and his/her message are seen as more credible and legitimate when there is organizational support. This can be done in a variety of ways, such as coordinating action, facilitating resurgence activism, and defining goals, to show commitment to social justice efforts. In addition, being part of a group, whether activist group or community group, can enhance activism efforts (Louis et al., 2016). The analysis of the data suggests adheres to this notion as participants noted that athletes being part of the group encouraged other athletes to engage in activism. This notion speaks to the community and ways that Athlete Ally can encourage athletes to partner with the organization. Broadly speaking, being part of a SMO as a group and as a community of activists allows athletes to have strong support mechanisms in place to help facilitate their activism. This can come in the form of credibility, legitimacy, and a safe space where activism is encouraged and valued.

\section{Cultural Resources}

Cultural resources are conceptual tools and specialized knowledge that have not become widely known (Edwards \& McCarthy, 2004). For example, specialized knowledge to organize a march or a sit in would be a cultural resource for a SMO. In the case of Athlete Ally, examples include hosting a panel of athletes to speak about LGBTQ inclusivity, collaborating with a professional sport organization to organize a pride night, or organizing a petition for athletes and their social media followers to sign. Moreover, Athlete Ally has positioned themselves to be the actor most knowledgeable on how to 
influence sport and provide more mechanisms for LGBTQ inclusiveness as they conduct research and engage with sport governing bodies. The organization can than efficiently disseminate its cultural resources (della Porta \& Diani, 2006) to their athletes so the organization can pool resources, coordinate action, and facilitate activism (McCarthy \& Zald, 1977; Scott, 1981). Interviews with Athlete Ally employees and board members suggested Athlete Ally provides a plethora of cultural resources for their athlete constituents. The cultural resources come in different forms: tangible documents describing anti-LGBTQ or pro-LGBTQ policies and best practices for engaging with political and athletic actors, collaborations on opinion editorials and social media posts, and finally intangible resources like counseling and trainings.

Tangible documents describing policies or practices were a main resource Athlete Ally provided its athletes. As Jess (employee) mentioned, "So, if there's a policy that is coming out, we'll provide them with a one sheeter of what's going on and what they can do". The one-page summary documents are intended to provide specialized knowledge that athlete constituents need to know about a certain policy or bill. In addition, Athlete Ally also provides their athletes with in-depth educational toolkits. The toolkits are documents that help college chapters or athletes in their activism, according to Logan).

The researcher was given access to an Athlete Ally Campus Resource Guide (educational toolkit), a 15-page document intended for college athletes who want to start an Athlete Ally chapter on their campus (Athlete Ally, 2017c). The tool-kit was broken into multiple parts: about Athlete Ally, recent campaign victories like Athlete Ally working with the NBA to move the All-Star game out of North Carolina because of an anti-LGBTQ law or launching the Athletic Equality Index, steps to starting a chapter, 
suggested on-campus initiatives and events, talking points for the college ambassador, and frequently asked questions. The initiatives and events section included six potential initiatives for campus chapters to engage: writings and op-eds, mass online pledge signing, mobilizing the student body, pride match, social media campaigns, and the use of the Athletic Equality Index. Athlete Ally has identified these six initiatives as key mobilizing actions, which can help athletes be successful in their activism (Athlete Ally, 2017c). These one-page policy summary sheets and toolkits may seem like material resources as they are tangible; however, the difference between the two is the level of specialized knowledge.

Some of these tool kits are not just for athletes, but other non-athlete constituents as well. Around Super Bowl time (February $2^{\text {nd }}, 2018$ ), Athlete Ally sent a "be a host" two-page document to their followers via email. The document contained information on how to host a party for a Super Bowl or World Cup and how to use that party as a fundraiser for Athlete Ally. The two-page program gave information about the impact and benefits of hosting a party, steps in hosting the party, and more information about the organization (Athlete Ally, n.d.-d).

The goal of the tool kits and one-page policy summaries are to provide athletes with education and awareness. As Kirk (board member) mentioned, "I think we can provide people [athletes] with education, awareness. There are plenty of allies all over the country that just don't know that there's a world out here. So, I think awareness is a big part of it." By providing the athletes with specialized knowledge, the organization can build awareness about combating anti-LGBTQ policies, supporting pro-LGBTQ polices, and practices to help assist the organization complete its mission in a quick and efficient 
manner. This is a common practice in activism related to sport (Carty, 2002). For example, anti-sweatshop SMOs disseminated similar tools over the internet to activists in their protest of Phil Knight and Nike's use of sweatshop labor. The internet served as a proficient means of disseminating this information to the activists in an efficient manner. This uniform information provides an opportunity for likeminded individuals to come together to create a larger collective identity (Carty, 2002). In the context of Athlete Ally, the findings support this idea. Athlete Ally can provide these resources easily to their athletes (all documents were found on the internet or provided via email) and create this larger collective identity of pro-LGBTQ inclusive athletic environments.

A key benefit of the one-sheet policy papers and tool kits is the time saved by athlete activists. Prior research suggests individuals with more control over their time and the ability to create their own schedule were most likely to engage in activism (Brady, Scholzman, \& Verba, 1999; Wiltfang \& McAdam, 1991). However, athletes are being pulled in many directions, as stated by the participants in this study. Time is one resource an athlete may not have after trainings and competitions. As such, the one-page summary documents and toolkits can serve as a mechanism to decrease the amount of time needed to engage in activism. Instead of the athlete needing to research a specific policy and its effects on his/her own time, the organization provides that to the athlete.

Second, the organization collaborates with athletes on making public statements. As both Dean (employee) and Logan (employee) mentioned, Athlete Ally provides sample social media tweets or content (e.g. logos) for the athletes if they want to send out a message. For instance, in March 2018 NBA player Reggie Bullock announced his partnership with Athlete Ally as he became an athlete ambassador. The tweet, from 
Bullock's personal account, had a similar structure and appearance to other tweets from

Athlete Ally's account (See Figure 1). The two tweets having similar logos, fonts, and design indicate that Athlete Ally helped the athlete design a tweet to send out announcing his newly formed relationship with Athlete Ally. One can assume that Athlete Ally provided the logos, fonts, and help craft the message for Reggie Bullock so he could send the tweet from his personal Twitter account.

(A)

Athlete Ally

We're proud to announce that @realfredrosser will join Athlete Ally as a professional Ambassador! Fred was the first openly gay active @WWE wrestler, and is an outspoke advocate for LGBTQ equality globally.

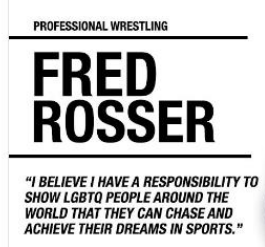

10:33 AM - 19 Mar 2018
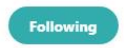

(n) 
strengths, bringing awareness and communicating major issues to the public

(Brockington, 2014; Kogen, 2015; Thrall et al., 2008). Utilizing this strategy can also cut down on the issue of celebrities not correctly articulating the issues (Kogen, 2015), as the organization guides the athlete through universal language. The op-eds, in addition to the tool-kits and one-page summary sheets, allow the organization to guide the athlete in what needs to be stated and articulated and how to do so.

Finally, the last major cultural resource the organization provides its athletes are availability for questions and counseling, in other words, general support. Research has noted the prevalence of homophobia within sport as athletes and coaches who identify as LGBTQ are stereotyped and labeled as other (Krane \& Barger, 2006; Sartore \& Cunningham, 2009). One way to create progress for the LGBTTQ sports movement is for athletes and coaches to recognize their sexuality and find support from those around them (Carrol, 2016). By being available for the athletes, the organization can support athletes as they recognize orientation and/or share their gender identity and/or sexual identity. The specialized knowledge of the experiences the athletes will go through can be an important resource for the athlete and is re-emphasized through employees of the organization and written materials. Jess (employee) noted that Athlete Ally is always available to answer questions for the athletes. The Campus Resource Guide mentions several examples of times that the organization wants to assist, is available for questions, and wants to stay in touch with their athletes (Athlete Ally, 2017c). In addition, the organization helps athletes who want to express their sexuality. Richard (board member) articulated this point, "We also provide support for LGBT athletes, and counsel athletes who are considering coming out, at every level, from middle school these days through 
professional." Athlete Ally employees, being comprised of LGBTQ members and having worked with LGBTQ athletes, have seen the process of athletes coming out and know recognize the experience of that process. Thus, they can help guide that athlete through the process and foreshadow the type of typical experiences of an athlete coming out. By being available for questions from their athletes or counseling them on major decisions, Athlete Ally can provide the athletes with specialized knowledge.

\section{Social-Organizational Resources}

Social-organizational resources can be divided into intentional socialorganizational and appropriable social-organizational resources (Edwards \& McCarthy, 2004). Intentional social-organizational resources are created specifically to further movement goals (e.g. social networks), while appropriable social-organizational resources (e.g., streets, sidewalks, and post offices) are available to athletes, but Athlete Ally does not create or provide those resources. Therefore, only intentional socialorganizational resources were examined in this analysis. Intentional social-organizational resources may include social networks (access to people) and other protagonist organizations. Per this study, Athlete Ally provides two social-organizational resources: a vast network and a platform to engage in activism.

One of the most frequently spoken about intentional social-organizational resource Athlete Ally employees mentioned was a strong social network. Because Athlete Ally partners with so many athletes and other pro-LGBTQ sport entities, the organization can provide access to a vast array of connections and access to other athletes as the SMO serves to be the basis for mobilization for a social movement (Caniglia \& Carmin, 2005). As Jess (employee) mentioned, “...it also seems like connections are very helpful. We 
have multiple chapters in North Carolina at Duke and UNC and we connect them all the time to do work with all of the horrible legislation that comes out of North Carolina." The network and knowledge Athlete Ally provides creates a strong system for the opposition of anti-LGBTQ policy. Instead of just one group of athletes at Duke University or the University of North Carolina, Athlete Ally can connect those two groups to create a joint statement in opposition of a bill or a policy. Jess (employee) also added "They're like, 'can you put me in contact with this chapter, because I really like what they're doing.' So, in that way, it's all about connections..." This seems to indicate that Athlete Ally is also connecting athletes to help learn from one another about best practices. Being the centerpiece, Athlete Ally can easily provide direct contact with different athletes or teams to share strategies, information, or collaborate. Part of the reasons this is so valuable is that a stronger social network of activists leads to future activist intentions (Louis et al., 2016). In theory, Athlete Ally can utilize their network to inspire activism in more parts of the country or in different sports. Logan (employee) boasted about the ability of Athlete Ally's network reach:

So, I think it increases dialogue, and it's also cross-sport, so it's not just...You're in your silo, and you're just a soccer player, or were a soccer player. It's more like bridging the gap with different sports so that there's a bit more of a conversation going on. And even men and women, because I think there's even that sort of division that happens.

Logan (employee) mentioned how they can reach out to other athletes across sport and gender via Athlete Ally. While no literature has investigated activism between different sports, literature has investigated activism regarding gender in a general activism sense 
(McAdam, 1992) and within the LGBT movement (Engel, 2001). In terms of general activism, women have felt more discrimination than male activists, often receiving jobs tied to administrative roles, instead of leadership roles and are more likely to be rejected for activism efforts than their male counterparts (McAdam, 1992). Athlete Ally, if cognizant of these issues, can assist in reducing the discrimination between genders, especially as the organization is involved in women's rights. Focusing on the LGBT movement, lesbian and gay activists have had a tumultuous history as the lesbian movement claimed the gay movement did not seek to advance gay and lesbian rights, just gay rights (Engel, 2001). Athlete Ally has the chance to break down both of these barriers through their network. Perhaps the commonality of sport as the driving force behind the partnerships or the association with Athlete Ally is bringing different sport and gender athletes together. Regardless, Athlete Ally provides a basis for those connections to occur.

In addition to networks, Athlete Ally also provides its athletes with a platform. As noted before, one of the most commonly discussed resources was a safe space to engage in activism. Just having a safe space may not be enough, though, without a platform to engage in activism. Athlete Ally is a platform for athletes to use and connect to other activists and protagonists. An athlete can share a story or make a statement through Athlete Ally's Twitter (23.1K followers at time of study) or Facebook (15.1 likes at time of study) and access a platform to reach thousands of individuals with their story or activism. Richard (board member) summarized the importance of Athlete Ally as a platform: 
So, there's that opportunity, especially for more prominent athletes at the collegiate, or at the professional level, and coaches who want to be a part of it. I mean, there's a ton of athlete activism going on right now, whether it's about racial equality, guns, LGBT equality, and we sort of provide that opportunity for athletes to use their voice. Because, they're heroed in our society and they have huge fan bases, and huge social media followings, and we give them the tools and opportunities to do that, as well.

Additionally, an athlete may speak at the Athlete Ally Action Awards, a fundraising gala to celebrate and honor activists helping to create LGBTQ inclusive athletic environments and eliminate homophobia and transphobia (Athlete Ally, 2017a), and provide a point of inspiration for the hundreds of donors and organizational partners in the room. While not specifically stated in past literature, this finding is interesting in that athletes are given a

figurative platform due to their status as an athlete (Agyemang, 2011; Kaufman \& Wolff, 2010; Wilson et al., 2015). Still, not all athlete activists have unlimited star power and media attention. Athlete Ally can serve as a platform to collaborate with initiatives, send out a social media post, or start a campaign to combat anti-LGBTQ legislation to the subscribers and followers of Athlete Ally for lesser known athletes. While athletes like Martina Navratilova and Andy Roddick may not need that platform given their star power, athletes in lesser known sports like quidditch or rowing may tap into that platform to engage in activism with other athletes and constituents.

\section{Human Resources}

Human resources are mainly the labor needed to advance movement goals, but can also include an individual's experience, skills, and leadership. For example, if an 
athlete ambassador wanted to hold a rally or a march, but needed physical bodies to mobilize to increase the size of the rally, Athlete Ally could reach out to any volunteers or followers to attend the rally. There was no mention from Athlete Ally employees and board members that this practice ever occured. The athletes are not the ones holding events and organizing activism efforts - the organization holds that responsibility. In one instance, Jess (employee) mentioned listening to athletes about the anti-LGBTQ policies in their respective sports or leagues. An athlete could come to Athlete Ally with an antiLGBTQ policy and Athlete Ally can post a petition on their website for their followers to sign supporting ending that policy. On October 31, 2017, in fact, Athlete Ally sent out a letter to World Rugby to adopt the International Olympic Committee's 2016 policies related to participation of transgender athletes in sport. When data were collected (March 2018), 492 signed the petition, when 250 signatures was the goal. In theory, an athlete could have brought the discriminatory policies to the attention of Athlete Ally and the organization could mobilize their constituents to sign a petition ending the policy. The above example would constitute a human resource that Athlete Ally could provide, however no participant mentioned this practice.

Athlete Ally lacking in human resources (only five full-time employees) is not an unsurprising finding. Social movement organizations are important for coordinating action (McAdam \& Zald, 1977), not necessary supplying bodies for a protest. In addition, Athlete Ally is a small organization. With only five full time employees and board members who average two hours of work for the organization per week (according to Athlete Ally's financial records), supplying human resources is not a role of the 
organization. Instead, the organization specializes in providing moral, cultural, socialorganizational, and material resources for its athlete constitutes.

\section{Material Resources}

Material resources are arguably the easiest resources to identify. They include tangible items like signs, money, equipment, and posters (Edwards \& McCarthy, 2004). Participants did note that the material resources provided to athletes were minimal. Almost every member mentioned stickers, t-shirts, graphics, and other "SWAG" as material resources provided to the athletes. These resources provide the athletes with awareness opportunities for the cause and Athlete Ally. For the LGBT movement specifically, using material resources like t-shirts and stickers was a strong way to get societal acceptance during the 1980s-1990s (Bernstein, 2003). In the case of LGBT SMOs in the US, the decision to create shirts and other tangible materials to raise awareness was a result of legal defeats, most notably a court's decision to claim same sex couples do not have privacy in the bedroom, unlike non-same sex couples. As a result, LGBT SMOs had to be proactive and create these tangible goods for activists to wear to create awareness about the issues in the LGBT community (Bernstein, 2003). In sport, athletes wear symbols, special clothing or unique clothing to raise awareness for a specific issue. Case in point, Ramogi Huma was a college football player at University of California, Los Angeles (UCLA) and president of the National College Players Association. He, and his UCLA teammates, planned to wear black arm bands during a nationally televised game against the University of Miami. The black arm bands were meant to symbolize the opposition to proposition 209 (legislation aimed to end affirmative action in higher education; Kaufman \& Wolff, 2011). The result was a swift 
response from coaches and administrators when the action was brought to their attention (Kaufman, 2008). Athlete Ally used a similar tactic in the Principle 6 campaign, where they provided Principle 6 clothing in response to Russia's anti-LGBTQ laws prior to the 2014 Winter Olympic Games. The level of awareness raised from the campaign helped society open their eyes to the issue, as Richard (board member) noted:

And I think it was Jason Lou, who did a very high-end beanie, Principle 6 beanie that went crazy viral on, I think Rhianna, and a same sort of Instagram post wearing it. And, you know, we achieved great success with very little money spent. We were able to get P6 into the conversation, not only having celebrities and athletes wearing P6 gear and posting about it, but literally, when Bob Costas opened the Olympics, as he always did until this year. With his opening narrative, he talked about be the movement and the anti-LGBT laws. David Remnick, was at the games sort of covering it for the New Yorker, and he wrote about it. He wore P6 gear. And there were a number of athletes who wore P6 stuff at, potentially great, personal peril because you don't know what's going to go on in Russia.

The use of celebrities and providing them visible unifying material goods helped Athlete Ally raise awareness for the Principle 6 campaign and bring issues into the societal conversation. What started off as a beanie, helped partly inspire journalists and media members to discuss the anti-LGBTQ Russian legislation. The material resources served to create a collective identity for the movement (Dorf \& Tarrow, 2014; Gamson, 1995). Uniting athletes and activists alike under similar logos and icons provides added awareness and a basis for mobilization (Caniglia \& Carmin, 2005). This tactic is further 
compounded by having celebrities wear these tangible goods to promote awareness (Brockington, 2014), thus providing more media attention for the movement as a whole (Thrall et al., 2008), as Richard noted. As noted above, the LGBT movement in the 1990s gained significant policy victories when celebrities and famous actors were allies (Engel, 2001). The same could be said for Athlete Ally, gaining a boost when a prominent athlete and/or protagonist wears or displays their material goods and bring awareness to the organization and its campaigns.

\section{Summary of Findings for RQ1a}

Athlete Ally provides a wide variety of resources for their athletes ranging from intangible to tangible. Overall, Athlete Ally serves as the central point for mobilization for LGBTQ issues, which has been noted in literature (Caniglia \& Carmin, 2005). From that central point, Athlete Ally can provide a safe space to insulate athlete activists (Antunovic \& Hardin, 2012) from harsh criticism (Agyemang, Singer, \& DeLorme, 2010; Frederick, Sanderson, \& Schlereth, 2017; Kaufman, 2008; Sanderson, Frederick, \& Stocz, 2016). Providing that safe space for athletes can minimize the amount of backlash the athlete receives for engaging in activism. Thus, it is crucial for sport SMOs to provide that safe space, credibility, and legitimacy, especially when athlete activism is not fully supported in the United States (Kaufman, 2008).

In addition, Athlete Ally coordinates activism via the specialized knowledge (e.g tool-kits, one-page summary sheets) they provide their athletes (Carty, 2002; della Porta \& Diani, 2006; McCarthy \& Zald, 1977; Scott, 1981). With professional and Olympic athletes navigating rigorous schedules, having expert knowledge on building a program, fundraising, or on a specific policy allows the athletes to access the information in an 
efficient manner. Athletes can be used as prominent speakers and communicators with the public (Brockington, 2014). A sport SMO should provide specialized knowledge so the athlete can focus on speaking and mobilizing constituents.

One of Athlete Ally's other main contributing resources is their vast social network. Having a large social network is beneficial for multiple reasons, including the retention of activists, the longevity of the SMO, and the ability to engage in more activism (Thrall et al., 2016). Athlete Ally's large network is also beneficial as it allows athlete activists to interact with one another to promote activism across sports and genders. In addition, it allows the athletes to grow their network to other athletes in their sport as they share a common support of LGBTQ rights. Thus, an implication of this study is the importance of cultivating a large social-network. While the athletes' social network is beneficial (discussed later), the organization's social-network is also valuable for the aforementioned reasons. Therefore, it would behoove a SMO dedicated to establishing relationships with athletes to have a large social network to assist their athletes.

Finally, Athlete Ally generates awareness through SWAG and t-shirts to create a collective identity of athlete activists (Dorf \& Tarrow, 2014). Having a specific logo with accompanying merchandise provides visibility to athletes who can be highly viewed as leaders in society (Wilson et al., 2015). Creating the SWAG and other promotional materials would be a wise investment for any social movement organization. This allows organizations to assist in either raising funds through their merchandise or providing awareness for the organization. An athlete celebrity can further boost the importance of 
this resource if s/he wears the materials, thus creating added awareness to the organization and movement (Brockington, 2014).

Unsurprisingly, the organization does not provide notable human resources as Athlete Ally only has five full-time employees. Athlete Ally simply does not have the numbers to distribute that type of resource. Instead, Athlete Ally provides specialized knowledge needed to facilitate activism by the athletes. Social movement organizations should recognize where their strengths and limitations lie. Having specialized knowledge of when and how to engage in activism should be a strength for the organization, while more than likely the size of the organization will be a limitation. Thus, building a large social network to access volunteers and constituents for mobilization is critical. Overall, the aforementioned resources provide a means of strong support for the athlete activists so they can focus on using their celebrity to engage in activism. From a broader sense, SMOs should recognize that providing the correct resources allows the athlete to reduce barriers to engaging in activism.

\section{RQ1b: What are the perceived resources athletes provide Athlete Ally?}

To this research question, the researcher asked Athlete Ally employees and board members about the perceived resources athletes provide Athlete Ally. A plethora of literature has noted the importance of resources celebrities and athletes (Brockington, 2014; Wilson et al., 2015) provide SMOs and peace promoting programs. This give and take with resources between the athletes and the SMO suggests a mutually beneficial relationship between the two entities. As Lane (employee) suggested, the relationship between Athlete Ally and their athlete constituents is a "symbiotic relationship." Like any great symbiotic relationship, both parties share resources to advance their own goals. 
Athlete Ally provides a variety of resources for their athletes. From intangible resources like a network of athletes and a community of athlete activists, to tangible resources like educational tool kits and one-sheeters, the organization supports its athletes in numerous ways. In return, the athletes themselves provide Athlete Ally with resources, which can be found in Table 2.2. The following section outlines the resources athletes provide Athlete Ally. Once again, the resources are broken up into the five resource types.

Table 2.2

Summary of Resources Athlete Constituents provide Athlete Ally

\begin{tabular}{ll}
\hline Type of Resource & Specific Resource \\
Moral & Credibility \& Legitimacy \\
& Celebrity \\
& Visibility \\
\hline Cultural & None \\
\hline Social-Organizational & Network to other athletes \& protagonists \\
& Access to people and spaces \\
\hline Human & Stories, lived experience \\
& Athlete supporters \\
\hline Material & Signed merchandise \\
& In-kind trades \\
\hline
\end{tabular}

\section{Moral Resources}

As mentioned before, two important resources that Athlete Ally provided its athlete constituents were credibility and legitimacy. Interestingly enough, the athletes also provide Athlete Ally with credibility and legitimacy through their numbers and celebrity. As Dean (employee) stated, "Well, you know, I think their name and likeness for us to be able to say we have 150 professional athletes, that lends a little credibility to the organization." The question remains how do athletes provide Athlete Ally with credibility and legitimacy? The number mentioned above in the passage, 150, is an important part of that quote. The number of athletes can contribute to media presence (Thrall et al., 2008). Social movement organizations with more celebrities gain more 
news coverage, which increases the awareness of the organization. This remains true in sport, as literature on athlete activism has focused on activism in groups: the Missouri football team (Frederick, Sanderson, \& Schlereth, 2017), the St. Louis Rams players onfield protest (Sanderson, Frederick, \& Stocz, 2016), Huma and fellow UCLA football players (Kaufman, 2008; Kaufman \& Wolff, 2010). Athlete activists are aware of the collaborations needed to enact social change (Kaufman \& Wolff, 2010), so joining with an organization to collaborate on social justice makes sense. The greater the number of athletes associated with the organization and willing to use their celebrity reputation to further the social cause, in theory, the greater chance of social change. Lane (employee) added, "They also raise the visibility of our organization, so the more athlete ambassadors we have on board, the bigger the names are, the more people get to know our work in that way." Lane also brings up way the athletes lend credibility and legitimacy other than just the number of athletes: celebrity status.

Celebrity and star power advocacy are crucial for mobilizing activists for SMOs and advocacy organizations (Simonson, 2001; Thrall et al., 2008). Logan (employee) provided an actual example, "Some of them [athletes] will show up at events, so for us that's a big, big thing. If you can get Jason Collins to attend a party, people are more likely to go." Jason Collins was the first active gay player in any of the four major North American sports. As Logan stated, having Jason Collins attend an event (i.e., Pride Night) provides more legitimacy for the event and draws more of the public to the event. Similarly, well-known Kenyan runners participated in Run-for-Peace events. Their participation gave the events legitimacy because the public was more likely to attend as people they respected were part of the event (Wilson et al., 2015). The point here is not 
on the number of athletes, but the star power of specific athletes. As Thrall and colleagues (2008) noted, star-power is important when creating infrastructure for SMOs. While celebrities struggle to set a strong agenda for the SMO in media, they are important for raising money and encouraging mobilization for action (discussed later). This remains true in the athletic environment. High profile ‘celebrity' athletes are in an appropriate position to lead activism efforts like mobilizing resources and influencing political entities (Wilson et al., 2015). All in all, athletes' transfer their celebrity status to Athlete Ally, providing the organization with a boon in awareness and credibility/legitimacy. Whether it is the quantity of athletes or the level of celebrity of the athletes, Athlete Ally can utilize those moral resources to build infrastructure, raise awareness, and mobilize constituents.

\section{Cultural Resources}

The participants did not note any cultural resources provided to Athlete Ally from the athlete constitutes. The athletes' specialty primarily resides in building awareness for the movement and social movement organization through their celebrity (Brockington, 2014). Their expertise is not in the coordination of action and organization of constituents, like a social movement organization. Therefore, it is not surprising that athletes do not provide Athlete Ally with cultural resources.

\section{Social-Organizational Resources}

Just as Athlete Ally provides athletes and college chapters with a network and connections to others, athletes provide Athlete Ally with a network and access to others. The athletes themselves lend a network to other athletes, connections to state based and local groups, and generally open doors to other potential protagonists or antagonists. Jess 
(employee), talking specifically about the college chapters stated, "We reached out to our college chapters and we said, can you share this with your networks? Can you spread the word?" Logan (employee) described it by saying:

They also help make introductions and relationships. Sort of like a spider web. They way we get to another athlete is often through another athlete. Or even just teams and leagues. So, someone will say, 'Oh, you should be talking to the head of Major League Soccer. I can get you that meeting.' That sort of thing.

The opportunity to expand a SMO's network through constituents is invaluable. A network of athletes for Athlete Ally is a crucial resource that cannot be overstated. Prior literature shows that activists get engaged and stay in activism longer if they have a social network of other activists (della Porta \& Diani, 2006; Louis et al., 2016; McPherson, Popielarz, \& Drobnic, 1992). With turnover minimized, the organization can dedicate more time to coordinating action rather than training new members. Additionally, athletes serve as a link between Athlete Ally and their own social network (Breiger, 1974; Simmel, 1955). Research shows that the majority of activists are recruited from their social network (Diani \& Lodi, 1988; Snow, Zurcher, \& Olson-Ekland, 1980). If an athlete participates in a team-focused sport (or even individual sports), Athlete Ally can recruit other members of that team to be athlete ambassadors. Thus, the importance of a strong social network is critically important as it helps recruit athletes to Athlete Ally and helps them remain committed.

But the network is not simply limited to athletes. Athletes, per Lane (employee), provide Athlete Ally access to "people and spaces, and that kind of access we might not have. Connecting with high level athletes or their agents, open doors for us to either 
access the other athletes, access to other people interested in the organization..." If it was not for the athletes providing this network with other high-level athletes, agents, or other protagonists/antagonists, Athlete Ally may not be able to gain access to those spaces. For example, there was anti-LGBT legislation in Indiana when Republican Mike Pence was governor. Richard (board member) noted the importance of a former athlete being able to access a space previously inaccessible. Richard stated:

We [Athlete Ally] brokered a meeting between Greg Louganis, who's on our advisory board, and Vice President Pence, which hasn't been often told. We got Lambda Legal lawyers in to meet with the Governor. And they had refused to meet with Lambda but, it turns out that the Governor was a big fan of Greg. Because Greg... I guess the diving program is based in Indiana? Or perhaps it's some relationship to the diving program and he took the meeting with Louganis. And Louganis was able to bring in Lambda and, my understanding is that, they either changed or he did not sign the law.

Greg Louganis gave Athlete Ally an incredible opportunity as the organization utilized his access to help defeat the anti-LGBTQ legislation. This example once again shows the strength of celebrity and athlete activists: the ability to connect and reach spaces a SMO cannot on its own (Brockington, 2014; Wilson et al., 2015). Athlete Ally was unable to get a meeting with then-governor Mike Pence of Indiana, but through a celebrity athlete, Greg Louganis, they were able to successfully change legislation. Just as the athletes of the Run-for-Peace event in Africa were utilized to reach spaces the event organizers could not, Athlete Ally can do the same. 


\section{Human Resources}

Athlete constituents provide a myriad of human resources, most notably their lived experiences and other activists (i.e. supporters of the athlete). For Logan (employee), athletes provide the organization with a "variety of voices" and a "patchwork or quilt of experiences" that aids the organization. Their lived stories represent human resources because they are not specialized knowledge, but rather are lived experiences inherent to the constituents. For an example, Dean (employee) talked about Greg Louganis, a gay former Olympic athlete, being adopted. Dean (employee) can then use Greg Louganis’ story to help combat an anti-LGBTQ adoption bill. Louganis' story can be used by Athlete Ally to help bring the issue into a real-life setting. Using an athlete's story is common practice for Athlete Ally. Jess (employee) described how the stories are used through different channels:

They [college chapters] provide us with a lot of stories, which we use in a lot of different ways. We use it on our communication front and even in the development front, when we ask donors for funds, or 'this is the kind of work we're doing, and these are the people it impacts in these stories of our college chapters'

It is important for Athlete Ally to use these personal stories because they can be a way to eliminate one of the biggest concerns for celebrity activists: lack of genuine interest in the social injustice (Davis, 2010; Huliaras \& Tzifakis, 2012; Winge, 2008). Further, general activists feel less committed to activism if they do not have a psychological commitment to the issues (Fendrich, 1977). By understanding and using personal athlete stories, Athlete Ally can ensure their celebrity athletes are genuine with their activism as it 
touches their lives and reflects commitment to the issue. This is further magnified as personal stories can combat the perception of athlete activists manufacturing issues, but not overcoming the issues (Frederick, Sanderson, \& Schlereth, 2017).

Stories are not the only human resource athletes provide Athlete Ally. The athletes, through their platform (Agyemang, 2011; Kaufman \& Wolff, 2010; Wilson et al., 2015), can help provide "traffic" like human signatures or visits to the website. For example, Dean (employee) stated:

So, it's good to have their name and affiliation, they send a lot of traffic our way in terms of promoting our pledge. So, we'll be getting... like they'll encourage their followers oftentimes and sustain a substantial following to sign the Athlete Ally pledge.

One of the most effective ways to utilize celebrity activists and advocates is to communicate to the public and encourage the public to volunteer for a cause (Brockington, 2014; Kogen, 2015; Wilson et al., 2015). Social movement organizations like Athlete Ally can then use those human resources mobilized by the athlete activists to volunteer for marches and events or sign pledges and other slacktivism related materials. Slacktivism equates to lazy activism, usually completed via the internet with little risk/effort to the activist, such as posting on social media or signing a pledge (Lim, 2013). Research has discovered, however, that individuals engaging in slacktivism are more likely to engage in actual activism, like donating money (Lee \& Hsieh, 2013). So, Athlete Ally can utilize their athletes to provide human resources to the organization and ultimately increase their number of constituents. 


\section{Material Resources}

Finally, material resources are the tangible resources athletes provide Athlete Ally. Many of the employees suggested signed merchandise as the main material resource that athletes provide Athlete Ally. Merchandise such as signed basketballs from Kareem Abdul-Jabbar are then used for auctions. Per an 2015 financial report obtained from Athlete Ally, most of the money from fundraising and donations was allocated to compensation to employees and board members, insurance, travel, office expenses, and legal fees. Another popular "package" provided to Athlete Ally by athletes are sport opportunities. For instance, Logan (employee) noted, “[we] auction of some cool packages, 'Getting to work out with Jason Collins,' and some unique sport stuff.' While the athletes may not provide any direct financial resource, they indirectly offer financial resources through their merchandise and time. Literature supports the notion that celebrities (Bockington, 2014) and celebrity athletes (Wilson et al., 2015) can provide this type of resource. It would be inefficient for Athlete Ally not to use their athletes for raising financial resources to use for organizational goals. While it may not be direct financial resources, the athletes are providing resources for fundraising purposes.

\section{Summary of Findings for RQ1b}

Athlete constituents provide Athlete Ally with a variety of resources. Most of them are a reflection of the celebrity that comes with being an athlete (Wilson et al., 2015). It is no secret that athletes are given an elevated platform in society (Agyemang, 2011; Kaufman \& Wolff, 2010; Wilson et al., 2015). Using that elevated status, or celebrity, the athletes can provide the organization with credibility and legitimacy. Being associated with an athlete who is committed to a social issue can help elevate the stature 
and media attention for the sport social movement organization (Carrol, 2016; Thrall et al., 2008). Therefore, it would behoove an organization to identify and establish partnerships with athletes to help build credibility, legitimacy, and awareness for their organization. Athletes also provide Athlete Ally with access to a broad social network of other athletes. This is a tangible benefit for Athlete Ally as it allows for more athletes and constituents to be recruited for activist work. In addition, the athletes can help open new avenues for movement progress that were previously inaccessible (Brockington, 2014). As a SMO, Athlete Ally can be shut out from political antagonists (Bernstein, 1997). Athletes can, and have in the case of Greg Louganis, reached previously unattainable actors. Another resource athletes provide Athlete Ally is their personal stories and experiences. These personal stories and experiences (as discussed later) can serve as starting points for SMO goals or even opportunities to fundraise. Athletes who are fully committed to Athlete Ally and their goals have a story or reason for their activism. A sport SMO should tap into these stories to understand why the athlete is committed to the organization and use those stories to mobilize various resources. Athletes also provide resources for the sole reason of fundraising. As athletes and celebrities are viewed as leaders in society (Brockington, 2014; Wilson et al., 2015), their merchandise can provide materials for fundraising. The one resource missing is cultural resources, but that is not surprising. As mentioned, the athletes' strength does not lie in pooling resources, coordinating action and being a basis for mobilization. Those roles are filled, and should be filled, by the SMO as it has the specialized knowledge for mobilization (Caniglia \& Carmin, 2005). A SMO should rely on the strengths of the athlete, including providing 
credibility, legitimacy, awareness, their social network, and tangible materials for fundraising efforts.

\section{Summary of Findings for RQ1}

Interestingly, many of the resources exchanged between Athlete Ally and its athlete constituents are similar. Both entities provide each other with legitimacy and credibility (moral resources), a strong social network (social-organization resources), and material goods for building awareness or fundraising (material resources). Moral resources are shared because the SMO provides a constant basis for mobilization (Caniglia \& Carmin, 2005) and the celebrity of the athletes helps raise awareness and respect for the organization (Brockington, 2014; Kogen, 2015; Thrall et al., 2008; Wilson et al., 2015). Social-organizational resources are both present because the activist opens up his/her social network, while tapping into the social network of the social movement organization (della Porta \& Diani, 2006). Finally, material resources transferred because the organization wants to create a collective identity through symbols (Carty, 2002; Dorf \& Tarrow, 2014) and the celebrity athletes can utilize one of their strengths in fundraising (Brockington, 2014). The shared resources indicate the mutually beneficial relationship between SMOs and athletes. While the SMO provides many resources to the athlete, so does the athlete to the social movement organization. Broadly speaking, it would be wise for athletes to partner with advocacy organizations if they wish to engage in activism, just as it would be wise for advocacy organizations to partner with athletes.

While the two entities have many similarities, cultural resources and human resources are not exchanged between both parties. Athlete Ally only provides cultural resources to its athlete constituents. This is not surprising as the SMO's strength lies in 
coordinating action and serving as the basis for mobilization (Caniglia \& Carmin, 2005; della Porta \& Diani, 2006). The organization has only five full-employees who are dedicated to disseminating cultural resources to athletes and other constituents, like policy one-sheet summaries and toolkits. With only five full-time members, the organization cannot help support athletes through the number of bodies they can contribute to a march or an event. Therefore, it would be wise for athletes to provide the SMO human resources, as they have numerous supports (Wilson et al., 2015). Additionally, the use of a strong social-network can assist athletes in mobilizing activists for the organization. Thus, a SMO partnering with athletes would be wise to make sure their strength lies in providing specialized knowledge to athletes. Athletes, on the other hand, should invest in growing their network and mobilizing human resources to maximize their benefit to a social movement organization.

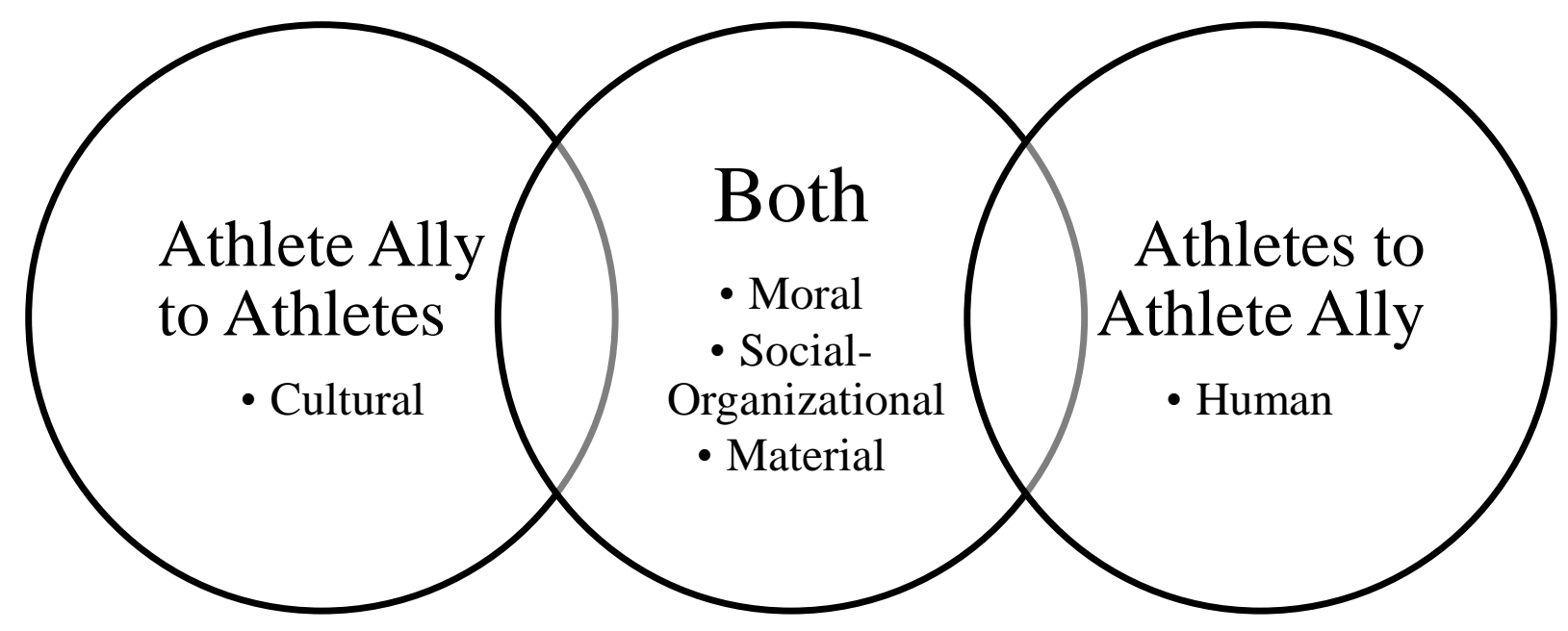

Figure 2. Comprehensive overview of resources exchanged between Athlete Ally and its athlete constituents. 


\section{RQ2: What strategies does Athlete Ally utilize to engage with various governing bodies?}

Political Process Theory (PPT) expands the scope of investigation from the specific social movement and accompanying organizations to the external structures surrounding the social movement and its actors (Caniglia \& Carmin, 2005). The framework is broken into three variables: political opportunity structures (POS), configurations of actors/power, and interaction contexts (Kriesi, 2004). First, the POS investigates the political institutions (i.e. institutional structures) and cultural aspects (i.e. acceptance of movement goals/claims as legitimate by public/governing body) surrounding the social movement. The political institutions can be open or closed, allowing for easier or more difficult input and slow or fast output, respectively. In addition to the strict political institution, the public or governing body's opinion can also influence the political opportunity structure. Public or the governing body's opinion can view the movement favorably or non-favorably. Historically, the more open the institution and more favorable the cultural opinion, the more likely for collaborative success between the movement and the political entity (Koopmans \& Statham, 1999). The tactics of the social movement and political entities will vary depending on the degree of openness and public/governing body support (Kriesi, 2004). Second, the configuration of actors/power notes the various actors in relation to the social movement at a given time. Actors can either be protagonists, antagonists, or bystanders. Protagonists are allies to the social movement, antagonists are adversaries to the social movements, and bystanders are outside of the social movement, but note the environment of the social movement and its cause. Movements will find more success (without using combative 
strategies) when protagonist actors are in government (Engel, 2001), compared to antagonist actors (McAdam, 2017). The configuration of actors/power describes the level of potential conflict and the context of the movement, but does not describe how the situation evolved or how it was created (Kriesi, 2004). Unlike the almost fixed POS, the configuration of actors/power is much more malleable and susceptible to SMO influence (Kriesi, 2004). Finally, the interaction context between the institutional structures and configurations of actors/power examines the agency and action that is a result of the interactions (Kriesi, 2004). Activists do not create strategies in a vacuum (Meyer, 2004), but based on the aforementioned characteristics. For a positive relationship between the political actors and SMO, the SMO will be more collaborative in nature (Amenta, 2005). If the relationship is not positive, the SMO will have to resort to more combative techniques (Bernstein, 1997). The following section outlines the POS, configuration of actors, interaction context, and discussion for the NCAA, NBA, and U.S. Government, respectivey. A concluding section will offer a summary of findings for the second research question.

\section{NCAA}

A Board of Governors, a group of 20 members from various titles and divisions, oversees NCAA operations. The NCAA president, chairs of Division I Council, Division II Management Council, and Division III Management Council serve as ex officio nonvoting members (unless there is a tie in voting members; NCAA, n.d.-b). The other 16 members are presidents and chancellors from Division I, II, and III. The Board ensures that each division operates consistently with the basic purposes, fundamental policies, and general principles of the NCAA, including electing the President of the 
NCAA. Following the Board of Governors and the President, each division (I, II, and III) governs the rules and policies in place for the specific division. Each division regulates itself with committees serving to implement division-specific policies and procedures. Committees are comprised of college and university presidents, athletic directors, coaches, student-athletes, staff, faculty members, and conference office personnel from the respective division. The committees propose rule changes and policy changes for the rest of the membership to vote on at annual meetings.

The above-mentioned governance structure constitutes an open and weak political institution. The structure is comprised of 20 members overseeing the entire organization, followed by each division having its own self-governing body, and committees made of various actors (including student-athletes) to create and implement policy. Just like the U.S. Government, the emphasis is placed on the lower levels to develop policy and rule changes to be voted on at the upper levels. While access to the NCAA is available through multiple members, the votes to change policy and rules happen once a year with many voting members.

In regard to the discursive opportunities, the NCAA it is a pro-LGBTQ entity. As evidence, the NCAA provides numerous resources for LGBTQ athletes and non-LGBTQ individuals, including: LGBTQ terminology, best practice recommendations, Safe Zone Ally stickers and magnets, campus climate surveys, links to pro-LGBTQ organizations, and other articles of interests (NCAA, n.d.-a). In addition, similar to the NBA, the NCAA had opted to pull championships out of Charlotte in response to North Carolina's HB2 on the basis of the "NCAA's commitment to fairness and inclusion..." (NCAA, 2016, para. 1). Despite these resources and actions, the NCAA has seemingly ignored the LGBTQ 
movement outside of the NCAA. For instance, the NCAA eventually awarded championships to the state of North Carolina after a modified version of HB2 passed. As a result, Athlete Ally noted the "hypocrisy" (Carr, 2017, para. 2) of the NCAA. Additionally, concerns that the NCAA does not have the LGBTQ community's best interest arise as they have member institutions, like Brigham Young University, who have anti-LGBTQ policies and practices (Athlete Ally, 2016). The NCAA, to the public's perception, attempted to change Brigham Young University's anti-LGBTQ stance. The differing narrative toward the NCAA creates a muddled picture. On one hand, the NCAA is attempting to provide resources and aid to LGBTQ individuals, thus acknowledging that the LGBTQ population faces discrimination. On the other than, the NCAA ignores discriminatory state legislation and NCAA member institutions anti-LGBTQ policies.

Shifting focus from the POS to the configuration of actors, the NCAA acts as both a protagonist and an antagonist to the LGBTQ movement. Providing resources for LGBTQ and non-LGBTQ students to be more inclusive indicates a governing body that is an ally to the LGBTQ movement. The NCAA, however, can be viewed as an antagonist for allowing schools with anti-LGBTQ policies to be a part of their membership. Additionally, the NCAA re-awarded championships to North Carolina after they passed a modified, but similar version of House Bill 2 (Carr, 2017).

Inside Athlete Ally, participants viewed the NCAA as mostly a protagonist to their cause. The strong relationships, as many participants commented, was a culmination of Hudson Taylor's work with the NCAA. In 2012, the NCAA commissioned Taylor to help create a report called Champions of Respect with LGBTQ and sport advocate Pat Griffin. The report outlines the importance of LGBTQ issues in intercollegiate athletics 
and policy and best practice recommendations (Griffin \& Taylor, 2012). As one employee, Dean (employee), stated, the Champions of Respect is "essentially the NCAA guidebook on inclusion.” The relationship has been strong between the NCAA and Athlete Ally since that time. Per past studies, organizations that adapt to a social movement are more likely to be open to future activist challenges (McDonnell, King, \& Soule, 2015). The NCAA, as a result of a successful collaboration with Hudson Taylor and Athlete Ally, has certainly been open to continuing to work with the organization. One way this relationship continues to be strong is that, as Logan (employee) stated, "there are a lot of people internally that are super supportive of our issues." Luke (board member) echoed that statement, claiming, "We have worked very hard and for a long time to build relationships with a few key people in positions where their policies are promulgated to have influence where we can.” This internal support provides a great working relationship, even though "[T]here are times where, publicly, there may be someone internally that's really pushing for some of these issues, but publicly, they can't always say it", according to Logan (employee). Within that statement, one can understand how the NCAA can be perceived as both a protagonist and an antagonist. Still, the NCAA and Athlete Ally have a strong relationship, leading Logan (employee) to consider them "one of the closer partnerships we have."

The final step of the PPT is investigating the interactions between the political entity and the SMO or social movement (Kriesi, 2004). Understanding that the NCAA is a protagonist actor to Athlete Ally, participants noted that in interactions and strategies Athlete Ally balances between "sage and watchdog." As mentioned, an important catalyst for the strong relationship between the NCAA and Athlete Ally stemmed from the 
Champions of Respect document that the NCAA commissioned Hudson Taylor to cocreate. By partnering with the NCAA, Athlete Ally helped collaborate on the inclusion policies and best practices to be used by the NCAA and its member institutions, while developing a relationship with the NCAA. Dean (employee), Logan (employee), and Jess (employee) all acknowledged working with the NCAA to establish and discuss policy and best practices. Instead of going directly to the NCAA member schools, Athlete Ally's initial strategy was to work with the NCAA's administration. Logan (employee) stated this best: "For us, it's sort of like going for the head of the body instead of... you know, that can kind of have a trickledown effect on the others." By creating inclusive policies with the NCAA, the hope was that the NCAA would push those policies on to their member institutions. Still, member institutions like Brigham Young University and Baylor University contain anti-LGBTQ policies and the NCAA returned to North Carolina with championships after a modified version of the HB2 passed. The trickledown strategy used by Athlete Ally did not obtain victories when engaging with the NCAA.

After some time, participants noted that the tone changed stemming from Hudson Taylor's mentality of "going from sage to watchdog," according to Logan (employee). One of the ways this happened was through a report Athlete Ally created called the Athletic Equality Index. The AEI is a ranking and recording of all Power 5 NCAA members (members in the Atlantic Coast Conference, Big 10, Big 12, Pac-12, and Southeastern Conference) on their inclusion policies and practices. Each school is graded on their nondiscrimination policy, accessible resources, LGBTQ-inclusive fan code of conduct, adoption of NCAA policy for transgender inclusion, presence of LGBTQ 
student-athlete group or initiative, outspoken or allied staff, collaborations with campus groups, and pro-LGBTQ campaign or statement. Each member (and conference as a whole) is awarded up to 100 points. The Pac-12 leads all conferences with an average score of 79.7 for all member institutions, the Atlantic Coast Conference's score was 72.0, the Big 10 compiled an average of 65.7, the Big 12 came in almost ten points lower with an average score of 56.8 and the Southeastern Conference finished last with 56.4 as an average score. Logan (employee) provides the strategy for the creation of the AEI:

It's like we gave them the model policies, or we said 'You should do what the NCAA encourages, 'blah, blah, blah. And they can do it or not, right? Well, once you start ranking and reporting, and making them public, that's where they're like, 'Shit, I got to do better on this stuff.'

As one may notice, this strategy is not targeted at the NCAA specifically, but the member institutions. For Logan (employee), the perception for Athlete Ally was that member institutions would be obliged to change when they are objectively measured against other institutions in their conference and across the nation. As Luke (board member) confirmed, the AEI represented a shift in strategy for Athlete Ally. Instead of working at the top with NCAA, Athlete Ally was using the AEI as a way to "work from the bottom up." This puts pressure on schools to make their policies more progressive and hopefully make their individual athletes more progressive. Luke (board member) noted this strategy was to build athlete activists and breed that accepted behavior. The board member noted this was a change in strategy as a response to the NCAA's decision to go back to North Carolina despite the House Bill 2. 
Lane (employee), a relatively new employee to the organization, echoed the current strategies employed by Athlete Ally: "We call them [the NCAA and member institutions] out on a lot of their non-inclusive and discriminatory policies and practices that perhaps are also not consistent throughout different aspects of the organization." As an example, on March 27, 2018, Athlete Ally sent an email to highlight Transgender Day of Visibility (March 31, 2018,). The email was a campaign for constituents and activists to join Athlete Ally in in "demanding college athletic departments adopt the NCAA's guidance for transgender participation in college sports." (email communication, March 27, 2018, para. 1). Interestingly, Athlete Ally utilized the NCAA's policy as the basis for their demand. The organization demanded that member institutions follow the policies set forth by their governing body. The campaign noted that only 10 of the 65 -member institutions of the NCAA Power Five conferences adopted the NCAA's guideline for transgender participation in collegiate athletics. The campaign serves to reinforce the idea that Athlete Ally is not afraid to call out NCAA institutions for non-inclusive policies. Just one day later, on March $28^{\text {th }}$, Athlete Ally sent another email detailing the progress of the campaign. Since their call to action a day ago, 11-member institutions had been in touch with Athlete Ally to discuss updating their transgender participation policies. Each member institution was noted by the Twitter account by Athlete Ally for engaging in conversations to adopt transgender participation policies. The act of calling out member institutions for their discriminatory policies, similar to using the vinegar method (i.e. highlighting discriminatory policies) of activism (Bundon \& Clarke, 2014), served to gain a response from some member institutions. Instead of working at the top and hoping for trickle down, Athlete Ally can take a combative stance against the member 
institutions and work from the bottom up. Still, this would not be possible if it were not for the close collaboration with NCAA to help legitimize their words and actions. The change, however, does not represent a complete shift in tactics for Athlete Ally. The organization still works with key administrators in leadership positions with the NCAA, but is also willing to work from the bottom up in a more combative manner. This speaks to the strength of the relationship as all participants continued to iterate that their relationship with the NCAA is strong and that the NCAA provides Athlete Ally's information as a resource on their NCAA and LGBTQ resources web-page.

This analysis of the NCAA suggests that it is an open governing body that acts as a protagonist to Athlete Ally's mission. An open governing body allows for easy access into the political system, but is slow to change (Eisinger, 1973; Krieisi, 2004). In other words, while inputs (interactions with political actors) are available for SMOs, outputs (social change) are slow to materialize for the organizations. As noted by Luke (board member), Athlete Ally spent a long time building relationships with the NCAA stemming from the Champions of Respect report. The report served as an opportunity to open the NCAA to working with Athlete Ally on future activist collaborations (McDonnell, King, \& Soule, 2015). They spent a vast amount of time establishing relationships with the open institution, but have witnessed only slow progress from the NCAA. In terms of the cultural opportunity, Athlete Ally's mission and actions are certainly visible to the NCAA. By dedicating an entire website page to providing resources for LGBTQ students and outlining best policies, the NCAA legitimizes Athlete Ally's mission and actions. Given the open institutional opportunities and available discursive opportunities, success is possible for Athlete Ally (Koopmans \& Statham, 1999). 
. As such, the NCAA should be more open to facilitating policy change and working favorably toward Athlete Ally's goals, rather than repressing them (Kriesi, 2004). Therefore, Athlete Ally should prepare strategies in accordance to a governing body that is willing to respond favorably toward the organization's mission.

Still, the reality is that the NCAA is not always a protagonist. Athlete Ally has two roles with the NCAA: sage and watchdog. The sage aspect refers to a non-combative form of engagement with college athletics' most prominent governing body when the NCAA creates LGBTQ inclusive policies. Collaborative strategizing takes place behind closed doors, discussing best practices and policy, similar to the Oregon LGBT SMOs' actions in the 1970s (Bernstein, 1997). The Oregon LGBT SMOs had access to the political entities and semi-insider status. Due to this strategy, mass mobilization and combative strategies were discouraged. Activists are not needed as much when cooperation is possible between Athlete Ally and the NCAA. Still, participants noted that they needed to be watchdogs when the NCAA acted as an antagonist. They created the AEI as a means of "calling out" member schools for their lack of inclusion efforts by using the NCAA's policies. Similar to how Kenyan runners utilized former-SecretaryGeneral of the United Nations, Kofi Annan, for peace efforts (Wilson et al., 2015), Athlete Ally utilized the NCAA's policies to call out their member institutions. For instance, Athlete Ally gave Baylor a negative score of -45 out of 100 . The overall average among the five power conferences (Atlantic Coast Conference, Big 10, Big 12, Pac-12, and Southeastern Conference) was a 66.1 (Athlete Ally, 2017b). Hudson Taylor even stated in the report, "The AEI brings our movement into a new era of advocacy, transparency and accountability" (p. 3). This strategy then can help mobilize constituents 
to highlight the exclusory practices of member school, a la the vinegar strategy employed by para activist athletes (Bundon \& Clarke, 2014). For Athlete Ally, using a combination of collaborative and combative strategy makes sense given the open and semi-protagonist classification of the NCAA.

In a broader sense, Athlete Ally's interaction can provide insight into how SMOs should determine interactions with governing bodies. Theoretically speaking, when actors are protagonists, the SMO will have an easier time creating social change. When the political actors are antagonists, the SMO will have a more difficult time creating social change (Koopmans \& Statham, 1999). Clearly, when the NCAA was a protagonist, Athlete Ally utilized collaborative relationships as they were able to successfully create new policies and practices. However, when the NCAA was an antagonist, Athlete Ally had a more difficult time creating social change and thus had to resort to a combative strategy working in a bottom-up approach. On a grander scale, this finding seems to confirm Koopmans and Statham (1999) and Bernstein's (1997) assessment that protagonist structures are best suited for collaborative strategies and antagonist structures are best suited for combative strategies. Other SMOs can take heed of this finding.

\section{NBA}

By definition the NBA (and WNBA) is also an open system, though much less open than the NCAA and U.S. Government. Per the NBA constitution, the NBA Board of Governors largely controls the operations of the NBA (NBA, 2012). The 30 Board of Governors are appointed by the majority owners of the NBA franchises, with a Chairman elected by the Governors at the annual meetings. The Chairman largely serves as a liaison between the Commissioner and the Board of Governors and conducts meetings in the 
Commissioner's absence. The Governors duties include, but are not limited to, appointing committees, voting on any issues that arise (e.g. adding a new member to the association), expelling a member, amending bylaws, approving unusual expenses, electing a Commissioner, removing the Commissioner, and rule/policy changes, and overall supervision of the affairs of the NBA (NBA, 2012). It is the role of the Commissioner to operate the day-to-day management, when compared to the Governors. The Commissioner, elected by the Board of Governors, acts as the Chief Executive Officer for the Association and protects the integrity of the game by resolving disputes among members, addressing the wrongdoings of the members, suspending, imposing fines, or penalizing members, players, coaches, and any other parties under the NBA, setting the date and times of all games, and interpreting and establishing policy and procedure, rules, regulations, resolutions, and agreements in respect to the provisions of the Constitution and bylaws (NBA, 2012).

With this given governance structure, the NBA is considered open as there is a clear separation of total power (Commissioner and Board of Governors), a voting system in place, and multiple actors in respect to the Board of Governors. By definition, that constitutes the NBA as an open system as the majority of the 30 Governors vote on policies and rules for the league. The NCAA and U.S. Government have far more members. Still, the presence of members and democratic voting implies that the NBA is an open system.

In terms of the cultural attitudes towards LGBTQ issues by the NBA, the NBA has shown it views LGBTQ issues as culturally important. Commissioner Adam Silver, and other NBA and WNBA employees and players marched in the New York pride 
parade, as reported in Athlete Ally's Twitter account. The support of the Commissioner and players indicates a strong acceptance of LGBTQ movement legitimacy. In addition, the NBA moved the 2017 NBA All-Star Game out of North Carolina because of the HB2 bill. The response to the anti-LGBTQ bill by the NBA indicates that the NBA mostly feels as if the LGBTQ community's issues are legitimate and resonates with the league as a whole.

The NBA, being open institution with opportunities for discursive action, lends itself as a natural protagonist to the LGBTQ movement. This is certainly the case as participants at all levels of the organization noted the strength of the relationship between the two entities. Richard (board member) stated, "So, they're [the NBA] sort of a model league, and would have to be a considered a model partner." The comment serves to showcase the NBA as a flagship league for social issues and a great partner with Athlete Ally. Logan (employee) added, "So, NBA is definitely, I think, one of our deepest partners. I mean, at the outset, they're one of our largest funders." With the NBA providing a large amount of resources to Athlete Ally, one could imagine there could be concerns if Athlete Ally disagreed or publicly condemned the NBA. Logan (employee) did acknowledge the perceived indebtedness to the NBA based on the amount of financial resources provided to Athlete Ally, but noted that was not the reality. In fact, when the NBA selected North Carolina for the 2019 All-Star Game, Logan (employee) noted:

...was actually when they increase their support to us. Because I think they thought... again there were internal people there at the top that was like 'shit, this sucks.' They don't have the power to change it. So, for them, the answer was, 
'Well, how do we invest more in the groups that are fighting this?' And/or, 'what can we do on the local level?' So, things like making sure that they only work with LGBT-friendly vendors when they are there. There are tangible things we can work with the on to make the best of a kind of a bad situation.

Despite the action of bringing the All-Star Game back to North Carolina due to “corporate pressures", per Luke (board member), the NBA tried to salvage the issue by utilizing specific vendors. Still, Athlete Ally expressed disappointment toward the NBA's decision to go back to North Carolina after a version of HB2 passed. Luke (board member) noted the strength of their relationship with the NBA was beneficial in their making public statements condemning the NBA. Luke claimed, "we were able to talk with them and hold their hands and vice versa, so they wouldn't get pissed at us when we turned on them." The organization was able to confront and oppose the NBA's decision, but still have a great relationship because of their relentless effort to establish those positive relationships.

With the understanding that the NBA is open and a strong protagonist, Athlete Ally's strategies with the entity should be collaborative in nature (Kriesi, 2004). As expressed, the NBA is considered to have the closest relationship with Athlete Ally of any major sport organizations. Every participant discussed how the NBA brings in Athlete Ally for trainings of various members of the association. As Dean (employee) stated, "For the fourth year in a row, we have trained every incoming NBA rookie on LGBT inclusion efforts." Every NBA rooking goes through a Rookie Transition Program when entering the NBA. Athlete Ally specifically speaks about the LGBTQ component of the segment on diversity and inclusion. As Dean (employee) stated, "So that's an 
opportunity to talk to hundreds of junior NBA coaches a year on coaching the next generation of basketball players, and what that means for creating men of character, talking about diversity and inclusion." Richard (board member) noted that this a result of the NBA being proactive on social justice Richard stated:

It's [Athlete Ally and the NBA] probably our most impactful, collaborative, relationship. In part because their senior leaders started NBA Cares and have just leaned in so much on these issues and have been outspoken. Whether it's after a player does something unfortunate, or more proactively, getting involved in, for example, the North Carolina situation to move the All-Star game.

The NBA, as Richard mentioned before, is a model league at least partly because of their conscientiousness about social issues. With the organization leaning in on social issues naturally, finding opportunities to get in front of athletes and coaches is easier as they are more receptive to engaging in social justice efforts.

Outside of trainings for members of the association, Athlete Ally collaborates with the NBA on differing levels. Per Logan (employee), Athlete Ally serves as unofficial advisers to the NBA on LGBTQ inclusion policies and practices. Both entities collaborate to organize Pride Nights, games with pregame panels and in-game content to highlight LGBTQ diversity, equality, and community (Dowd, 2018). Athlete Ally also collaborated with the NBA to help move the 2017 All-Star Game out of North Carolina, in response to HB2. Whether it is through trainings, creating policy, or helping create specific rallies/nights for the NBA, Athlete Ally uses multiple means to help the NBA be more inclusive and further the goals of LGBTQ inclusivity within sport. Luke (board member) attributes this to the NBA's mindset towards inclusivity and diversity. $\mathrm{He}$ 
claimed, "The most responsive league by far and the one that is clearly committed to diversity is the NBA and that's where we've had the most traction."

Given the open nature of the NBA and opportunities for discursive action, one can theorize that Athlete Ally will be successful in their mission for social change within the league (Koopmans \& Statham, 1999). Once again, this is aided by the fact that Athlete Ally has powerful actors in the organization who are sympathetic to their movement. As one participant stated, the NBA is one of Athlete Ally's deepest partners. This is obvious as Athlete Ally trains every incoming rookie and new coach/administrator on LGBTQ inclusion efforts. Athlete Ally also partners with the NBA on creating LGBTQ inclusion policies and practices, collaborating on Pride Nights, and helped move the 2017 All-Star Game out of North Carolina. Allowing Athlete Ally to teach the NBA's coaches and rookies, creating LGBTQ inclusion practices and collaborating with the SMO, means the NBA is assisting Athlete Ally in achieving their mission. The level of impact the NBA has on the LGBTQ community and LGBTQ movement in sport, however, has not been measured. However, the notion that the NBA is a protagonist, lends itself to the understanding that it helps facilitate Athlete Ally's goals of ending transphobia and homophobia in sport. Investigating the actual tactics, Athlete Ally uses a collaborative strategy for engaging with the NBA, instead of a combative strategy. Once again, reminiscent of the Oregon LGBT SMOs in the 1970s (Bernstein, 1997), Athlete Ally mainly works outside the public view to enact social change. Athlete Ally does not need to mobilize activists to demand action because their claims are not heard or understood. The SMO has access to a pro-LGBTQ organization and can make positive change. While the public may fail to see progress being made because the meetings private (Bernstein, 
1997), the organization is making gains through their work. This strategy is successful on multiple fronts as collaborative methods are more appropriate in favorable situations (Amenta, 2005). The reason for this successful partnership stems from the NBA's dedication to athlete activism and LGBTQ issues and Athlete Ally recognizing that protagonist tendency. While there are still times that Athlete Ally must "call out" the NBA for a policy that may run counter to Athlete Ally, the organization can primarily focus on ways to take a honey approach (i.e. highlighting inclusion policies) and develop policies and trainings that are inclusive (Bundon \& Clarke, 2014).

Dealing with a mainly protagonist actor in the NBA, Athlete Ally utilizes mostly collaborative strategies with the governing body. This speaks to the importance of the relationship between the two organizations. As one participant noted, the NBA is considered Athlete Ally's closest partner. This relationship was nurtured over time. Organizations that seek to enact social change should note how the strength of the relationship allows Athlete Ally to work collaboratively with the NBA. This creates a formidable relationship and allows the SMO to work behind closed doors, outside the view of media or a potential countermovement, to enact change.

\section{U.S. Government}

Perhaps the easiest POS to understand is the U.S. Government. The U.S. Government is an open and decentralized political entity. The U.S. puts emphasis on multiple points of access at the national, regional, and local level. Through local government to states' representation in the Senate and House of Representatives, and the separation of legislative, judicial, and executive branch, the U.S. Government fits the definition of an open political institution (Kriesi, 2004). As for the public opinion on pro- 
LGBTQ policies/issues, a recent Pew Research Center poll noted the majority of people in the US (62\%) support same-sex marriage, while only $32 \%$ oppose it. This is a significant change from 2001, when $35 \%$ of people in the US were in favor of same-sex marriage, while 57\% opposed it (Pew Research Center, 2017). While pro-same-sex policies do not directly equate to cultural acceptance of LGBTQ individuals in the US, one can presume people in the US feel LGBTQ issues and policies are legitimate. More importantly, while the US public is mostly pro-LGBTQ, the presidential administration at the time of the study has expressed anti-LGBTQ claims. The National Center for Transgender Equality has even gone so far as to call the President Trump the most antitransgender President in US history, citing rolling back protections for LGBTQ individuals and appointing actively anti-LGBTQ senior officials (National Center for Transgender Equality, n.d.). The rights and protections for LGBTQ individuals are not a legitimate concern for the current executive branch of the U.S. Government.

In terms of the U.S. Government, multiple participants routinely discussed the "current administration". While the rest of the U.S. Government (legislative and judicial) can be considered as points of examination, the participants focused on the executive branch. Dean (employee) used the 2016 presidential election as a changing moment for him and many individuals. Dean (employee) stated, "I think many of us were witnessing and say that the progress we made on a lot of points over eight years of the Obama administration was going to quickly be reversed or threatened by the Trump administration." It was clear that the Obama administration was a protagonist to the work Dean (employee) did for the LGBTQ community. The next administration, Trump's presidency, revealed itself to be an antagonist to Athlete Ally's work. This stance was 
evident among all participants in the study, regardless of their employment status (employee or board member). Richard (board member) stated, "I think we have had a collaborative relationship with the state department under President Obama and Secretary [John] Kerry, and then [Hillary] Clinton around some of the global issues." This passage indicates that it was not just one individual that was a political ally, but multiple political allies within the U.S. government. Kirk (board member) had an interesting point in terms of the antagonist nature of the current administration and his work, "I actually think it's [mobilizing donors] harder under President Trump, because so much is so fucked up that you need to focus on the basics in some ways." The basics that Kirk (board member) referred to were basic human rights like women's' rights, immigrants' rights and minority rights. Kirk (board member) believed it was more difficult to mobilize donors for a sport specific SMO when sport can be seen as a luxury. Speaking about many basic social issues like women's or LGBTQ issues, Logan (employee) stated, “I don't think, under current administration, that it's a priority." Overall, the current president's administration can be viewed as an antagonist to Athlete Ally.

The U.S. Government is an open institution, but contains antagonistic opinions toward LGBTQ issues. Theoretically speaking, Athlete Ally should engage in combative strategies to mobilize against the U.S. Government (Bernstein, 1997; Ghaziani, Taylor, \& Stone, 2016). When political actors or entities are unresponsive to movement claims, SMOs have found success in using more combative strategies. For instance, in the 1970s, LGBT SMOs had no political allies in New York. Instead of working with political actors behind closed doors, the LGBT SMOs had to mobilize activists to use combative strategies like "kiss-ins" (instead of sit-ins) at straight bars, demonstrations against police 
brutality, and refusing to dress according to gender roles and heterosexual norms.

Activists in the LGBT movement realized they had little to lose facing a hostile political entity, but much to gain by using radical political action. In Oregon, where access to political actors was open and protagonist (particularly for white gay males) strategies of cooperation were more successful. Oregon LGBT SMOs' claims were legitimized by local political entities, thus not requiring radical political action, but rather collaborative political action (Bernstein, 1997). Therefore, Athlete Ally should either utilize combative strategies or attempt to influence the configuration of actors.

Athlete Ally, as a 501(c)(3) organization however, cannot legally attempt to substantially influence the government. As Dean (employee) stated, "We're a 501(c)(3), which means we can't lobby, there's a difference between a (c)(3) and a (c)(4) organization. So, we cannot directly mobilize people around specific pieces of legislation or senate appointments." Other participants echoed this same barrier of being a 501(c) (3) organization. Kirk (board member) noted, "There's lines around actual lobbying, showing up at the governor's office and lobbying, we can't cross those lines. But, it would be crazy if we were an organization that wouldn't get into political issues that our community cares about." Despite the barriers, participants noted they still had to find a way to impact political issues in their community and nation. Participants noted the different ways they can indirectly work with the U.S. Government. As Jess (employee) stated:

I know Athlete Ally uses its network of Ambassadors and collegiate athletes, and Olympic athletes to sort of push for any reforms that are happening. So, say our state based group is working on shutting down an anti-LGBT bill, we would say, 
'Hey we have these four athletes from that state, and we have these collegiate athletes who live in that state, we'll connect you with them, and you let them know like, what sort of messages you want them to share.'

Here, Athlete Ally is using its network to let athletes engage in activism to influence political actors. Per the 501(c)(3) guidelines, Athlete Ally cannot influence political entities, but they can indirectly inspire their constituents to influence political entities. Logan (employee) noted as similar sentiment:

But I think it's more about the role we play in leveraging others. Another example is in Texas, where they were possibly going to do a bad bathroom bill similar to North Carolina. We were able to work with folks like Mark Cuban. And, again, it's all under the offices of Mark Cuban, so it doesn't really have our name all over it. But I think leveraging him, who, as a sports owner and a businessman down there, has a lot of sway. Right? So, when he's saying, 'This is bad for the state,' legislators are going to listen.

The strategy of working through other constituents to influence political actors is common and absolutely needed, according to participants. For example, Mark Cuban, owner of the NBA's Dallas Mavericks and entrepreneur, can act as a celebrity activist in opposition of a particular legislation or promote a certain agenda (Brockington, 2014; Wilson et al., 2015).

Expanding on the overall philosophy of Athlete Ally, Luke (board member) noted that Athlete Ally tried not to change strategies after President Trump's took over the White House. The organization wanted to stay the course, despite the switch from a protagonist to an antagonist in the President's office. After all, the configuration of actors 
is more likely to change than the actual structures of the institution (Kriesi, 2004).

Changing the entire organization's mission and vision would be folly given the political actors could change rapidly. Luke (board member) also mentioned that the organization needed to stay away from the perception of being a "negative resistance" organization, but be more focused on the "pushing positive change, not overcome negativity." This mentality and tactic centered on the board's decision to recognize that they are working in sport as an athlete advocacy organization and not a political organization, despite other LGBTQ SMOs condemning the administration. Despite these claims, the organization sends out letters condemning legislation (like the Texas SB6 bill) with the names of their athlete ambassadors at the end of the letter. In addition, the organization launches campaigns to oppose those discriminator bills, once again signed by their athlete constituents. The participants noted the importance of working through people to engage with politics is a must, despite being a 501(c)(3) organization.

The U. S. Government may also be an open institution, perhaps the most open, but it is currently also the most antagonistic. With a President and a Senate that are largely anti-LGBTQ, Athlete Ally will have to utilize more mobilization strategies than collaborative strategies. Per Koopmans and Statham (1999), a political entity that is open, but lacks discursive opportunities means Athlete Ally is likely to be without sufficient gain and movement goals will not be met. Perhaps legal and cultural victories for Athlete Ally may slow or raising funds will be more difficult because of the inability of Athlete Ally to collaborate successfully with the administration. Participants frequently noted the difficulty in working with the current antagonist administration (Donald Trump), while echoing the protagonist in office prior to Trump (Barak Obama). This rapid switch from 
having a protagonist in the executive branch to an antagonist in office speaks to the lack of stability of the configuration of the actors/power. Still, Donald Trump's administration was viewed as antagonistic to LGBTQ issues. For a strategy, Athlete Ally should focus on assertive strategies to interact with political entities.

As for actual strategies, it is clear that Athlete Ally utilizes mobilization strategies with the U.S. Government. The organization will reach out to activist athletes and other prominent individuals in their network to volunteer, educate, and mobilize their constituents. They may get a constituent of celebrity status, like Mark Cuban, to weigh in on political issues and communicate issues to the public (Brockington, 2014). Utilizing celebrity mobilizations is a common strategy for sport specific advocacy organizations and events (Wilson et al., 2015). Additionally, they will make statements on their websites and social media about political legislation to note their stance for constituents to follow. For instance, in multiple instances, Athlete Ally sent out an open letter, specifically signed by activist athletes and partners, letting their constituents understand a ceratin discriminatory policy and take action. Athlete Ally is not utilizing non-combative strategies (like closed door meetings with the key political actors) as they are primarily prohibited from doing so due to their 501(c)(3) status. Their strategies are similar to the New York LGBT SMOs of the 1970s. Per Bernstein (1997), the SMOs were forced to hold rallies and mobilize activists as they were excluded from a political interaction due to the antagonistic relationship between New York political elite and the LGBT social movement organizations. While options are limited for Athlete Ally, they still are able to interact with political entities through their strong network of athlete activists and allies, despite being legally excluded from political channels (Armstrong \& Bernstein, 2008). 
With the understanding that the current U. S. Government is an antagonist to LGBTQ movement as a whole, Athlete Ally relies on mostly combative strategies for engaging with the political entity. This was not always the case, as President Obama was a protagonist to the movement and that lead to a strong relationship between Athlete Ally and the U. S. Government. Political actors, however, are easier to change than political institutions (Kriesi, 2004). Thus, Athlete Ally and other "Left" movements are faced with an antagonist actor in the White House. Therefore, it would be wise for SMOs to publicly combat the discriminatory policies and practices offered by the current U. S.

Government.

\section{Summary of RQ2}

All three of the governing bodies mentioned - the NCAA, NBA, and US

Government - provide unique opportunities and challenges for Athlete Ally to enact change. With all three entities being open systems, the chance for Athlete Ally to engage with a political actor is more likely (della Porta \& Diani, 2006, Kriesi, 2004). However, the outputs or capacity for the political entities is weaker to act. The organizations represent differing cultural views towards LGBTQ movements with the NCAA being both a protagonist and an antagonist, the NBA being a protagonist, and the U.S. Government being antagonists at the time of the study.

As a whole, Athlete Ally interacts with the aforementioned governing bodies in a closed-door and collaborative manner when the governing body is a protagonist and in a combative manner when the governing body is an antagonist (Bernstein, 1997;

Koopmans \& Statham, 1999; Kriesi, 2004). With the NBA and the NCAA (when it is a protagonist), Athlete Ally regularly collaborates behind closed doors with the governing 
bodies. Specific training for employees and members of the leagues, collaborating on policies, or co-hosting Pride Nights are ways for Athlete Ally to engage with the governing bodies in a productive manner. Mobilizing activists and constitutes is not needed as success is achieved in a synergistic manner with the NBA and a pro-LGTBQ NCAA.

However, when the NCAA is acting as an antagonist as is the U.S. Government, Athlete Ally has to rely on more combative and mobilization strategies (Bernstein, 1997; Koopmans \& Statham, 1999; Kriesi, 2004). For the NCAA, this entailed "calling out" the member institutions for their lack of progressive policies through an objective tool that ranks the universities (Bundon \& Clarke, 2014). When interacting with the U.S. Government, who is regularly an antagonist under the current administration, Athlete Ally has to mobilize activists and constituents to make any gain for the movement. As mentioned, activists do not create strategies in a vacuum (Meyer, 2004) and the patterns shown in the data supports this idea.

From a broad perspective, the second research question highlights the importance of a SMO using a carefully thought out strategy to engage with a political institution. The patterns in the data suggest that when the entity is a protagonist, collaborative strategies are the more effective strategy. That makes sense as a governing body that is open and willing to work with a SMO does not need public condemning. Instead, working behind closed doors allows for a better chance for successful change. Conversely, when a governing body is an antagonist, public and combative strategies are necessary. The SMO needs to convince the public that the issue is important and salient to individuals' lives. 
This can create a cultural acceptance that has shown to lead to a political acceptance (Bernstein, 1997; Schwirian, Curry, \& Woldoff, 2001).

\section{RQ3: How does Athlete Ally create resonant (credible and salient) frames?}

Cultural Theory/Frame Analysis guided the last research question. Cultural

Theory/Frame Analysis derives from two claims: (1) new social movements indicate a shift to a postindustrial economy and (2) new social movements are unique from older, working class movements (Pichardo, 1997). The LGBTQ movement represents a new social movement because it focuses on cultural understandings, norms and identities, not

economic distribution (Williams, 2004). The theory specifically examines the affirmation of expressive needs of the LGBT community through symbols, language, discourse, identity, and other cultural artifacts within a SMO or social movement (della Porta \& Diani, 2006; Williams, 2004).

The theory focuses on framing (Goffman, 1974), specifically the credibility and salience of frames articulated by a SMO. Credible frames are a function of three factors: frame consistency, empirical credibility, and credibility of the frame articulators. Salient frames are a function of: centrality, experiential commensurability, and narrative fidelity (Benford \& Snow, 2000). The following sections outline the efforts Athlete Ally utilizes to ensure their frames are credible and salient to their constituents.

\section{Credible Frames}

The first factor, frame consistency, refers to the agreement between an SMO's articulated beliefs, claims, and actions (Benford \& Snow, 2000). This can be a difficult task as athletes and members have different voices, perspectives, and modes of communication (e.g. social media, op-eds on Athlete Ally's website, press conferences, 
etc.). Additionally, one can imagine with the sheer number of individual protagonists under the Athlete Ally umbrella (athletes and employees/board members), keeping a consistent message can be difficult. Athlete Ally needs to ensure that the messages portrayed by athletes resonate with the public, but still allow the athletes to use their own voices. Maintaining the athlete's own voice in the frames is important as it can combat against failing to articulate the issue to the public (Kogen, 2015) or distracting from the real injustice because of their celebrity status (Brockington \& Hensen, 2015). If the organization provides a strict script, the athlete may seem disingenuous toward the activism and harm the activism efforts (Panis \& van Den Bulck, 2012). This is noted by Logan (employee), “... a lot of times [athletes] get something and they're like, 'Oh, this isn't how I would say it."' To solve this issue, Athlete Ally articulates a set of core values and consistent terminology to their followers and athletes.

Athlete Ally ensures that the organization can consistently portray the same message by creating core values and using universal terminology. Lane (employee) stated, "We are portraying the same understanding of the organization's core values across all channels." The core values, as Lane noted, were expanded upon by Jess (employee), "Yeah, this [consistency of frames] is something we are working on, but we kind of have been shifting to focusing on three pillars of work: Education, policy, and advocacy." Instead of working on memorizing the mission and everything Athlete Ally does, the organization focuses specifically on their three pillars. The channels, as Lane alluded to, are their spokespeople, employees, social media, and website. As an example, under the "Our Work" portion of the Athlete Ally website, the core values of the organization are listed: "We Educate" (para. 1), "We Change Sport Policy" (para. 2), and 
"We Advocate for LGBTQ Rights" (Athlete Ally, n.d.-c, para 3). When employees, board members, or even athletes are asked about the mission of Athlete Ally, they can always revert back to their core values. These core values can manifest themselves in a universal language as Dean (employee) noted, 'No matter what we're talking about, we'll have universal language. We believe everyone should have equal access opportunity and experience in sports regardless of sexual orientation, gender identity, gender expression, that's a universal belief." The core values and universal language serve as a strength of the SMO as it helps build the collective identity of the organization and its allies (Carty, 2002; Dorf \& Tarrow, 2014). Specifically, establishing core values serves to benefit the organization as it provides a basis for group organization and establishes a collective identity. Without said core values, the identity could crumble (Conversi, 1990; Smolicz, 1988). Establishing core values is important as it allows the organization and the athletes to create a system to pivot their activism around. Maintaining their system allows consistency in the messages as the individual can always revert back to the core values. Without that system and core values, the message can become unclear. By having core values, athletes and other constituents can utilize those core values or pillars as a basis for their speaking points. Thus, it is important for SMOs, particularly sport specific SMOs, to maintain a strong set of core values to help consistently produce frames.

The second factor, empirical credibility, refers to the fit of the frames to the events of the world (Benford \& Snow, 2000). Athlete Ally fits their frames into the events of the world by grounding their strategies and messages in personal anecdotes from athletes and using hard data. Multiple organizational members stated that athletes' 
stories were used to make sure their frames were legitimate. For instance, Jess (employee) noted:

I think the way we make it relevant is that we base it in real people's anecdotes. We often don't come from a place of like, we think this would be a good idea. We come from a place where some athlete is like, 'hey this has really affected me and I need support.' That was a huge push with USA Rugby. We didn't just think like, 'oh, USA Rugby should have these policies because they're so outdated, it was that an athlete came to Athlete Ally and said this is happening and I want support in this'

By grounding their understanding of the issues in sport in their athletes' stories, the organization perceives its frames to be empirically valid. If athletes are reporting stories to Athlete Ally about policies or practices that are discriminatory, they must be happening. For instance, on Transgender Day of Visibility, Athlete Ally hosted a panel with trans athletes and athletes impacted by trans issues. One of the panelists noted that she could not change in specific locker rooms, was mocked by other athletes, and noted that some states do not allow trans athletes to compete. Using these studies allows Athlete Ally to display frames at the moment and establish an emotional response for an individual. McAdam (2017) noted that activism can fail if the issues activists mobilize around are too distant. For instance, the climate control movement has failed to successfully sustain itself because the issue seems too distant for the public to understand its impact. While empirical data may show the eventual issues associated with climate control, the idea that the worst effects of climate change will happen in the distant future prevents a successful mobilization of activists (McAdam, 2017). Athlete Ally instead 
utilizes the athletes' stories at the current moment to highlight a sense of urgency. The personal stories can be used to elicit an emotional response and a psychological commitment to the movement (Fendrich, 1977). This is an effective strategy for Athlete Ally and can serve as a guide for other social movement organizations.

Logan (employee) reiterated the use of personal stories to help the organization, but also indicated a new tactic for Athlete Ally, "I think definitely, earlier, it was personal stories. I think now we're shifting more to hard data with things like the [Athletic Equality Index], shifting a bit to some fact-based stuff." It is interesting point that the organization feels the need to shift to hard data instead of personal anecdotes. One thought is that the use of a few anecdotal stories from athletes may be powerful, but not representative of the struggles of a population. Instead, using statistics and facts describing a larger population can inspire more of an emotional response due to its generalizability to the population as a whole. As evidence to their commitment to using statistics and facts, Athlete Ally's Campus Resource Guide included facts about LGBTQ issues in sport on the first page. The Guide stated that, " $84 \%$ of people have witnessed or experienced homophobia in sports, $1 \%$ of people believe LGBTQ people are completely accepted in sports, and a 2001 study found that the most common reason an athlete felt comfortable to come out on their team was because of a visible or vocal ally" (Athlete Ally, 2017c, page 1). Using statistics and facts also puts the issue in the forefront of people's minds. Instead of being too far away (McAdam, 2017) current facts and statistics paint a picture of the current athletic environment. The aforementioned statistics on the Campus Resource Guide, paired with the AEI can help donors, bystanders, and constituents understand the larger issues of homophobia and transphobia in sport. 
Finally, the frame makers must be credible in articulating the frames. In order for frames to be credible, the frame makers (the organization and its athletes) must be perceived as credible (Williams, 2004). Athlete Ally routinely puts out frames in response to policy decisions, collaborations with other organizations, or any other type of news. For example, Athlete Ally noted their support for HB1319 that added protections for trans citizens. Athlete Ally also established a 2018 partnership with Major League Quidditch. As such, the organization needs to maintain credibility amongst their constituents. Lane (employee) speaks to this: "Who do you have working for you, right? Values and frames [of Athlete Ally] are reflected by the staff that work at the organization. You know, we are queer, we are people of color." Lane brought up a story about the H\&M clothing-retail store which had an advertisement with a young black male in a hoodie sweatshirt with the phrase "coolest monkey in the jungle." The advertisement received harsh criticism for racist views of black males. Lane pointed out, "The fact that nobody at $\mathrm{H} \& \mathrm{M}$ understood that that was an incredibly racist thing to do, to a young black child and then make it an advertising campaign is unbelievable" to which Lane concluded, "They have no people of color in positions of power." Lane speaks to the credibility of identity when it comes to making claims. Logan (employee) confirmed this is a broader sense, “...Hudson's amazing, but being a white straight guy, it can be limiting at times." Because Athlete Ally employs people of color and people of different genders and sexual orientation, they can be more credible in their claims. This is particularly important for the LGBTQ community. Within the political context, one of the major catalysts for pro-LGBTQ legislation was the influence of openly gay senators (Bernstein; 2003; Smitton, 2017). Thus, having LGBTQ representation is important as people in that 
group can speak and translate the issues felt by the LGBTQ community to a larger scale (Smitton, 2017). Thus, it is imperative for SMOs to have a diversity of staff to articulate the issues they face.

In addition to the organization, athletes are also articulating frames on behalf of Athlete Ally. This can be a difficult task as the athletes are at distanced from the organization to varying degrees and commitment levels. Athlete Ally has to be cognizant about who is going to be a claims maker and what they are discussing. When deciding on who can be an athlete ambassador, Athlete Ally does not have an extreme vetting process. As Dean (employee) stated, the process of becoming an Athlete Ally is very minimal: In terms of how do we judge credibility in terms of coming on board, with a potential ambassador, it's not overly robust. It involves us getting on a phone call with them, understanding their story, understanding why they're passionate about this, understanding what they hope to get out of being an ambassador.

Seemingly, the organization is more intent on learning about the athlete and his/her goals for partnering with Athlete Ally than any other metric. However, an athlete's passion can help the organization determine the level of sincerity the athlete has for the issue. Ultimately, the sincerer the celebrity activist is to the issue, the more credible s/he will appear (Ellcessor, 2016; Huliaras \& Tzifakis, 2012). Therefore, the SMO is wise to ask about the passion for the issue by the athlete. Lane (employee) spoke about the strategy for the lack of an intense vetting process:

In general, the philosophy was quantity, where I think years ago Hudson was just trying to get as many people on board. But I do think that not anyone can join. 
But, I think it takes something pretty egregious for us to say, 'We don't want to work with you'.

To build up credibility and legitimacy, the organization utilized a quantity over quality approach. This was noted in RQ1 as the sheer number of athlete ambassadors (over 150) provides Athlete Ally with credibility and legitimacy. As mentioned before, the more celebrity activists, the greater the amount of media attention (Thrall et al., 2008) and awareness (Brockington, 2014). Now that the organization has more athletes, it is can be slightly more selective in who wants to be an athlete ambassador, but as Lane (employee) noted, it would take something extreme to eliminate a partnership between an athlete and the Athlete Ambassador program. For instance, Lane (employee) stated "We don't want to have an ambassador speaking out for LGBTQ issues that's a racist, you know?" The lack of extreme vetting process seems to indicate the platform athletes have in society. Athletes are looked up to and viewed as leaders in society (Agyemang, 2011; Kaufman \& Wolff, 2010; Wilson et al., 2015). Presuming they are not overly discriminatory, they provide instant credibility for the social movement organization.

Athlete Ally not only has to determine who is credible to be a claims maker, but must also ensure that their athletes are credible on what they are discussing. Celebrity activists can struggle with articulating the real social injustices in society (Kogen, 2015). This may be because of the celebrity's platform that an individual does not have sufficient information (Brockington, 2014) or from the fact that celebrities oftentimes do not understand the complexities of the issue (Kogen, 2015). Thus, SMOs should be cognizant as to how athletes are articulating the issues they support. Once again, terminology can be used to help build credibility in what the athlete is saying. As Richard 
(board member) stated, "Of course, we do our best to train up athletes for the right terminology. So, those who wanna, you know, speak in a way that's going to be most embraced by the community." Athlete Ally finds it important to use correct terminology to make sure the community at least perceives the athlete to be credible. For example, Logan (employee) noted, "We actually don't really publicly use the word 'straight."” To Athlete Ally, as Logan mentioned, being gay or straight does not matter, it is important that the athlete is standing up for people and being an ally. Thus, the organization will seldom use the word straight for the word ally. To Logan's point, on Athlete Ally's social media accounts, documents provided to the researcher, and its website, the word straight rarely appears. Instead, the organization uses the word ally. The certain terminology helps Athlete Ally and their constituents become engrained in the community. The use of specific language is not a foreign concept to the LGBT movement (Bernstein, 2003; Engel, 2001; Kulick, 2000). Ever since World War II, the LGBTQ movement went through different names as the movement evolved. The movement was called the "homophile movement" during the 1950s-1960s and evolved to the "gay and lesbian movement" following the Stonewall Riots. After additional identities were empowered, the movement evolved into the "LGBT" movement (Engel, 2001). Activists of the entire movement understood the importance of language as it provided the movement with an identity. Still, Kulick (2000) notes the difficulty of language within the LGBTQ movement. It is important, therefore, for the SMO to provide terminology within the LGBTQ movement so the community can embrace the athletes.

Another way for the claims makers to be credible is to use their athletes' intersectionality of identities. As Dean (employee) stated: 
I'll give you an example. Greg Louganis was adopted; Alicia Clarendon, person of faith, deep faith. So, you're starting to get intersectional identities about people, so in Indiana, when they introduced an anti-LGBTQ adoption bill, we know Greg Louganis is adopted. In Florida, when they've introduced an expansion of hate crime legislation to protect LGBTQ people, we know Martina [Navratilova] lives in Florida. We have this map of all these different kinds of criteria.

Athlete Ally notes and understands the different identities of their athlete ambassadors. Therefore, they utilize those identities to help find the most credible claims maker to provide a statement about a certain policy or issue. Logan (employee) agreed, stating, "I think it's [credibility] is a lot more powerful on a local level. If we're talking about H2B in North Carolina, getting a North Carolina player, or someone with a tie there, right?" The reason that Athlete Ally relies on the intersectionality or life stories of their athletes is that it can help build credibility when the social issue is salient to the activist (Fendrich, 1977) and his/her celebrity activist (Ellcessor, 2016; Huliaras \& Tzifakis, 2012). Personal stories bring a sense of sincerity that specific scripts cannot. Speaking about this notion, Richard (board member) noted, "Well ... Because I'm not a believer in the same thing. I mean, I think, people bring unique perspectives and backgrounds to this, and it's really important for athletes to own it in their own way." Celebrities can run the risk of being perceived as insincere with their activism (Panis \& van Den Bulck, 2012). As noted, an effective tool for SMOs to combat this concern is by allowing the athletes to use their own story or background when engaging in activism. 


\section{Summary of Credible Frames}

One of the ways that Athlete Ally can ensure their frames resonate with the public is by creating frames that are credible (Benford \& Snow, 2000; Snow \& Benford, 1988). Three manners speak to the credibility of frames: consistency of frames, empirical credibility, and the credibility of claims makers (Benford \& Snow, 2000; Snow \& Benford, 1988). Athlete Ally creates consistency in their frames by creating core values and a universal language for their protagonists to use. This helps create a collective identity for the constituents as well (Dorf \& Tarrow, 2014). Therefore, the idea for SMOs to create core values and a universal language is important and recommended. It allows the constituents to mobilize around a consistent set of ideals and a vision.

To guarantee their frames contain empirical credibility, Athlete Ally utilizes athletes' stories and hard data. This allows the organization to ground the issues they focus on and subsequent messages in real life experiences and facts. This interesting discovery lends itself to future research projects. Specifically, is each form of data (stories and statistics) equally impactful for audiences? Regardless, advocacy organizations that work with athletes should utilize athletes' stories to help ground their messages, followed up by hard data that paints a larger picture of the issues faced by the LGBTQ in sport community. This ensures that the frames are grounded in reality and not viewed as too distant from those impacted (McAdam, 2017).

Finally, Athlete Ally uses multiple methods to ensure their claims makers are credible. The organization's staff is diverse with people of different races, genders, and sexual orientations to make sure they are getting a wide arrange of perspectives (Smitton, 2017). In addition, the athletes have to be credible. Athlete Ally employs their athletes 
where their intersectional identities work best. If an athlete is pro-LGBTQ and adopted or a person from Texas, those individuals can speak to the legislation or policies that are antagonistic towards Athlete Ally to gain credibility. This helps ground the athletes' frames in sincerity as the issues impact their lives and avoids perceptions of insincerity (Ellcessor, 2016; Huliaras \& Tzifakis, 2012). Therefore, it is recommended that SMOs that partner with athletes or celebrity activists understand their intersectionality of identities. This can help provide sincerity between the athlete and their frames.

\section{Salient Frames}

Frame salience is also broken into three factors: centrality, experiential commensurability, and narrative fidelity (Benford \& Snow, 2000; Snow \& Benford, 1988). Centrality references the correspondence of the frames being relevant to the realworld setting. Prior to the 1940s and WWII, the LGBTQ movement was not relevant in a real-world setting (Engel, 2001). The LGBTQ movement was not central to the lives of activists and the public; instead, movements based on economic differences were more central (Williams, 2004). However, over time, the LGBTQ movement was centralized into the cultural context of US society (Bernstein, 2003; Engel, 2000). The LGBTQ movement in sport, however, has been slow to progress (Carrol, 2016; Sartore-Baldwin, 2012; Sartore \& Cunningham, 2009). One concern, as mentioned by board member Kirk (board member), is that the LGBTQ movement in sport, specifically, can be seen as a marinalized issue in today's setting since Donald Trump took presidential office. When Donald Trump was inaugurated, policies and paradigms toward human rights issues, like women's rights, Black rights, Muslim rights, LGBTQ rights, immigrant rights, etc., were 
dramatically shifted (National Center for Transgender Equality, n.d.). As Kirk (Board member) stated:

So, I think Athlete Ally's job is even harder, because you've got to convince people why sports are still so central, when the very foundation of their lives has been shaken by a madman in the White House. So, they want to go out and march and protest, but they're not marching and protesting for athletes and sports, they're marching and protesting because they don't believe that Muslims should be detained.

To summarize, the new administration made it more difficult to come out with frames that were salient to the real world because it caused LGBTQ communities to fight for basic rights. The LGBTQ movement experienced this before during the AIDS movement (Engel, 2001). At the time, the gay and lesbian movement had to halt progress and focus on the movement as the AIDS movement as that was much more central to the lives of activists. Today, donors and other protagonists of the LGBTQ movement are so preoccupied with general LGBTQ protections that they struggle to find LGBTQ protections in sport as salient. Kirk (board member) reiterated, about sport being "extra": Certainly, if you're a swimmer from George Washington University, it doesn't feel like an extra if you're getting bullied in the pool. It doesn't feel like an extra if you're on kiss cam at City Field and people are making fun of you because you're two guys. None of that feels like an extra. But, when we're asking allies to engage around the country, and they feel like their civil liberties are under threat, that's where it can feel like an extra if we're not able to tie in why the threat matters, and why we matter to the threat. 
Being able to articulate the importance of sport inclusivity represents a significant challenge for Athlete Ally as it continues its mission. While it is easy to articulate the challenges of LGBTQ individuals in sport, articulating why LGBTQ issues in sport are important proves to be more difficult. One way to convince donors that LGBTQ issues in sport are not "fringe" is to speak about the importance of sport and athletes their influence in US society. Athletes have a tremendous platform (Agyemang, 2011; Kaufman \& Wolff, 2010; Wilson et al., 2015) to be activists and create social change, especially LGBTQ athletes (Carrol, 2016). Articulating not only the trans- and homophobia in every day sport and the power of athletes to create larger change outside of society is a strategy SMOs should use if their niche includes social justice within sport.

Experiential commensurability refers to the ability to create frames that are congruent with the everyday individual the organization is trying to mobilize. In other words, do the frames resonate with the target audience's personal experiences? For example, Jess (employee) stated, "I think that the stories are inherently relevant because we're telling LGBTQ athlete stories and we're telling stories about allies who are like, 'I'm here, and I'm supporting you.' We use those stories to speak directly to LGBTQ athletes." The organization knows its audience and the best frames to portray a salient message to mesh with the life of those individuals. Past research strongly suggested that LGBTQ athletes are often discriminated against, marginalized, and demonized in sport (Bush, Anderson, \& Carr, 2012; Carrol, 2016; Krane \& Barger, 2006; Sartore-Baldwin, 2012; Sartore \& Cunningham, 2009). However, as mentioned before, Athlete Ally is made up of a diverse staff. Additionally, almost every study participant had a history of sport experience, including multiple collegiate athletes. The staff and athlete ambassadors 
live the experiences of having an LGBTQ identity in sport. They know what is congruent to the lives of the athletes and can speak to those issues. Once again, the benefits of a SMO having a staff including diverse athlete activists persist.

When speaking to non-athlete constituents like donors or activists, Athlete Ally utilizes targeted messaging to ensure their frames are relevant to those they are trying to mobilize. Athlete Ally recognizes that not every individual is receptive to every frame sent out by the organization:

...the best thing I think successful organizations do today is understand who they're talking to and where they're talking to them, and how they should be talking to them. Because targeted messaging today is extremely important, so we can, at a very high level, communicate values and beliefs (Dean).

Dean speaks to the importance of having the correct frames delivered to the correct audience. While, theoretically, every individual constituent associated with Athlete Ally is pro-LGBTQ, the same may not be true for other forms of activism. As evidence, Dean (employee) noted:

Now, the challenge then becomes drilling that down to who and when we communicate that [specific activism frames] to. $50 \%$ of America doesn't believe that. $50 \%$ of people actually don't believe in take the knee is active activism. So, we may not talk to certain audiences specifically about athlete activism.

While activism is one of Athlete Ally's core principles, the distinction between LGBTQ activism and general activism matters. If one is a constituent or partnered with Athlete Ally, s/he is more than likely an ally to the movement and finds the frames about LGBTQ activism appropriate. General athlete activism, however, is not consistently predictable. A 
donor or athlete may be receptive to marching in a pride parade, but not support athletes kneeling during the national anthem. Therefore, a SMO has to be selective in their messaging. Frames will not resonate with the public if their values, beliefs, and priorities are not understood and articulated (Schwirian, Curry, \& Woldoff, 2001). Seemingly, Athlete Ally has the ability to recognize and target their messaging to specific audiences. While they may believe in athletes taking a knee during the national anthem, none of their emails to their constituents mention that form of activism. Instead, the frames are revolve around LGBTQ issues in sport, as that is the mission of the organization.

Understanding the message's target audience is crucial for the success of the frames and should be repeated by other SMOs and advocacy organizations.

Finally, narrative fidelity is the ability of the frames to correspond to the existing cultural world. The frames have to fit within the stories, myths, and folk tales that are part of the society's cultural heritage (Gamson \& Modigliani, 1989). Athlete Ally demonstrated how their frames existed in the cultural model of the U.S. in an obvious way: sport. Sport is clearly a large part of US culture and has shown to be a prominent vehicle for social change (Kaufman, 2008; Kaufman \& Wolff, 2010; Pelak, 2002; Pelak, 2005; Wilson et al., 2015). Using sport as a way to put the social movement into context starts with the founder of the organization:

Even when he [Hudson Taylor] talks to athletes, the idea that the key values in sport, he says, are essentially the values that we're arguing for as a social justice movement. He's basically saying, on the field, it kind of doesn't matter who your teammate is. It only matters, really, how they perform. Right? So, it shouldn't matter that your teammate is sleeping with men, as long as ... Does he perform or 
not on the field? Right? And when you put it in those terms to athletes, they so get it. Doesn't matter what religion they are, what race they are. How do you perform as a player, right (Logan)?

The use of sport here is almost a metaphor to help ensure that the frames fit into an existing cultural model and that model is one of a high importance on sport. Dean (employe) eloquently summarized this notion:

What is unique about Athlete Ally is the wide spectrum of people we can reach. Why? Because ultimately sport is universal. Sport transcends politics, it transcends religion, it transcends race, it transcends sexual orientation, it pretty much transcends everything. That's a very wide spectrum of people.

Dean (employee) even went as far to say that Athlete Ally holds a competitive edge over other LGBTQ non-profits because of sport:

Those who are ultra conservative, white straight male in the south and the complete opposite of that is LA and New York. A lot of LGBTQ non-profits that are in the space don't have the ability to diversify who they're talking to the extent that we do. They're constituency is often LGBTQ people, whereas we, because of who our messengers are, because of athletes in these leagues, we really have the opportunity to reach unmovable middle, a more conservative audience whose support can help drive policy change, help change hearts and minds. We can actually move some of those more harder targets.

Dean mentions that it is because of the athletes that Athlete Ally is able to reach a more moveable middle. By moveable middle, Dean was talking about bystanders who were neither protagonists nor antagonists to the movement (Kriesi, 2004). This was 
echoed by Kirk (board member), "If there is a major issue tomorrow, and I speak out on it, who in the athlete community cares that some political hack from New York cares about something? They care about what athletes think." Athletes, as celebrities, are looked up to with respect (Wilson et al., 2015) and thus are given a culturally relevant platform. Athletes who identify as part of the LGBTQ community are able to bring media and cultural awareness to their issues and further the LGBTQ movement (Carrol, 2016). Athlete Ally wisely uses athletes, as well as the notion of sport, to remain culturally salient. This is part of the Athlete Ally's niche. Disney and Gelb (2000) spoke on the notion of the importance of a SMO's niche within a crowded social movement like the LGBTQ social movement. For Athlete Ally, their niche is athlete activism for reducing homophobia and transphobia in sport. Identifying and understanding that niche is important for SMOs as athletes are amongst the most visible activists in today's society (Coombs \& Cassio, 2017).

\section{Summary of Salient Frames}

Besides ensuring their frames are credible, Athlete Ally also has to create salient frames for their constituents and the public. Salience can be analyzed as three factors: centrality, experiential commensurability, and narrative fidelity (Benford \& Snow, 2000; Snow \& Benford, 1988). One hurdle Athlete Ally faces is keeping LGBTQ issues in sport central to real-world events when fundamental rights are being threatened by the administration at the time of the study. Still, participants were insistent that the importance of their work was never more critical than at this moment. Athlete Ally, and other sport specific SMOs, can utilize the platform athletes possess as a way to impact greater society (Agyemang, 2011; Kaufman \& Wolff, 2010; Wilson et al., 2015). By 
advocating for LGBTQ rights within sport, LGBTQ activists can influence society outside of sport. Focusing on the individual, and not society, Athlete Ally frames their messages through athletes' stories and targeted messaging to their constituents and the public. Athletes' and celebrities' stories have proven to be extremely influential to the greater society (Carrol, 2016; Ellcessor, 2016). In the case of Athlete Ally, they can help recruit LGBTQ and ally athletes by utilizing stories of other LGBTQ and ally athletes. This allows the frames to resonate with the individuals as LGBTQ athletes are also marginalized through sport (Bush, Anderson, \& Carr, 2012; Carrol, 2016; Krane \& Barger, 2006; Sartore-Baldwin, 2012; Sartore \& Cunningham, 2009).

Additionally, the use of targeted messaging helps maintain their salience with non-athletes as well. Frames are effective when they articulate the beliefs, values, and norms of the target audience (Schwirian, Curry, \& Woldoff, 2001). While most constituents would more than likely be pro-LGBTQ, the same cannot be said for other movements like the Black Lives Matter movement and the Women's movement. SMOs have to be careful when sending out frames to their audience. This is especially true if the SMO utilizes its athletes' intersectionality of identities. Social movement organizations have to know and understand who they are talking to and how they are talking to their intended audience to ensure their frames will be salient to the individual.

Finally, Athlete Ally utilizes sport to correspond with the cultural world. Sport being a prominent tool for social change (Kaufman, 2008; Kaufman \& Wolff, 2010; Pelak, 2002; Pelak, 2005; Wilson et al., 2015) speaks to sport's cultural importance. As participants noted, sport reaches a large audience and can be utilized to reach a target market that otherwise would be non-responsive to Athlete Ally's frames. The use of 
sport, and athletes by extension, for LGBTQ activism falls within Athlete Ally's niche (Disney \& Gelb, 2000). This finding speaks to the power of sport and, by extension, athlete activists. Social movement organizations within the athletic environment are definitely afforded benefits that non-sport SMOs cannot achieve through regular celebrities.

\section{Summary of Findings for RQ3}

The third research question investigated how Athlete Ally ensured their frames resonated with the constituents they attempt to mobilize. Frame resonance is broken into credibility and salience (Benford \& Snow, 2000; Snow \& Benford, 1988). Overall, one of the prominent benefits of a formal relationship with athletes for Athlete Ally is their development and implementation of frames. Because sport holds tremendous value in today's society and athletes are given a prestigious platform (Agyemang, 2011; Kaufman \& Wolff, 2010; Wilson et al., 2015), the organization can reach an audience that nonsport SMOs cannot. Through sport, these athletes are given credibility. This credibility can be expanded upon when the organization utilizes the real-life stories of athletes and their experiences as LGBTQ or ally athletes. These stories can be used to recruit other athletes or provide the basis for frames or fundraising efforts. While some may argue that the LGBQT movement in sport can be seen as "fringe", the successes of pro-LGBTQ policies and ideologies can influence society outside of sport (i.e. North Carolina HB2).

Additionally, the organization's make up and culture is important for success. One way to ensure their frames are resonating with their constituents is to establish a diverse staff. The diverse staff of individuals of different races, gender identities, sexual orientations, and ages allows the organization to bring in a diversity of opinions and 
perspectives (Smitton, 2017). These perspectives allow the organization to make sure their messages resonate with different constituents. The importance of a diverse staff for SMO success cannot be overstated. Also, Athlete Ally has strong core values that the organization and accompanying athletes can utilize. These core values serve not only as the basis of a belief system (Conversi, 1990; Smolicz, 1988), but to maintain consistency among all protagonists to the organization. Athletes are still allowed to tell their story to remain sincere about their activism (Kogen, 2015), but can refer to the core values when articulating the importance of the social issues to the public. Thus, creating an organization with a diverse staff and strong core values serves as a major boon for a social movement organization.

\section{Summary of Findings \& Implications}

The purpose of this study was to investigate the resources exchanged between athlete activists and Athlete Ally, tactics Athlete Ally utilizes for engaging with different governing bodies, and frames utilized by Athlete Ally using the theoretical framework of Social Movement Theory. As athlete activism becomes more common in today's landscape (Coombs \& Cassilo, 2017), social movement organizations like Athlete Ally can provide numerous benefits for athlete activists as they serve as the basis for mobilization (Caniglia \& Carmen, 2005). The following section outlines a summary of the findings for the study.

The study viewed resources exchanged between Athlete Ally and athletes through the lens of Resource Mobilization Theory. Resource Mobilization Theory provides researchers a framework for investigating what resources SMOs utilize for advocacy and/or allocate to their members, the attributes of those resources, and how resources are 
acquired (Edwards \& McCarthy, 2004; McCarthy \& Zald, 1977). As a means of facilitating activism, Athlete Ally provides its athletes credibility and legitimacy, a platform and community of accepted athlete activism, a strong social network, policy and event toolkits, and tangible materials like stickers and shirts to build awareness. Credibility, legitimacy, and a platform and community of accepted athlete activism are resources that can combat the negative consequences for athletes engaging in activism (Agyemang, Singer, \& DeLorme, 2010; Cunningham \& Regan, 2012; Frederick, Sanderson, \& Schlereth, 2017; Kaufman, 2008; Sanderson, Frederick, \& Stocz, 2016). Athlete Ally specifically noted these resources as prominent contributions to athlete activism. For instance, participants noted that athletes were able to accomplish more under the umbrella of Athlete Ally as they were lent credibility and legitimacy from Athlete Ally. For other SMOs operating in the athletic realm, offering these resources can be an attractive incentive to get athletes to partner with the organization. The resources seem to allow athletes to engage with activism in a more efficient and personally safe manner. Instead of being shunned by teammates and coaches (Kaufman, 2008), athletes can access sport specific SMOs and find a network of other athlete activists who share similar views toward the movement. The current study articulates that sport specific SMOs can provide support mechanisms to athletes. Future research, from the vantage of the athlete, can investigate if those support mechanisms help athletes remain engaged in activism (discussed later).

Furthermore, developing a strong relationship with a SMO can serve to provide athletes with a stronger social network. Athlete Ally noted a strong social network was a prominent resource provided to athletes. Strong social networks allow athletes to gain 
access to other athletes and activists through the organization, increasing their likelihood of retention to the organization (McPherson, Popielarz, \& Drobnic, 1992) and continuing to engage with more activism (Thrall et al., 2016). Theoretically, an athlete can seek to engage in more activism by gaining access to athletes with different perspectives and intersectionalities. A SMO could use this as a recruiting tool to establish more athlete ambassador relationships. Comparatively, athletes can form relationships with SMOs to engage with a community that accepts and expects activism.

The second set of resources Athlete Ally provides its athletes are policy and event toolkits and awareness building materials like stickers and shirts. SMOs hold the cultural knowledge needed to engage in activism (Edwards \& McCarthy, 2004). While athletes do have natural connections to activism (Kaufman \& Wolff, 2010) and are cognizant of what past athlete activists have accomplished (Agyemang, Singer, \& DeLorme, 2010), SMOs should be the experts in mobilizing constituents and gaining information to assist the movement. Athlete Ally utilizes this strategy as they provide educational tool kits for holding a fundraiser or creating a college chapter and providing one-page summary sheets of specific legislation. The sheets may also be used to educate individuals unfamiliar with a particular social movement. Moreover, these artifacts provide athletes with information in an efficient and consistent manner. This is a key component for an SMO attempting to share its message through athletes who have limited schedules. The SMO should be the entity providing information on when, where, and how to mobilize against a social injustice. Therefore, a SMO would be wise to invest in knowing and understanding different political and cultural challenges to the movement and articulate those challenges to athletes in a succinct manner. 
Other tangible merchandise like t-shirts, posters, and stickers, also unify constituents under the movement's identity and builds awareness for the organization (Dorf \& Tarrow, 2014; Gamson, 1995). This tactic is used often in the LGBTQ movement (Bernstein, 2003; Gamson, 1995). An example of utilizing tangible merchandise to build awareness can be found in the origin of Athlete Ally. Athlete Ally's founder, Hudson Taylor, wore an equality sticker from the Human Rights Campaign while competing in NCAA wrestling. Because of the attention and letters of personal experiences from LGBTQ individuals he received from wearing the sticker, Taylor was inspired to start Athlete Ally and mobilize activists against transphobia and homophobia in sport (Athlete Ally, n.d.-a). Years later, Athlete Ally still utilizes this strategy to build awareness for specific campaigns. For instance, the organization recently partnered with Major League Quidditch (MLQ). Athlete Ally plans on collaborating with MLQ to develop pride merchandise for sale, and $10 \%$ of proceeds would go back to Athlete Ally (Carr, 2018). Interestingly enough, Athlete Ally merchandise is not available for purchase on their website. Social movement organizations would be wise to provide their constituents with merchandise and other "SWAG" with the logo and name of the organization. This allows organizations to either raise funds through their merchandise or simply provide awareness for the organization. This is especially important if the SMO can get a celebrity or a celebrity athlete to wear the merchandise to further boost the awareness of the organization and movement (Brockington, 2014).

Conversely, athletes can also provide SMOs with resources. Similar to resources an SMO may provide to its activists, athlete ambassadors provide Athlete Ally with credibility/legitimacy, celebrity, access to people and spaces, a social network to other 
protagonists, lived experiences through stories, and merchandise for fundraising. For many SMOs like Athlete Ally, celebrity activists can provide creditability, legitimacy, and access to otherwise inaccessible populations (Brockington, 2014; Wilson et al., 2015). Celebrities are able to accomplish this because society often holds them at a higher status by virtue of their talent and popularity (Kogen, 2015; Thrall et al., 2008). Sport celebrities occupy a similar place of being respected, especially sport celebrities engaging in activism (Wilson et al., 2015). Athlete Ally seems to be aware of this fact as they utilize their athletes often. Participants noted the importance of gaining credibility and legitimacy by having athletes support the organization. Additionally, the participants were aware that they provide access to individuals the organization alone cannot reach. An implication of this study is to highlight the importance athletes represent to a social movement organization. Sport specific SMOs and celebrities need to capitalize on the celebrity a professional, Olympic, or international athlete provides. As mentioned, celebrities (including athletes) facilitate access to people with social, political, and economic power; promote general awareness; and campaign, fundraise, and reward existing supporters (Brockington, 2014; Wilson et al., 2015). Utilizing athletes can supply these different resources and provide a large windfall for social movement organizations.

Another resource mentioned -- access to spaces and people who were previously inaccessible -- speaks to the strength of the social network athletes provide Athlete Ally. Studies show that activists are mainly recruited through their social network (Diani \& Lodi, 1988; Snow, Zurcher, \& Olson-Ekland, 1980). Athlete Ally can recruit coaches, teammates, on-field opponents, referees, and/or administrators through an athlete to help 
grow the network. This is extremely beneficial as activists are more likely to remain committed to organizations when they have social ties to members of the organization (McPherson, Popielarz, \& Drobnic, 1992). Thus, another benefit to partnering with athletes is access to more athletes and potential constituents. Social movement organizations should not only encourage mobilization for and against LGBTQ practices and policies, but also encourage athletes to speak to any teammates or someone in their network that is a protagonist to the cause. This can help grow the network of the SMO and help retain their athletes as partners.

Finally, athletes can provide the SMO with material resources for fundraising efforts. Athlete Ally not only utilizes signed merchandise like basketballs for fundraising efforts, but also offers experiences. These experiences can be playing basketball with an NBA player or soccer with a USWNT member for a financial donation. Once again, a product of the athlete's celebrity (Brockington, 2014), SMOs would be wise to utilize athletes signed merchandise or expertise in sport as a means to generate financial resources.

In addition to the resource exchanged between athletes and Athlete Ally, the study also sought to understand how Athlete Ally interacted with different governing entities. The entities were the NCAA, NBA, and U.S. Government. All three organizations represented open political systems, but the organizations differed in their relationships to Athlete Ally. The NBA represented a protagonist, the U.S. Government was, at the time of the study, an antagonist, and the NCAA acted as both a protagonist and antagonist. Theoretically speaking, political entities that are open and protagonist to the movement are more collaborative in nature than closed and antagonistic political entities (Koopmans 
\& Statham, 1999). For example, when faced with an open and protagonist political entity, Oregon LGBT SMOs opted to have closed door meetings with political actors to enact change. Facing a closed and antagonistic political entity, New York LGBT SMOs took to the streets to protest the discriminatory legislation and policy (Bernstein, 1997). Thus, it makes sense for Athlete Ally to collaborate with the NBA and NCAA (when the NCAA is a protagonist) and combat the U.S. Government and NCAA (when the NCAA is an antagonist). Activists and SMOs do not, nor should they, create strategies for engaging in activism in a vacuum (Meyer, 2004). Instead, SMOs should first understand the institutional structure (i.e. open and closed) they are attempting to mobilize either with or against. Next, the SMO should understand the configuration of actors (i.e. protagonists, antagonists, or bystanders) of the governing bodies that SMOs are trying to influence. Then, the SMO can develop effective strategies.

For the NBA and NCAA (when the NCAA is a protagonist), strategies like specific trainings for employees and administrators of the leagues, collaborating on policies, or co-hosting Pride Nights are strategies that Athlete Ally utilizes. These strategies are only possible because Athlete Ally developed a strong relationship with political actors who were open to their movement's goals. Social movement organizations can utilize this information by focusing on fostering relationships with the governing bodies they are trying to influence. These relationships can turn into collaborations to enact positive change. This happens because the governing body is in an open political system and is a protagonist to the movement (Koopmans \& Statham, 1999). This allows the SMO to work behind the scenes to enact change in an efficient manner without needing public displays of activism. 
Conversely, creating visible campaigns and marches are effective against the antagonistic governing bodies. When a political entity is open but antagonistic toward the movement, the challenger or SMO will achieve no sufficient gain. Change is possible, but at a slow manner and often times stifled by the antagonist (Koopmans \& Statham, 1999). In this instance, LGBT SMOs in particular have found success opting to create cultural acceptance of their movement by public tactics of activism (Bernstein, 1997). Athlete Ally routinely utilizes this strategy by creating campaigns where they demand changes to an anti-LGBTQ policy, practice, or legislation. These campaigns appear on the organization's website and in emails to followers, are signed by prominent athletes, and act in a petition-like manner. The organization also deploys athletes to speak out against a specific policy or practice. These strategies are often times more public than the collaborative strategies a SMO is seeking to gain cultural acceptance, which is generally a precursor to political change (Bernstein, 1997; Kriesi, 2004; Schwirian, Curry, \& Woldoff, 2001; Wilson et al., 2015). Thus, an important finding from this study is the intentional use of strategy for SMOs when interacting with sport and non-sport governing bodies. When interacting with an open and protagonist governing body, SMOs should utilize collaborative strategies. When facing an open and antagonistic entity, having public and combative strategies are more likely to lead to success for the movement.

An interesting strategy with sport-specific governing bodies, not yet identified in the broader body of SMO and SMT literature, was that Athlete Ally attempted to collaborate on policy development and best practices with the NCAA and NBA in the infancy of their relationships. This strategy was intended to influence the top of the organization, so that those pro-LGBTQ views could trickle down throughout the 
organization. While Athlete Ally still employs that strategy to a degree, the organization recognized they were not achieving their desired gains. Specifically, participants pointed to the NCAA re-awarding championships to North Carolina after a modified version of the HB2 passed. The organization, in response, created the Athletic Equality Index as a means of working from the bottom-up. The organization shifted to then include strategies of affecting the bottom of the organization, so pro-LGBTQ views would work their way up the organization. This is not just for the NCAA, but the NBA, too. For instance, Athlete Ally provides all NBA coaches and administrators with training specifically from Athlete Ally. For the NCAA, Athlete Ally uses a combative strategy and called out individual NCAA member institutions for their lack of pro-LGBTQ policies through the Athletic Equality Index. Participants noted that the NCAA was a protagonist, but did not address whether they will continue to collaborate with the NCAA as a national governing body after the NCAA re-awarded championships to North Carolina. The strategy of working from the bottom-up serves to build a foundation of future coaches, school administrators, and athletes who are accustomed to practices aiming to reduce transphobia and homophobia in sport. Athlete Ally has witnessed some success with this strategy as members noted the commitment to social issues by many members of the NBA and increasing their number of schools who are adopting pro-LGBTQ stances. While advocating for a SMO to use a bottom-up approach with sport governing bodies is risky, the strategy might be beneficial for an organization. The logic applies that creating activists and inclusion among new athletes, coaches, and administrators can help establish new paradigms over time. 
Despite being a 501(c)(3), Athlete Ally still maintains an ability to interact with the U.S. Government. Celebrity activists and athlete activists are able to reach political actors that SMOs or general activists are unable to reach (Brockington, 2014; Wilson et al., 2015). A prime example of this occurred when Athlete Ally utilized swimmer and diver Greg Louganis to gain access to meet with the governor of Indiana to prevent an anti-LBTQ bill from passing. Louganis did not meet with the governor as a member of Athlete Ally, but was able to advocate as a citizen as to the effect of the bill. Thus, utilizing athletes SMOs who partner with athletes should utilize their athletes in a similar manner.

The final research question of this study attempted to investigate how the organization creates frames and messages that resonate with their constituents and the public. Frame resonance is accomplished by ensuring the frames are credible and salient with their intended audiences (Benford \& Snow, 2000; della Porta \& Diani, 2006; Williams, 2004). Athlete Ally's strategy for creating credible and salient frames includes creating core values and a universal language, utilizing athletes' stories and hard data, having a diverse staff and a wide intersectionality of athlete ambassadors, and using sport as a vehicle for social change. Creating core values and a universal language allows the organization to mobilize under a collective identity (Dorf \& Tarrow, 2014). While the organization is not utilizing a specific script for athletes, they are guiding their activism through the use of core values and universal language. An obvious strategy, therefore, is for a SMO to create core values and a universal language. A SMO would be best suited to allow the athlete to utilize their platform (Kaufman, 2008) to speak on their experiences with the social issue, but guide the athlete with core values. 
Speaking on the experiences of the athlete, Athlete Ally utilizes athletes' stories and hard data to create empirically valid claims and messages. Athletes' stories helped build the foundation for Athlete Ally. The founder of the organization created Athlete Ally as he witnessed homophobia in sport and heard from others about the prevalence of homophobia and transphobia in sport. Athlete Ally has continued to use athlete's stories and experiences to identify what policies or practices needed to be investigated and as opportunities to engage with the public. For instance, an athlete Jess (employee) noted that an athlete in the rugby community noted that World Rugby had yet to adopt a protrans participation policy. Instead, World Rugby's policy required athletes to undergo a series of surgical, medical, and legal barriers to play rugby. As a result, Athlete Ally authored an open letter to World Rugby to change their policy. By grounding their strategies and fundraising efforts in these stories, Athlete Ally avoids the risk of failing to mobilize constituents because the activism is out of sight or too distant from the individual (McAdam, 2017). As noted above, athletes' stories allow SMOs to ground their frames in a real-life setting. This allows the organization to reach the individual and elicit an emotional response. Another strong benefit for SMOs in partnering with athletes is to utilize their stories to ground their practice in real events and reach the public.

Athlete Ally, however, has noted that their strategy is evolving to the use of hard data and statistics. This is a strategy to expand their communication efforts from a few personal stories to the entire population of the LGBTQ community via quantitative data. Quantitative data helps Athlete Ally show how transphobia and homophobia in sport may impact athletes, coaches, fans, sponsors, and other stakeholders. Further, objective data could also help Athlete Ally determine if their organization, activities, and (perhaps more 
importantly) their donors and athletes are making a positive impact on the LGBTQ and sport movement. While athletes' stories are an invaluable resource for connecting with individuals, they represent case studies by a few athletes. The use of hard facts and statistics (e.g. percentage of LGBTQ athletes who experience homophobia or transphobia in sport) can provide evidence of the overall presence and impact of transphobia and homophobia in sport. Showing the larger impact of the discriminatory practice is another powerful tool for a social movement organization. In addition, using quantitative data can provide an objective measurement tool for a social movement organization. Therefore, it would be wise for SMOs to utilize a combination of their athletes' stories and hard data and statistics to paint a complete picture of the LGBTQ and sport movement.

Another tactic Athlete Ally uses to build resonance of frames is the diversity in organizational makeup and the intersectionality of their athletes. As noted by participants, Athlete Ally is comprised of diverse individuals of different races, gender identities, sexual identities, and ages. This makeup allows the organization to be cognizant as to what frames are being sent out and how best to make those frames resonate with their constituents and the public. Having diverse identities on staff ensures the organization is accounting for different perspectives when sending out frames into political spaces (Smitton, 2017) and thus are more likely to resonate. Social movement organizations, if they do not already do so, should attempt to diversify their organizations as much as possible.

Having a diverse staff and athlete constituents allows the organization to utilize each individual's intersectionality to better the organization. The intersectionality of athlete identities, in particular,is also something important for a SMO to note. Athletes 
have different identities as they come from different geographical locations, play different sports, have different upbringings, and bring a variety of other attributes. Athletes are able to use these differing attributes to speak authentically about different issues (Carrol, 2016; Ellcessor, 2016; Huliaras \& Tzifakis, 2012). By doing so, the frames can resonate to a high degree with the public. As mentioned by the participants, Texans does not want to hear from a New York political activist when a player or coach from Texas can speak on the same issue. The latter individual has more perceived credibility to the Texas population and can articulate the salience of the issue to the public more effectively. Utilizing the intersection of identities provides the SMO with a unique perspective that can overall increase the resonance of the frames. The SMO has to know, understand, and properly deploy the athletes to best utilize their intersectionality.

Finally, Athlete Ally can build frame resonance by using the platform of sport. As participants noted, sport transcends race, religion, and "pretty much everything" because of its cultural importance. Despite sport being one of the most culturally important aspects of US culture, some may argue that sport is neutral and exists outside of the political realm (Sage, 1998). However, the prominence of athlete activism and social movement studies (Agyemang, 2011; Agyemang, Singer, \& DeLorme, 2010; Bundon \& Clarke, 2014; Coombs \& Cassilo, 2017; Frederick, Sanderson, \& Schlereth, 2017; Kaufman, 2008; Pelak, 2002; Pelak, 2005; Sanderson, Frederick, \& Stocz, 2016; Schmidt et al., 2018; Wilson et al., 2015) certainly combats that notion. Knowing that sport is not neutral, SMOs should utilize the power of sport to create change. As several participants noted, sport is a tremendous platform that reaches people that were once inaccessible. Whether it is an antagonistic government official or a moderate public that can be 
swayed, athletes and sport can reach across audiences. This is a major competitive advantage and argument for sport-specific social movement organizations. Sport specific SMOs have the ability to create substantive change for a greater movement by focusing on the movement in sport. While sport can be seen as being "fringe" or "extra" when basic civil liberties are under attack, sport specific SMOs have to clearly articulate the importance of sport and the work that the SMO accomplishes.

From a theoretical perspective, this study investigated a sport specific SMO through the lens of Social Movement Theory. The study showed the importance of both athletes and the SMO to the LGBTQ and sport movement. Both entities provide each other with resources, interact with different governing bodies, and create resonate frames in a symbiotic relationship. Social movement organizations with an expertise in sport would be wise to use the athletic environment to engage in activism. Both sport and those within sport hold a high platform in society (Kaufman, 2008; Wilson et al., 2015) and can reach traditionally inaccessible populations. It is crucially important, however, for gathering resources, interaction with political actors, and creating frames, that these SMOs partner with athletes. Athletes provide the perceived leadership (Wilson et al., 2015) and attention (Carrol, 2016) that few possess. Athletes would also wise to partner with SMOs as they provide a basis for mobilization (Caniglia \& Carmen, 2005). The support of a strong SMO provides athletes with invaluable resources that can help mitigate potential barriers of engaging in activism. When both the SMO and athlete create a mutually beneficial relationship, both have the ability to advance social movements in sport and greater society. 


\section{Future Research}

The current study was one of the first to investigate a sport specific SMO that utilizes athlete ambassadors through the lens of Social Movement Theory. The study responded to the call from Davis-Delano and Crosset (2008) who encouraged social movement research in sport to "serve social movements that they value by doing research that may help the activists to understand how their movements succeed and fail" (p. 131). Social Movement Theory provides an accurate framework for answering this call. While this study was a case study of one specific SMO, future studies should continue to seek out and collaborate with other sport specific SMOs to help gain an understanding of why sport specific movements succeed or fail. For example, other sport-related advocacy organizations, like Women's Sports Foundation, Athletes for Hope, National College Players Association, Advocates for Injured Athletes, LGBT SportsSafe, Pro Athletes Outreach, and Athletes for Animals exist. They often partner with current and former professional and collegiate athletes to advance their mission. Researchers can collaborate with these organizations, comparing and contrasting their operations and mobilization tactics using SMT, to help paint a clearer picture of activism inside the sport realm. Moreover, additional research into the subject of athlete activism is necessary for the academic discipline of sport management. Athlete activism is a continuing trend in sport (Coombs \& Cassilo, 2017). Sport organizations and organizations collaborating with sport entities need to understand how athlete activism impacts their league, teams, and personnel both on and off the playing field. For example, research shows that an athlete activist can diminish the brand image of a sponsor (Schmidt et al., 2018) and that fans will threaten to sever ties with a sport team if their players engage in activism 
(Sanderson, Frederick, \& Stocz, 2016). Additionally, researchers also need to grasp the experiences of the athletes engaging in activism, not just the organizations. Following the lead of Agyemang, Signer, and DeLorme (2010), and Kaufman and Wolff (2010), understanding the athlete's experience can allow researchers and practitioners to further understand athlete activism. More research into the impact of this new wave of activism is beneficial for the industry as a whole.

As mentioned, SMT provided a strong theoretical foundation for this study. Future research studies can and should utilize this theory as the proper framework for investigating other athlete activism related studies. For instance, utilizing Resource Management Theory, future research can compare the different resources exchanged between athletes and organizations with different sport specific social movement organizations. While the current study addressed this question for one SMO (Athlete Ally), others may exchange different resources with athletes. Additionally, future research should investigate the athletes' point of view regarding resources. This study investigated the perceived resources Athlete Ally provides athletes. However, this study was unable to get the athletes' perspective on the resources. Therefore, future researchers should investigate if athletes are actually receiving those resources or additional resources they are provided from the social movement organization. For instance, Athlete Ally may believe it provides a safe space where activism is encouraged, but is that the reality? Is that even a beneficial or necessary resource for athlete activists? Understanding these specific questions allows sport specific SMOs to determine the resources most crucial for movement success. 
Focusing on one specific resource -- social networks - also provides a wealth of opportunities for future research. Social networks are important in general activism as they lead to strengthening ties to an organization (McPherson, Popielarz, \& Drobnic, 1992) and increased opportunities to engage in more activism (della Porta \& Diani, 2006; Louis et al., 2006). Per this study, Athlete Ally provides its athlete constituents with a large social network and vice versa. The impact of that social-network on the LGBT movement (and other social movements) has yet to be examined. An investigation into how the social-network operates, via social network analysis, is a future research project that could benefit both organizations and athletes. Investigating how connected the social-network is between athletes and the organization could serve as a recruiting tool for SMOs and as an opportunity for athletes to expand their networks. Future research would be wise to study the impact of a social-network on the SMO and athletes and how both entities can use a strong social-network for engaging in activism and other manners. Another resource of interest -- support and community -- is a topic for future investigation. Specifically, what types of benefits do athletes receive from the support and community of accepted activism provided by Athlete Ally? Activism in the athletic environment receives a fair amount of criticism (Agyemang, Singer, \& DeLorme, 2010; Frederick, Sanderson, \& Schlereth, 2017; Kaufman, 2008; Sanderson, Frederick, \& Stocz, 2016). However, athletes could utilize a SMO to enter a space where there is no backlash for engaging in activism. As a result, can the athletes engage in more activism? Does their 'activist identity' (Louis et al., 2006) increase being around athletes who are also engaging in activism? Investigating the impact of the support and community could 
identify a space where athletes can increase social justice efforts as they experience positive reinforcement for their activism, not harsh criticism.

While RMT is proficient for the study of resources, it cannot be used to study the entirety of a social movement (Buechler, 1993). Thus, additional theoretical frameworks can help capture other important aspects of how SMOs engage with political institutions. Given the findings of this study, the researcher recommends continued use of Political Process Theory as it provides SMOs a framework to evaluate political institutions and determine proper strategies for interacting with said entities. For example, one of the most interesting trends reported by Athlete Ally employees was their strategy for interacting with the NCAA. Initially, the organization collaborated with the top officials at the NCAA, in hope that the pro-LGBTQ policies would trickle down to member institutions. However, the organization is shifting focus to exposing member institutions that provide significant support to LGBTQ athletes, as well as those institutions that do not. This shift represents a change in strategy as Athlete Ally hopes pro-LGBTQ policies and practices move up through coaches, athletes, and administrators. The natural future research question is which strategy is more effective - top-down policy implementation or a more grassroots approach from institutional stakeholders? Clearly, Athlete Ally feels the need to invest resources in the grassroots approach after interacting with the top of the NCAA for many years. However, given that athletes are only at the organization for four years at the most and coaches and administrators frequently switch jobs, is the grassroots approach creating sustained progress towards the organization's mission? Future research can investigate the strengths and weaknesses in each approach. 
Future research can also investigate the strategies and tactics of sport governing bodies and non-sport governing bodies. The current study investigated Athlete Ally's interaction with the NCAA, NBA, and U. S. Government. Other leagues (e.g. high school associations, National Associations of Intercollegiate Athletics, NFL, NHL, MLS, the International Olympic Committee, to name a few) could also provide unique opportunities to investigate how SMOs interact with sport governing bodies. For example, which strategies are more effective with different leagues/associations? Additionally, determining why certain strategies are more effective than others could provide SMOs with ideal practices for mobilization. Additionally, understanding exactly how these interactions with sport-related entities are similar and differ from non-sport related entities could be a site for future research. Are the tactics utilized for the NFL the same and as effective as tactics utilized for engaging with a state legislator? The current study did not seek out to compare the strategies, but determined the context and interactions with the aforementioned governing bodies. Future studies should investigate sport specific SMOs engagement with sport and non-sport governing bodies.

Additional future research can also include the effectiveness of Athlete Ally using generalizable quantitative statistics, instead of just athletes' stories for engaging with the public. Athlete Ally's initial goal was to elicit an emotional response by using the athletes' stories of facing adversity due to their LGBTQ identity. Athlete Ally switched to using hard facts as a strategy/frame for engaging with audience members. While it is unclear from this study as to why Athlete Ally switched tactics, investigation into the different responses from athletes' stories to objective facts and statistics can assist SMOs' decisions on what is the appropriate strategy to employ. Perhaps the two different 
strategies and frame types benefit from one another or particular frames resonate with different individuals.

The final tenet, Cultural Theory/Frame Analysis investigates how a SMO creates frames or messages that resonate with audiences. For a movement to gain cultural acceptance, its frames and messages must coincide with societies beliefs and values (Schwirian, Curry, \& Woldoff, 2001). The focus of this study was to investigate this issue from the perspective of the organization. Thus, this study was only able to determine how Athlete Ally perceives their messages to resonate with their audiences. A natural research question, then, includes the perspective of the audience. Do the frames created and sent out to athletes and non-athletes resonate with their intended audiences? In addition, what is the impact of using sport to reach an otherwise immovable audience? Put another way, is an individual more likely to have favorable views when from a sport-related LGBTQ frame compared to a non-sport related LGBTQ frame? The aforementioned future research study could be used to investigate the impact of using sport to create frames.

Another future research study could examine the difference in the frame sender. The credibility of the frame maker is an important component in creating a resonate frame (Benford \& Snow, 2000; Williams, 2004). As noted in the first research question, Athlete Ally helps create social media posts and other frames with their athletes. For example, Figure 2 showed the similar frame sent out by an athlete ambassador's social media account and Athlete Ally's social media account. An obvious question is: which frame is more credible to the audience? Is the celebrity activist considered more credible due to his/her status (Brockington, 2014)? Or is the organization more credible as they are a formalized organization and the basis for mobilization (della Porta \& Diani, 2006)? 
Comparing the effectiveness of the frames sent by the athlete and the organization is a future research project that can help other SMOs create resonate frames.

The structure of this study, a case study of the SMO Athlete Ally, provided a strong foundation for future research. As such, additional studies could use a similar approach for an SMO or multiple SMOs over time. Obviously, one of the limitations of a case study approach is the lack of generalizability (Flyvjerg, 2011; Snow \& Trom, 2002; Yin, 2009). However, researchers can investigate other sport-related SMOs, to help discover results that may be transferrable to other SMO contexts. Comparing and contrasting various sport specific SMOs allows for evolved tactics and, hopefully, success for movement goals. In addition, future research should investigate these SMOs over a long period of time. Participants noted the change in strategies and collaborations over the short lifespan of the organization. Investigating and researching the actual lifespan of a sport specific SMO can help determine what leads to political and cultural successes and failures. Future research would be wise to incorporate a diversity of sport specific SMOs in a longitudinal manner.

Finally, a future research study can investigate Athlete Ally's overall impact on the general LGBTQ movement. Athlete Ally operates in the LGBTQ plus sport movement, where they aim to establish pro-LGBTQ policies and practices in the athletic environment. While they do sponsor campaigns against specific legislation that is not tied to sport, the majority of their interactions are through sport and in sport. Does working through sport, however, impact the overall LGBTQ movement? Sport has the power to have a major impact on society (Wilson et al., 2015), but how much of an impact can a sport specific SMO have on a non-sport social movement? Future research should not 
only investigate sport specific social movements with a closer examination, but the impact of sport specific social movements on greater societal social movements.

\section{Conclusion}

The purpose of this study was to examine the resources exchanged between Athlete Ally and their athlete constituents, strategies for engaging with various governing bodies, and tactics for ensuring frame resonance by Athlete Ally using Social Movement Theory. The study answered the call from Davis-Delano and Crosset (2008) to engage with social movement research to assist activists in the understanding of how their movements succeed and fail. Additionally, the study aims to further the paucity of literature on athlete activism by specifically studying a sport specific social movement organization. Finally, the study highlights the ability of Social Movement Theory to apply to a sport related social movement and social movement organization.

Overall, results speak to the vast support a SMO can provide athlete activists. It should be no secret that athletes face negative consequences when engaging in activism (Agyemang, Singer, \& DeLorme, 2010; Cunningham \& Regan, 2012; Frederick, Sanderson, \& Schlereth, 2017; Kaufman, 2008; Sanderson, Frederick, \& Stocz, 2016; Schmidt et al., 2018). As such, a SMO can provide resources to help minimize the impact of those negative consequences. For instance, providing a safe space and access to other athlete activists who share their beliefs can allow an athlete to engage in activism knowing a SMO is supporting the athlete. It cannot be stated enough, SMOs provide athletes with a plethora of resources to help them engage with activism in a more efficient and effective manner. On the other side, athletes also provide SMOs with resources. Most notably, athletes provide a vast social-network for the SMO to utilize. 
From recruitment of other athlete ambassadors, like teammates, or raising awareness for the organization, athletes can be proficient resources that few other celebrities can match.

The study also investigated the interactions between Athlete Ally and the NCAA, NBA, and U. S. Government. The results overwhelmingly indicate that SMOs should engage with a protagonist in a collaborative manner and an antagonist in a combative manner. This is a consistent finding with the literature (Bernstein, 1997; Koopmans \& Statham, 1999; Kriesi, 2004). An interesting finding, and one that should be expanded upon, is the idea that Athlete Ally is shifting strategies from a top-down approach to a bottom-up approach. This may provide the SMO with an opportunity to engage with a younger and larger bystander population.

Finally, Athlete Ally creates resonate frames by providing their athletes' stories to their audiences. Celebrities have been known to use their personal stories to engage in activism in a meaningful way in the past (Ellcessor, 2016). In addition, athlete celebrities have also engaged in personal stories or struggles to help mobilize the public (Wilson et al., 2015). Thus, an organization can utilize athletes' stories as means of creating resonate and salient frames. The athletes' stories, coming from the athlete, lends credibility to the claims maker while making the issue salient and central to the audience. This is an effective strategy that, once again, speaks to the power of athletes as activists. 


\section{REFERENCES}

Adande, J. A. (2014, December 10). Purpose of "I Can't Breathe"t-shirts. Retrieved from http://www.espn.com/nba/story/_/id/12010612/nba-stars-making-statementwearing-breathe-shirts

Agyemang. K. J. (2011). Black male athlete activism and the link to Michael Jordan: A transformational leadership and social cognitive theory analysis. International Review for the Sociology of Sport, 4(47), 433-445.

Agyemang, K. J., Singer, J. N., \& DeLorme, J. (2010). An exploratory study of Black male college athletes' perceptions on race and athlete activism. International Review for the Sociology of Sport, 419-435.

Alimahomed, S. (2010). Thinking outside the rainbow: women of color redefining queer politics and identity, Social Identites, 16(2), 151-168.

Amenta, E. (2005). Political contexts, challenger strategies, and mobilization: Explaining the impact of the Townsend Plan. In D. Meyer, V. Jenness, and H. Ingram (Eds.). Routing the opposition: Social movements, public policy, and democracy (pp. 2964). Minneapolis, MN: University of Minnesota.

Anderson, E. (2011). Updating the outcome: Gay athletes, straight teams, and coming out at the end of the decade. Gender \& Society, 25, 250-268.

Andrews, A. T., \& Edwards, B. (2004). Advocacy organization in the U.S. political process. Annual Review of Sociology, 30, 479-506.

Antunovic, D. \& Hardin, M. (2012). Activism in women's sports blogs: Fandom and feminist potential. International Journal of Sport Communication, 5(3), 305-322. 
Armstrong, E. A. \& Bernstein, M. (2008). Culture, power, and institutions: A multiinstitutional politics approach to social movements. Sociological Theory, 26(1), 74-99.

Aschburner, S. (2016, July 21). NBA decides to move 2017 All-Star Game from Charlotte. Retrieved from http://www.nba.com/2016/news/features /steve_aschburner/07/21/nba-moves-2017-all-star-game-from-charlotte/

Athlete Ally. (n.d.-a). Athlete Ally. Retrieved from http://www.athleteally.org/about/

Athlete Ally. (n.d.-b). Host a party for Athlete Ally. Retrieved from https://www. athleteally.org/hosting/

Athlete Ally. (n.d.-c). Our Work. Retrieved from https://www.athleteally.org/overview/ Athlete Ally. (n.d.-d). Pro Allies. Retrieved from https://www.athleteally.org/allies/ Athlete Ally. (2016, October 17). Athlete Ally and NCLR help halt Big 12 expansion to $B Y U$. Retrieved from https://www.athleteally.org/athlete-ally-and-nclr-help-haltbig-12-expansion-byu/

Athlete Ally. (2017a). Athlete Ally Action Awards 2017. New York: Author.

Athlete Ally. (2017b). Athletic equality index. New York: Author.

Athlete Ally. (2017c). Campus chapter resource guide. New York: Author.

Badenhausen, K. (2017, June 9). Michael Jordan leas the NBA's biggest shoe deals at $\$ 110$ million this year. Retrieved from https://www.forbes.com/sites/ kurtbadenhausen/2017/06/09/the-nbas-biggest-shoe-deals/\#3120dac61520

Baxter, P., \& Jack, S. (2008). Qualitative case study methodology: Study design and implementation for novice researchers. The Qualitative Report, 13(4), 544-559. 
Bayat, A. (2005). Islamism and social movement theory. Third World Quarterly, 26(6), p. 891-908.

Benford, R. D. (2007). The college sports reform movement: Reframing the “edutainment” industry. Sociological Quarterly, 48(1), 1-28.

Benford, R. D., \& Snow, D. A. (2000). Framing processes and social movements: An overview and assessment. Annual Review of Sociology, 26, 611-639.

Bernstein, M. (1997). Celebration and suppression: The strategic uses of identity by the lesbian and gay movement. American Journal of Sociology, 103(3), 531-565.

Bernstein, M. (2003). Nothing ventured, nothing gained? Conceptualizing social movement "success" in the lesbian and gay movement. Sociological perspectives, 46(3), 353-379.

Bevington, D., \& Dixon, C. (2005). Movement-relevant theory: Rethinking social movement scholarship and activism. Social Movement Studies, 4(3), 185-208.

Blumer, H. (1951). Collective behavior. In A. M. Lee (ed.). Principles of Sociology (pp. 166-222). New York: Barnes \& Noble.

Booth, D. (1998). The race game: Sports and politics in South Africa. London: Frank Cass.

Brady, H. E., Scholzman, K. L., \& Verba, S. (1999). Prospecting for participants: Rational expectations and the recruitment of political activists. The American Political Science Review, 93(1), 153-168.

Breiger, R. L. (1974). The duality of persons and groups. Social Forces, 53(2), 181-190. Broadhurst, C. J. (2014). Campus activism in the 21st century: A historical framing. New Directions for Higher Education, 167, 3-15. 
Brockington, D. (2014). Celebrity advocacy and international development. London: Routledge.

Brockington, D., \& Henson, S. (2015). Signifying the public: Celebrity advocacy and post-democratic politics. International Journal of Cultural Studies, 18(4), 431448.

Buechler, S. M. (2004). The strange career of strain and breakdown theories of collective action. In D. A. Snow, S. A. Soule, \& H. Kriesi (Eds.), The Blackwell companion to social movements (pp. 47-66). Malden, MA: Blackwell Pub.

Buechler, S. M. (1993). Beyond resource mobilization? Emerging trends in social movement theory. The Sociological Quarterly, 34(2), 217-235.

Bundon, A., \& Clarke, L. H. (2014). Honey or vinegar? Athletes with disabilities discuss strategies for advocacy within the Paralympic movement. Journal of Sport and Social Issues, 1-20.

Bush, A., Anderson, E., \& Carr, S. (2012). The declining existence of men's homophobia in British sport. Journal for the Study of Sports and Athletes in Education, 6(1), $107-120$

Cacciola, S. (2017, June 25). At the pride parade, the N.B.A. embraces hard-won victories. Retrieved from https://www.nytimes.com/2017/06/25/sports/prideparade-nba.html

Calvo, K., \& Trujillo, G. (2011). Fighting for love rights: Claims and strategies of the LGBT movement in Spain. Sexualities, 14(5), 562-579.

Candaele, K., \& Dreier, P. (2015). Where are the jocks for justice? The Nation, 278(25), $21-24$ 
Caniglia, B. S., \& Carmin, J. (2005). Scholarship on social movement organization: Classic views and emerging trends. Mobilization: An International Journal, 10(2), 201-212.

Carrol, H. J. (2016). The present explosion of LGBT sports. Law \& Inequality: A Journal of Theory and Practice, 34(2), 499-510.

Carr, T. (2017, April 4). Athlete Ally reacts to hypocritical NCAA decision on HB2. Retrieved from https://www.athleteally.org/athlete-ally-reacts-hypocritical-ncaadecision-hb2/

Carr, T. (2018, March 22). Athlete Ally announces 2018 partnership with Major League Quidditch. Retrieved from https://www.athleteally.org/athlete-ally-announces2018-partnership-major-league-quidditch/

Carty, V. (2002). Technology and counter-hegemonic movements: The case of Nike Corporation. Social Movement Studies, 1(2), 129-144.

Chapin, A. (2017, March 11). Four decades after the Battle of the Sexes, the fight for equality goes on. Retrieved from https://www.theguardian.com/sport/2017 /mar/11/billie-jean-king-battle-of-the-sexes-tennis

Chesters, G., \& Welsh, I. (2011). Social movements: The key concepts. New York, NY: Routledge.

Conversi, D. (1990). Language or race?: The choice of core values in the development of Catlan and Basque nationalisms. Ethnic and Racial Studies, 13(1), 50-70.

Coombs, D. S. \& Cassilo, D. (2017). Athletes and/or activists: LeBron James and Black Lives Matter. Journal of Sport and Social Issues, O(0), 1-20. 
Crabtree, B. F. \& Miller, W. L. (1992). A template approach to text analysis: Developing and using codebooks. In B. F. Crabtree \& W. L. Miller (Eds.), Doing qualitative research (pp. 93-109). Newbury Park, CA: Sage.

Cress, D. M., \& Snow, D. A. (1996). Mobilization at the margins: Resources, benefactors, and the viability of homeless social movement organizations. American Sociological Review, 61(6), 1089-1109.

Creswell, J. W. (2013). Qualitative inquiry \& research design: Choosing among five approaches (3rd ed.). Thousand Oaks, CA: Sage.

Crotty, M. (1998). The foundations of social research. Thousand Oaks, CA: Sage.

Czech, M. (2016, June 9). Muhammad Ali-Muslim and activist. Retrieved from http://chicagomonitor.com/2016/06/muhammad-ali-muslim-and-activist/

Cunningham, G. B. (2015). LGBT inclusive athletic departments as agents of social change. Journal of Intercollegiate Sport, 8, 43-56.

Cunningham, G. B., \& Regan, M. R. (2012). Political activism, racial identity and the commercial endorsement of athletes. International Review for the Sociology of Sport, 47, 657-669.

Das, A. (2016, March 31). Top female players accuse U. S. Soccer of wage discrimination. Retrieved from https://www.nytimes.com/2016/04/01/sports /soccer/uswnt-us-women-carli-lloyd-alex-morgan-hope-solo-complain.html

Dator, J. (2016, June 25). NBA and WNBA stand alongside LGBT community at pride parade. Retrieved from https://www.sbnation.com/2016/6/26/12033830/nbawnba-new-york-city-pride-photos-kevin-durant-tweet 
Davis, H. L., (2010). Feeding the world a line?: Celebrity activism and ethical consumer practices from Live Aid to Product Red. Nordic Journal of English Studies, 9(3), 89-118.

Davis-Delano, L. R., \& Crosset, T. (2008). Using social movement theory to study outcomes in sport-related social movements. International Review for the Sociology of Sport, 43(2), 115-134.

della Porta, D. (2014a). Social movement studies and methodological pluralism: An introduction. In D. d. Porta (Ed.), Methodological practices in social movement research (pp. 1-21). Oxford, UK: Oxford University Press.

della Porta, D. (2014b). In-depth interviews. In D. d. Porta (Ed.), Methodological practices in social movement research (pp. 228-262). Oxford, UK: Oxford University Press.

della Porta, D., \& Diani, M. (2006). Social movements: An introduction. Malden, MA: John Wiley \& Sons.

Denzin, N. K., \& Lincoln, Y. S. (2011). Introduction: The discipline and practice of qualitative research. In N. K. Denzin \& Y. S. Lincoln (Eds.). The Sage handbook of qualitative research (pp. 1-21). Thousand Oaks, CA: Sage.

Diani, M., \& Lodi, G. (1988). Three in one: Currents in the Milan ecology movement. International Social Movement Research, 1, 103-124.

Dieter, H., \& Kumar, R. (2008). The downside of celebrity diplomacy: The neglected complexity of development. Global Governance, 14, 259-264.

Dimitrov, R. (2008). Gender violence, fan activism and public relations in sport: The case of "Footy Fans Against Sexual Assault". Public Relations Review, 34, 90-98. 
Disney, J. L., \& Gelb, J. (2000). Feminist organizational "success": The state of U.S. women's movement organizations in the 1990s. Women \& Politics, 21(4), 39-76.

Dorf, M. C., \& Tarrow, S. (2014). Strange bedfellows: How an anticipatory countermovement brought same-sex marriage into the public arena. Law \& Social Inquiry, 39(2), 449-473.

Dowd, T. (2018, January 17). Nets host second pride night. Retrieved from http:// www.nba.com/nets/community/2018/01/17/nets-host-second-pride-night

Edwards, B., \& McCarthy, J. D. (2004). Resources and social movement mobilization. In D. A. Snow, S. A. Soule, \& H. Kriesi (Eds.), The Blackwell companion to social movements (pp. 116-153). Malden, MA: Blackwell Pub.

Edwards, H. (1979). The Olympic Project for Human Rights: An assessment ten years later. The Black Scholari, 10(6-7), 2-8.

Eisenhardt, K. M. (2002). Building theories from case study research. In A. M.

Huberman \& M. B. Miles (Eds.), The qualitative researcher's companion (pp. 537). Thousand Oaks, CA: Sage.

Eisinger, P. K. (1973). The conditions of protest behavior in American cities. The American Political Science Review, 67(1), 11-28.

Ellcessor, E. (2016). "One tweet to make so much noise": Connected celebrity activism in the case of Marlee Matlin. New Media \& Society, 1-17.

Elliott, T., A., Amenta, E., \& Caren, N. (2016). Recipes for attention: Policy reforms, crises, organizational characteristics, and the newspaper coverage of the LGBT movement, 1969-2009. Sociological Forum, 31(4), 926-947. 
Ellis, R. (2017, February 10). 'Bathroom bill': NC could lose more NCAA events, sports group says. Retrieved from https://www.cnn.com/2017/02/10/us/bathroom-billnorth-Carolina-ncaa-lgbt/index.html

Engel, S. M. (2001). The unfinished revolution: Social movement theory and the gay and lesbian movement. Cambridge, UK: Cambridge University Press.

Ferree, M. M. (1992). Building social movement theory. In A. D. Morris \& C. M. Mueller (Eds.), Frontiers in social movement theory (pp. 3-25). New Haven, Conn.: Yale University Press.

Fendrich, J. M. (1977). Keeping the faith or pursuing the good life: A study of the consequences of participation in the Civil Rights Movement. American Sociological Review, 42, 144-157.

Fendrich, J. M., \& Turner, R. W. (1989). The transition from student to adult politics. Social Forces, 67(4), 1049-1057.

Flacks, R. (1967). The liberated generation: An exploration of the roots of student protest. Journal of Social Issues, 23(3), 52-75.

Frederick, E., Sanderson, J., \& Schlereth, N. (2017). Kick these kids off the team and take away their scholarships: Facebook and perceptions of athlete activism at the University of Missouri. Journal of Issues in Intercollegiate Athletics. 10, 17-34.

Flyvjerg, B. (2011). Case study. In N. K. Denzin \& Y. S. Lincoln (Eds.). The Sage handbook of qualitative research (301-317). Thousand Oaks, CA: Sage.

Gamson, J. (1995). Must identity movements self-destruct? A queer dilemma. Social Problems, 42(3), 390-407. 
Gamson, W. A. \& Modigliani, A. (1989). Media discourse and public opinion on nuclear power: A constructionist approach. American Journal of Sociology, 95(1), 1-37.

Ghaziani, A., Taylor, V., \& Stone, A. (2016). Cycles of sameness and difference in LGBT social movements. Annual Review of Sociology, 42, 165-183.

Gibbs, L. (2016, September 20). Tracking the Kaepernick effect: The anthem protests are spreading. Retrieved from https://thinkprogress.org/national-anthem-sportsprotest-tracker-kaepernick-284ff1d1ab3e/

Goffman, E. (1974). Frame analysis: An essay on the organization of experience. New York, NY: Harper \& Row.

Goodwin, J. \& Jasper, J. M. (1999). Caught in a winding, snarling vine: The structural bias of political process theory. Sociological Forum, 14(1), 27-54.

Gonyea, D. (2016, June 10). In political activism, Ali pulled no punches - and paid a heavy price. Retrieved from http://www.npr.org/2016/06/10/481523465/inpolitical-activism-ali-pulled-no-punches-and-paid-a-heavy-price

Griffin, P. \& Taylor, H. (2012). Champions of respect: Inclusion of LGBTQ studentathletes and staff in NCAA programs. Retrieved from http://www.ncaapublications.com/productdownloads/CRLGBTQ.pdf

Grossman, E. (2016, July 13). NBA stars address racial injustice, violence before ESPY awards. Retrieved from http://www.nydailynews.com/sports/basketball/nba-starsaddress-racial-injustice-violence-espy-awards-article-1.2710404

Grossman, N. (2014). What is the NBA? Marquette Sports Law Review, 25(1), 102-126.

Guba, E. G., \& Lincoln, Y. S. (1989). Fourth generation evaluation. Thousand Oaks, CA: Sage. 
Guigni, M. (2004). Social protest and policy change: Ecology, antinuclear, and peace movements in comparative perspective. Oxford, UK: Rowman \& Littlefield Publishers, Inc.

Hancock, D. R., \& Algozzine, B. (2006). Doing case study research. New York, NY: Teachers College Press.

Harvey, J., Horne, J., \& Safai, P. (2009). Afterglobalization, global social movements, and the possibility of political transformation through sport. Sociology of Sport Journal, 26, 383-403.

Hays, D. G., \& Singh, A. A. (2011). Qualitative inquiry in clinical and educational settings. New York: Guilford Press.

Heberle, R. (1951). Social movements: An introduction to political sociology. Des Moines, IA: Meredith.

Hodges, C., \& Fanning, R. (2017). Long shot: The triumphs and struggles of an NBA freedom fighter. Chicago, IL: Haymarket Books.

Huliaras, A., \& Tzifakis, N. (2012). The fallacy of the autonomous celebrity activist in international politics: George Clooney and Mia Farrow in Darfur. Cambridge Review of International Affairs, 25(3), 417-431.

Hunt, S. A., Benford, R. D., \& Snow, D. A. (1994). Identity fields: Framing processes and the social construction of movement identities. In E. Laraña, H. Johnston, \& J. R. Gusfield (Eds.), New Social Movements: From Ideology to Identity (pp. 185208). Philadelphia, PA: Temple University Press.

Kane, M. D., (2010). You've won, now what? The influence of legal change on gay and lesbian mobilization, 1974-1999. The Sociological Quarterly, 51(2), 255-277. 
Kaufman, P. (2008). Boos, bans and other backlash: The consequences of being an activist athlete. Humanity \& Society, 32, 215-237.

Kaufman, P., \& Wolff, E. (2010). Playing and protesting: Sport as a vehicle for social change. Journal of Sport and Social Issues, 34(2), 154-175.

Keck, M. E., \& Sikkink, K. (2014). Activists beyond orders: Advocacy networks in international politics. Ithaca, NY: Cornell University Press.

Kennedy, M. (2016, July 24). WNBA rescinds fines against players wearing shifts supporting shooting victims. Retrieved from http://www.npr.org/sections/thetwoway/2016/07/24/487237380/wnba-rescinds-fines-against-players-wearing-shirtssupporting-shooting-victims

Kerpelman, L. C. (1969). Student political activism and ideology: Comparative characteristics of activists and nonactivists. Journal of Counseling Psychology, $16(1), 8-18$.

Kitschelt, H. (1986). Political opportunity structures and political protest: Anti-nuclear movements in four democracies. British Journal of Political Science, 16, 57-85.

Klar, M., \& Kasser, T. (2009). Some benefits of being an activist: Measuring activism and its role in psychological well-being. Political Psychology, 30(5), 755-777

Kogen, L. (2015). For the public good or just good publicity? Celebrity diplomacy and the ethics of representation. Mass Communication and Society, 18(1), 37-57.

Koopmans, R., \& Statham, P. (1999). Ethnic and civic conceptions of nationhood and the differential success of the extreme right in Germany and Italy. In M. G. Giugni, D. McAdam, \& Tilly, C. (Eds.), How social movements matter (pp. 225-252). Minneapolis: University of Minnesota Press. 
Krane, V., \& Barger, H. (2006). Identity tensions in lesbian intercollegiate coaches. Research Quarterly for Exercise and Sport, 76(1), 67-81.

Kriesi, H. (2004). Political context and opportunity. In D. A. Snow, S. A. Soule, \& H. Kriesi (Eds.), The Blackwell companion to social movements (pp. 67-90). Malden, MA: Blackwell Pub.

Kulick, D. (2000). Gay and lesbian language. Annual Review of Anthropology, 29, 243285.

Lahausen, C. (1996). The rhetoric of moral protest: Public campaigns, celebrity endorsement, and political mobilization. Berlin: Walter de Gruyter

Le Bon, G. (1897). The crowd. London: Unwin.

Lee, Y., \& Hsieh, G. (2013, April). Does slacktivism hurt activism?: The effects of moral balancing and consistency in online activism. Paper presented at the Proceedings of the SIGCHI Conference on Human Factors in Computing Systems. Paris, France.

Lim, M. (2013). Many clicks but little sticks: Social media activism in Indonesia. Journal of Contemporary Asia, 43(4), 636-657.

Louis, W. R., Amiot, C. E., Thomas, E. F., \& Backwood, L. (2016). The "activist identity" and activism across domains: A multiple identities analysis. Journal of Social Issues, 72(2), 242-263.

Lynch, A. (2016, February 10). Kobe confirms he'll get the Jordan treatment from Nike after retirement. Retrieved from http://www.foxsports.com/nba/story/kobebryant-los-angeles-lakers-nike-signature-shoes-michael-jordan-retirement-12-13xii-xiii-021016 
Macur, J. (2014, June 24). U.S. Women's soccer stars take lead on risks of heading. Retrieved from https://www.nytimes.com/2014/06/25/sports/worldcup/uswomens-soccer-stars-take-lead-on-risks-of-heading.html

Maese, R. \& Babb, K. (2015, November 8). Missouri football players threaten to boycott season amid racial tension. Retrieved from https://www.washingtonpost.com /sports/missouri-football-players-threaten-to-boycott-season-amid-racialtension/2015/11/08/5c11c456-8641-11e5-9a07-453018f9a0ec_story.html?utm _term=.ab011b69d7c0

Marx, K., \& Engels, F. (2002). The communist manifesto. New York: Penguin.

Mason, M. (2010). Sample size and saturation in phd studies using qualitative interviews. Forum: Qualitative Social Research, 11(3).

McAdam, D. (1986). Recruitment to high-risk activism: The case of Freedom Summer. American Journal of Sociology, 92(1), 64-90.

McAdam, D. (1989). The biographical consequences of activism. American Sociological Review, 54, 744-760.

McAdam, D. (1992). Gender as a mediator of the activist experience: The case of Freedom Summer. American Journal of Sociology, 97(5), 1211-1240.

McAdam, D. (1999). Political process and the development of black insurgency, 19301970 ( $5^{\text {th }}$ ed.). Chicago, IL: University of Chicago Press.

McAdam, D. (2017). Social movement theory and the prospects for climate change activism in the United States. Annual Review of Political Science, 20, 189-208.

McAdam, D., Tarrow, S., \& Tilly, C. (2001). Dynamics of Contention. Cambridge: Cambridge University Press. 
McCarthy, J. D., \& Zald, M. N. (1977). Resource mobilization and social movements: A partial theory. The American Journal of Sociology, 82(6), 1212-1241.

McCracken, G. (1988). The long interview. London: Sage.

McDonnell, M., King, B., G., \& Soule, S., A. (2015). A dynamic process model of private politics: Activist targeting and corporate receptivity in social challenges. American Sociological Review, 80(3), 654-678.

McDonogh, M. O. (2011). The case of the Women's United Soccer Association (Unpublished doctoral dissertation). University of Louisville, Louisville.

McNamee, S. J., \& Miller, R. K., Jr. (2004). The meritocracy myth. Lanthan, MD: Rowman \& Littlefield.

McPherson, J. M., Popielarz, P. A., \& Drobnic, S. (1992). Social networks and organizational dynamics. American Sociological Review, 75(2), 153-170.

Meyer, D. S. (2004). Protest and political opportunities. Annual Review of Sociology, 30, $125-145$.

Miceli, M. S. (2005). Morality politics vs. identity politics: Framing processes and competition among Christian right and gay social movement organizations. Sociological Forum, 20(4), 589-612.

Minkoff, D. C. (2002). Macro-organizational analysis. In B. Klandermans \& S. Staggenbord (Eds.), Methods of social movement research (pp. 260-287). Minneapolis, MN: University of Minnesota Press.

Mueller, C. M. (1992). Building social movement theory. In A. D. Morris \& C. M. Mueller (Eds.), Frontiers in social movement theory (pp. 3-25). New Haven, Conn.: Yale University Press. 
NBA. (2012). Constitution and by-laws of The National Basketball Association.

Retrieved from http://prawfsblawg.blogs.com/files/221035054-nba-constitutionand-by-laws.pdf

NCAA. (2016, September 12). NCAA to relocate championships from North Carolina for 2016-2017. Retrieved from http://www.ncaa.org/about/resources/mediacenter/news/ncaa-relocate-championships-north-Carolina-2016-17

NCAA. (n.d.-a). Board of Governors Retrieved from http://web1.ncaa.org/committees/ committeesroster.jsp?CommitteeName $=\mathrm{EXEC}$

NCAA. (n.d.-b). LGBTQ Resources. Retrieved from http://www.ncaa.org/about /resources/inclusion/lgbtq-resources

National Center for Transgender Equality (n.d.). Trump's record of action against transgender people. Retrieved from https://transequality.org/the-discriminationadministration

Nicodemo, A. (2017, April 4). The NCAA has officially sold out the LGBT community. Retrieved from https://www.outsports.com/2017/4/4/15178008/ncaa-hb2-lgbtreturn

Oberschall, A. (1973). Social conflict and social movements. Englewood Cliffs, NJ: Prentice-Hall, Inc.

Oliver, P. E., \& Marwell, G. (1992). Mobilizing technologies for collective action. In A. D. Morris \& C. M. Mueller (Eds.), Frontiers in social movement theory (pp. 251272). New Haven, Conn.: Yale University Press.

Olson, M. (1965). The logic of collective action. Cambridge, MS: Harvard University Press. 
Orkand, B. (2017, June 27). 'I ain't got no quarrel with them vietcong'. Retrieved from https://www.nytimes.com/2017/06/27/opinion/muhammad-ali-vietnam-war.html

Owen, T. (2010, April 29). NCAA elects Mark Emmert as new president. Retrieved from https://onwardstate.com/2010/04/29/ncaa-elects-mark-emmert-as-new-president/

Panis, K., Van Den Bulck, H. (2012). Celebrities' quest for a better world. Jovnost - The Public: Journal of the European Institute for Communication and Culture, 19(3), $23-42$.

Park, R. E. \& Burgess, E. W. (1921). Introduction to the science of sociology. Chicago, IL: University of Chicago Press.

Patton, M. Q. (2015). Qualitative evaluation and research methods (4th ed.). Thousand Oaks, CA: Sage.

Pelak, C. F. (2002). Women's collective identity formation in sports. A case study from women's ice hockey. Gender \& Society, 16(1), 93-114.

Pelak, C. F. (2005). Athletes as agents of change: An examination of shifting race relations within women's netball in post-apartheid South Africa. Sociology of Sport Journal, 21, 59-77.

Pew Research Center (2017, June 26). Changing attitudes on gay marriage. Retrieved from http://www.pewforum.org/fact-sheet/changing-attitudes-on-gay-marriage/

Pichardo, N. A. (1997). New social movements: A critical review. Annual Review of Sociology, 23, 411-430.

Powell, S. (2008) Souled out? Ho w Blacks are winning and losing in sports. Champaign, IL: Human Kinetics.

Principle 6 (n.d.). What is principle 6? Retrieved from http://www.principle6.org/ 
Ross Initiative in Sports for Equality. (2017). From protest to progress: Athlete activism in 2016. Retrieved from http://www.risetowin.org/activismreport2016

Renn, K. A. (2010). LGBT and Queer research in higher education: The state and status of the field. Educational Researcher, 39(2), 132-141.

Sage, G. H. (1998). Power and ideology in American sport: A critical perspective (2nd ed.). Champaign, IL: Human Kinetics Press.

Sanchez, M. (2017, May 5). Girl Scouts unfairly targeted in debate over abortion and contraception. Retrieved from http://www.chicagotribune.com/news/columnists /sns-201705051202--tms--msanchezctnms-a20170505-20170505-column.html

Sanderson, J., Frederick, E., \& Stocz, M. (2016). When athlete activism clashes with group values: Social identity threat management via social media. Communication and Society, 19(3), 301-322.

Sartore-Baldwin, M. (2012). Lesbian, gay, bisexual and transgender athletes in sport. Journal for the Study of Sports and Athletes in Education, 6(1), 141-152.

Sartore, M. L., \& Cunningham, G. B. (2009). The lesbian stigma in the sport context: Implications for women of all sexual orientations. Quest, 61, 289-305.

Schmidt, S. H., Shreffler, M. B., Hambrick, M. E., \& Gordon, B. S. (2018). An examination on activism effort and cause and purchase intent. Sport Marketing Quarterly, 27, 31-43.

Schmittel, A., \& Sanderson, J. (2015). Talking about Treyvon in 140 characters: Exploring NFL players' tweets about the George Zimmerman verdict. Journal of Sport and Social Issues, 1-14. 
Schwandt, T. A. (2000). Three epistemological stances for qualitative inquiry. In Denzin, N. K., \& Lincoln, Y. S. (Eds.), The handbook of qualitative research (pp. 189213). Thousand Oaks, CA: Sage.

Schwartz, M., \& Paul, S. (1992). Building social movement theory. In A. D. Morris \& C. M. Mueller, (Eds.), Frontiers in social movement theory (pp. 3-25). New Haven, Conn.: Yale University Press.

Schwirian, K. P., Curry, T. J., \& Woldoff, R. A. (2001). Community conflict over arena and stadium funding: Competitive framing, social action, and the socio-spatial perspective. Sociological Focus, 34(1), 1-20.

Scott, R., W. (1981). Organizations: Rational, natural and open system. Englewood Cliffs, NJ: Prentice Hall.

Shuster, R. (2013, May 22). Billie Jean King: Tennis star least of her important roles. Retrieved from https://www.usatoday.com/story/sports/2013/05/22/billie-jeanking-icons-innovators-world-team-tennis-womens-rights/2159071/

Simmel, G. (1955). Conflict and the web of group affiliations. New York: Free Press. Simonson, P. (2001). Social noise and segmented rhythms: News, entertainment, and celebrity in the crusade for animal rights. The Communication Review, 4, 399420.

Smelser, N. J. (2011). Theory of collective behavior. New Orleans, LA: Quid Pro Books. Smith, E. (2010). Sociology of sport and social theory. Champaign, IL: Human Kinetics. Smith, T., \& Steele, D. (2008). Silent gesture: the autobiography of Tommie Smith. Philadelphia, PA: Temple University Press. 
Smitton, B. (2017). The LGBT movement inside the United States government: Analyzing social movement networks in political spatialities. Journal of Young Investigators, 33(5), 108-121.

Smolicz, J. J. (1988). Tradition, core values and intercultural development in plural societies. Ethnic and Racial Studies, 11(4), 387-410.

Snow, D. A., Soule, S. A., \& Kriesi, H. (2004). Mapping the terrain. In D. A. Snow, S. A. Soule, \& H. Kriesi (Eds.), The Blackwell companion to social movements (pp. 317). Malden, MA: Blackwell Pub.

Snow, D. A., Rochford, E. B., Worden, S. K., \& Benford, R. D. (1986). Frame alignment processes, micromobilization, and movement participation. American Sociological Review, 51(4), 464-481.

Snow, D. A. \& Benford, R. D. (1988). Ideology, frame resonance, and participant mobilization. International Social Movement Research, 1, 197-218.

Snow, D. A., \& Trom, D. (2002), The case study and the study of social movement. In B. Klandermans, \& S. Staggenborg (Eds.), Methods of social movement research (pp.146-172). Minneapolis: University of Minneapolis Press.

Snow, D. A., Zurcher, L. A., \& Ekland-Olson, S. (1980). Social networks and social movements: A microstructural approach to differential recruitment. American Sociological Review, 45(5), 787-801.

Tarrow, S. (1998). Power in movement: Social movements, collective action, and politics. New York: Cambridge University Press.

Tilly, C., \& Wood, L. J. (2013). Social movements 1768-2012 (3rd ed.). Boulder, CO: Paradigm Publishers, LLC. 
Thrall, A., T., Lollio-Fakhreddine, J., Berent, J., Donnelly, L., Herrin, W., Paquettte, Z.,... Wyatt,. A. (2008). Star power: Celebrity advocacy and the evolution of the public sphere. The International Journal of Press/Politics, 13(4), 362-385.

Turner, R. H. \& Killian, L. M. (1972). Collective behavior (2nd ed.). Englewood Cliffs, NJ: Prentence-Hall, Inc.

Van Stekelenburg, J., \& Roggeband, C. (2013). Introduction: The future of social movement research. In J. Van Stekelenburg, C. Roggeband, \& B. Klandermans (Eds.), The future of social movement research: Dynamics, mechanisms, and processes (xi-xxii). Minneapolis, MN: University of Minnesota Press.

Vega, M. (2015, April 16). Big changes for Boston Marathon's wheelchair division. Retrieved from https://www.bostonglobe.com/sports/2015/04/16/big-changeshave-arrived-wheelchair-divisions/ilwQ6lzj988ZSHwVNzdzpO/story.html

Washington, J., \& Evans, N. (1991). Becoming an ally. In N. Evans \& V. Wall (Eds.), Beyond tolerance: Gays, lesbians, and bisexuals on campus (pp. 195-204.

Alexandria, VA: American College Personnel Association.

Wheeler, R. T. (2009). Nonprofit advertising: Impact of celebrity connection, involvement and gender on source credibility and intention to volunteer time or donate money. Journal of Nonprofit \& Public Sector Marketing, 21(1), 80-107.

Wheeler, M. (2011). Celebrity diplomacy: United Nations' goodwill ambassadors and messengers of peace. Celebrity Studies, 2(1), 6-18.

White, D. W., Goddard, L., \& Wilbur, N. (2009). The effects of negative information transference in the celebrity endorsement relationship. International Journal of Retail \& Distribution Management, 37(4), 322-335. 
Williams, R. H. (2004). The cultural context of collective action: Constraints, opportunities, and the symbolic life of social movements. In D. A. Snow, S. A. Soule, \& H. Kriesi (Eds.), The Blackwell companion to social movements (pp. 91115). Malden, MA: Blackwell Pub.

Wilson, B., van Luijk, N., \& Boit M. K. (2015). When celebrity athletes are 'social movement entrepreneurs': A study of the role of elite runners in run-for-peace event in post-conflict Kenya in 2008. International Review for the Sociology of Sport, 50(8), 929-957.

Wiltfang, G. L., \& McAdam, D. (1991). The costs and risks of social activism: A study of the Sanctuary Movement activism. Social Forces, 69(4), 987-1010.

Winge, T. M. (2008). "Green is the new black": Celebrity chic and the "Green" commodity fetish. Fashion Theory, 12(4), 511-524.

Waldron, T. (2014, January 7). Where did all the activist athletes go? Retrieved from https://thinkprogress.org/where-did-all-the-activist-athletes-go-be6e62592e9e

Washburn, G. (2016, July 19). The activist athlete is revived. Retrieved from https://www.bostonglobe.com/sports/celtics/2016/07/29/the-activist-athleterevived/psAkjM2KcK1zm00M2seNvL/story.html

Wyche, S. (2016, August 27). Colin Kaepernick explains why he sat during national anthem. Retrieved from http://www.nfl.com/news/story/0ap3000000691077 /article/colin-kaepernick-explains-why-he-sat-during-national-anthem

Yin, R. K. (2009). Case study research: Deign and method (4th ed.). Thousand Oaks, CA: Sage. 
Zald, M. N., \& Ash, R. (1966). Social movement organizations: growth, decay, and change. Social Forces, 44(3), 327-341.

Ziegler, C. (2016, September 13). NCAA must kick out BYU and anti-gay members, or North Carolina move is meaningless. Retrieved from https://www.outsports.com /2016/9/13/12905930/byu-ncaa-north-Carolina-gay-lgbt 


\section{Appendix A - Interview Guide}

\section{General Introduction Questions:}

1) Tell me a bit about yourself.

a. Tell me about your experiences within sport (probe)

2) How did you get involved with Athlete Ally?

3) What was your inspiration in working with Athlete Ally?

\section{Resource Mobilization Theory Questions:}

1. What are the resources Athlete Ally provides its athlete ambassadors?

a. What are tangible resources (physical, touchable assets, money, signs)? (probe)

b. What are intangible resources (non-physical assets, credibility, legitimacy)? (probe)

2. What are resources athlete ambassadors provide Athlete Ally?

a. What are tangible resources (physical, touchable assets, money, signs)? (probe)

b. What are intangible resources (non-physical assets, credibility, legitimacy)? (probe)

\section{Political Process Theory}

1. Politics play a role sport, state and federal law, how does Athlete Ally work with political entities?

a. Focusing on the NCAA, how does Athlete Ally work with the NCAA? (probe)

b. Focusing on the Professional leagues like the NBA, WNBA, how does Athlete Ally work with those leagues? (probe)

c. Now expanding to the United States government, how does Athlete Ally work with those leagues? (probe)

\section{Cultural/Frame Analysis}

We are going to talk about the resonance of Athlete Ally collective action frames. Collective action frames are defined as "action-oriented sets of beliefs and meanings that inspire or legitimate the activities and campaigns of a social movement organization (Benford \& snow, 2000, p. 614). Resonance refers to the credibility and importance of the frames. So, we are looking at the credibility and importance of Athlete Ally's beliefs and meanings.

1. Focusing on credibility, how does Athlete Ally maintain their beliefs and meanings towards the world in a credible way? (probe)

a. How does Athlete Ally maintain consistency in their beliefs and messages?

b. How does Athlete Ally ensure their statements to the public are culturally relevant?

c. How does Athlete Ally judge credibility of the spokespeople when partnering with athletes?

2. Moving to importance, how does Athlete Ally make their beliefs and meanings important to those who the organization is trying to impact? (probe)

a. How does Athlete Ally utilize make claims relevant to the lives you are trying to impact? 
b. How does Athlete Ally ensure their beliefs and meanings are personal to the targets you try to mobilize (other athletes, supporters, donors)?

\section{Demographic questions}

To which gender identity do you most identify? M__ F__ Other___ Prefer not to answer

Sexual Identity: LGBT__ Non_LGBT____ Prefer not to answer:

Employment Status: Employed___ Unemployed: ___ Retired: ___ Student:

Race/Ethnicity: Asian___ Black__ Hispanic___ American Indian/Alaska Native Native Hawaiian/Other Pacific Islander White

Age: $18-25 \_26-33 \_34-41 \_42-49 \_50+$

Relationship Status: Single___ Partnered___ Married ___ Divorced

Widowed

Parental Status: No children___ One child___ Two or more children 


\title{
CURRICULUM VITAE
}

\section{EDUCATION}

\author{
Samuel H. Schmidt
}

Ph.D. University of Louisville

Educational Leadership, Evaluation and

Organizational Development

Specialization: Sport Administration

Dissertation: A qualitative case study examination of Athlete Ally using Social Movement Theory (Chair: Dr. Meg G. Hancock)

M.S. University of Louisville

2014

Sport Administration

\section{B.S. University of Wisconsin-La Crosse}

2013

Sport Management Major

Business Administration Minor

\section{Current Academic Position}

Term Faculty Member, Sport Administration (August 2016 to present)

Classes taught include:

- SPAD 180 - The Sport Spectator Experience

- SPAD 281 - Principles of Sport Management (online and in-class)

- SPAD 382 - Organizational Behavior in Sport

- SPAD 401 - Career Development in Sport (practicum)

- SPAD 402 - Internship in Sport Administration

- SPAD 490 - Senior Seminar (online)

- SPAD 571 - Sport for Development and Peace (elective)

Additional program responsibilities:

- Serve as faculty co-advisor for Sport Administration Association (student organization of 70+ students/year)

- Oversee between 15-20 interns per semester for SPAD 402, Internship in Sport Administration

- Liaison, Central High School Sport Marketing magnet and dual credit partnership 
- Coordinator, online SPAD master's program

- Member, Health and Sport Sciences Student Engagement Committee

- Member, SPAD marketing committee

- Member, SPAD master's admissions committee

\section{RESEARCH}

\section{REFEREED PUBLICATIONS}

Frederick, E. L., Hambrick, M. E., Schmidt, S. H., \& Shreffler, M. B. (2019). Queue the drama: Netflix's Last Chance $U$ and the portrayal of myths in sport films and documentaries. Journal of Sports Media.

Schmidt, S. H., Shreffler, M. B., Hambrick, M. E., \& Gordon, B. S. (2018). An examination of activism effort and cause and purchase intent. Sport Marketing Quarterly, 27(1), 31-43.

Shreffler, M. B., Schmidt, S. H., \& Weiner, J. (2018). The importance of sales training in career preparation: An examination of sales curricula in sport management education. Sport Management Education Journal, 12(1), 15-25.

Shreffler, M., Hancock, M. G., \& Schmidt, S. H. (2016). Self-representation of female athletes: A content analysis of athlete avatars. International Journal of Sport Communication, 9(4), 460-475.

Hums, M. A., Schmidt, S. H., Wolff, E., \& Novak, A. (2016). Universal Design Moving the Americans with Disability Act from access to inclusion. Journal of Legal Aspects of Sport, 26(1), 36-51.

Shreffler, M. B., Hancock, M. G., \& Schmidt, S. H. (2015). Organizational representation through Twitter: An examination of the WNBA. Global Sports Business Journal, 3(3), 42-52.

\section{BOOKS, BOOK CHAPTERS, \& CASE STUDIES}

Schmidt, S. H. (April, 2016). Athletes and social responsibility. In G. Presley, Shreffler, M. B., Schmidt, S. H., \& Hancock, M. G. (Eds.) Ethical Issues in Sport. Dubuque, IA: Kendall Hunt.

Schmidt, S. H. (April, 2016). Sport and technology. In G. Presley, Shreffler, M. B, Schmidt, S. H., \& Hancock, M. G. (Eds.) Ethical Issues in Sport. Dubuque, IA: Kendall Hunt.

Schmidt, S. H. (April, 2016). Power and politics in sport. In G. Presley, Shreffler, M. B, Schmidt, S. H., \& Hancock, M. G. (Eds.) Ethical Issues in Sport. Dubuque, IA: Kendall Hunt. 
Shreffler, M. B., Presley, R., \& Schmidt, S. (2015). Getting clipped: An evaluation of crisis management and the NBA response to the Donald Sterling incident. Case Studies in Sport Management, 4.

\section{RESEARCH IN PROGRESS}

Schmidt, S. H., Frederick, E. L., Pegoraro, A., \& Spencer, T. C. (in review as of April, 2018). An analysis of Kaepernick, Rapinoe, and the National Anthem protests. Submitted to Communication and Sport.

Hambrick, M. E., Schmidt, S. H., \& Cintron, A. M. (in review as of March, 2018). Using recreational running training groups as a constraint negotiation strategy: A social network analysis. Submitted to Managing Sport and Leisure.

Shreffler, M. B., Schmidt, S. H., \& Weiner, J. (in review as of October, 2017). Motivations for Twitter use: An examination of intercollegiate athletes through impression management. Submitted to Journal of Issues in Intercollegiate Athletics.

Schmidt, S. H., \& Hancock, M. G. (data collection in progress). An examination into retention tactics employed by a sport advocacy organization.

Schmidt, S. H., Hancock, M. G., Hums, M. A., Alagaraja, M., \& Frederick, E. L. (data collection in progress). A qualitative case study examination of athlete ally using Social Movement Theory.

\section{SCHOLARLY PRESENTATIONS}

Schmidt, S. H., Frederick, E. L., Pegoraro, A., \& Spencer, T. C. (2017, June). An analysis of Kaepernick, Rapinoe, and the National Anthem protests. Presented at the 2017 North American Society for Sport Management conference (NASSM), Denver, CO.

Schmidt, S. H., Shreffler, M. B., \& Hambrick, M. E. (2016, November). Good guy, good buy: An experimental look at activism and brand image/purchase intent. Presented at the 2016 Sport Marketing Association conference (SMA), Indianapolis, IN.

Shreffler, M. B., Schmidt, S. H., \& Paras, M. (2016, June). Need for experiential learning in career preparation: An examination of sales training in sport administration education. Presented at the 2016 North American Society for Sport Management conference (NASSM), Orlando, FL.

Hums, M. A., Schmidt, S. H., Novak, A, \& Wolff, E. (2016, February). Universal Design-Moving the Americans with Disabilities Act from access to inclusion. Presented at the 2016 Sport and Recreation Law Association conference (SRLA), New Orleans, LA. 
Schmidt, S. H., Levine, J., \& Hanna, C. (2016, February). Exploring a New World: An introduction and review of the legal concerns of eSport. Presented at the 2016 Sport and Recreation Law Association conference (SRLA), New Orleans, LA.

Schmidt, S. H. (2015, November). \#ICantBreathe and \#Ferguson: An investigation of social activism by athletes. Presented at the 2015 North American Society for the Sociology of Sport conference (NASSS), Santa Fe, NM.

Schmidt, S. H. (2015, October). Motivations for eSport consumption: A road map for sports online spectating. Presented at the 2015 Sport Marketing Association conference (SMA), Atlanta, GA.

Shreffler, M. B., Schmidt, S. H., \& Presley, G. (2015, October). An examination of college athletes through impression management. Presented at the 2015 Sport Marketing Association conference (SMA), Atlanta, GA.

Schmidt, S. H. (2015, March). A new challenger approaches: eSport's effect on traditional sports. Presented at the annual conference of the Spring Research conference at the University of Louisville, Louisville, KY.

Svensson, P., \& Schmidt, S. H. (2015, March). Opportunities and challenges for athletes to promote social change: A case study of the \#LGBTSportsChat. Presented at the annual Ali Center Athletes and Social Change Forum conference, Louisville, KY.

\section{FUNDING}

Schmidt, S. H. (2017) North American Society for Sport Management Doctoral Research Grant. Grant intended to provide doctoral students with support for research projects in the amount of $\$ 1,593$. Funded

Schmidt, S. H. (2015) University of Louisville International Service Learning Program Award. Funded by the University of Louisville International Service Learning Program for travel to Trinidad and Tobago for service learning course in the amount of $\$ 700$.

\section{Funded}

Schmidt, S. H. (2014) Sport Administration Association Award. Funded by the University of Louisville Sport Administration Association for travel to Trinidad and Tobago for service learning course in the amount of \$200. Funded

Schmidt, S. H. (2014) College of Education and Human Development Graduate Student Registration Award. Funded by the University of Louisville College of Education and Human Development in the amount of $\$ 55$. Funded 


\section{TEACHING}

\section{UNDERGRADUATE COURSES}

SPAD 180 - The Sport Spectator Experience (Spring 2018)

Bachelors Level: This course presents an overview of the sport industry from the perspective of the fan/spectator.

SPAD 281 - Principles of Sport Administration (Online Fall 2015, 2016, 2017, Spring 2018; In-Class Spring 2017)

Bachelors Level: This course is designed to promote principles and theory of administration and management as they apply to the administration and management of sport, fitness, leisure and recreation services, and programs.

SPAD 382 - Organizational Behavior in Sport (Spring 2016, 2017)

Bachelors Level: This course is designed to expand student's understanding of various management theories, research and their application to sport organization and administration.

SPAD 401 - Career Development in Sport Administration (Fall 2016, Spring 2017, Fall 2017)

Bachelors Level: This course is designed to provide the student an orientation of the professional careers within the sport industry. The course is designed to prepare the student for an internship or full-time employment with a sport organization.

SPAD 402 - Internship in Sport Administration (Fall 2016, Spring 2017, Fall 2017)

Bachelors Level: An individually arranged course that combines work experience with a related academic or creative project.

SPAD 490 - Senior Seminar in Sport Business (Spring, 2018 online)

Bachelors Level: The course will serve to prepare students for careers in the sport industry through analysis of sport industry segments, critical examination of case studies, and professional development.

SPAD 571 - Sport for Development and Peace (Fall 2016, 2017)

Bachelors Level: This course will introduce students to sport for social change, often referred to as Sport-for-Development-and-Peace. Through this class, students will develop practical and theoretical knowledge of this field by learning 
about key issues and concepts. The goal of this class is to help students understand their position within society as sport managers and athletes by encouraging self-reflection and studying past deeds of athletes and sport managers who have used their platform given to them by sport to benefit society.

\section{GUEST LECTURES}

- SPAD 635 - Research Methods in Sport Administration, Fall 2016, University of Louisville, Conducting a literature review

- ESS 307 - Sport Leadership and Governance, Spring 2016, Manchester University, Current issues with community and youth sport-eSports

- SPAD 382 - Organizational Behavior in Sport, Fall 2015, University of Louisville, Reward systems

- SPAD 390 - Sport Governance, Fall 2015, University of Louisville, Professional individual sport

- SPAD 383 - Sport Marketing, Summer 2015, University of Louisville, Sales in sport management

- SPAD 401 - Career Development in Sport, Summer 2015, University of Louisville, Resources for internship and students and the interview process

- SPAD 402 - Internship in Sport Management, Summer 2015, University of Louisville, Benefits and goals of an internship for employers and students

- SPAD 382 - Organizational Behavior in Sport, Spring 2015, University of Louisville, Motivation and satisfaction

- SPAD 383 - Sport Marketing, Spring 2015, University of Louisville, Sport sponsorship

- SPAD 382 - Organizational Behavior in Sport, Fall 2014, University of Louisville, Functions of sport managers

\section{SERVICE}

\section{COLLEGE of EDUCATION \& HUMAN DEVELOPMENT SERVICE}

Spring Research Conference Planning Committee

Event and Facility Chair

$2017-2018$

\section{HEALTH \& SPORT SCIENCES DEPARTMENT}


Health and Sport Sciences Student Engagement Committee

Committee Member

2017-2018

Sport Administration Tenured/Tenure-Track Faculty Search

Student Representative

Sport Administration Master's Admissions Committee

Committee Member

$2015-2018$

Sport Administration Association, University of Louisville

Advisor

2016-2018

Executive Board

2013-2015

Conversations with Champions, University of Louisville

Committee Member

2014-2015

SPAD Speaker Summit, University of Louisville

Committee Member

2013-2014

Sports Administration Marketing Committee, University of Louisville Member

2013-2014

\section{PROFESSIONAL SERVICE}

North American Society for Sport Management (NASSM)

Abstract Reviewer

Rowman \& LIttlefield Publisher

Invited Book Prospectus Reviewer

2017

International Journal of Exercise Science

Invited Reviewer

North American Society for Sport Management (NASSM)

Conference Moderator

2016 North American Society for Sport Management (NASSM)

Conference Moderator

2016 Sport Recreational and Law Association (SRLA)

Conference Moderator

3rd Annual Ali Center Athletes and Social Change Forum

Conference Moderator 


\section{COMMUNITY SERVICE}

IRONMAN Louisville

Volunteer Captain

Central High School and University of Louisville Partnership Guest Lecturer

- SWOT analysis

- Sales and Promotion

Chase Minnifield Football Camp, Lexington, KY

Operations and Classroom Assistant

Louisville Catholic Sports Athletic Association, Louisville, KY

Assistant Tennis Tournament Director

Kentucky Derby Festival Marathon and miniMarathon, Louisville, KY Operations Volunteer

\section{PROFESSIONAL DEVELOPMENT WORKSHOPS}

Attended workshops presented by the Delphi Center for Teaching and Learning:

- Building your Teaching Philosophy

- Dissertation Boot camp

- Rolling in the Deep: Thinking deeply and critically about diversity in your classroom

- Literature search for a literature review: Using the library and other resources to find literature for a literature review

- Delphi U Principles of Online Course Design

- Dine and Discover - Collect and Use Feedback from your students: Do you know what your students know?

\section{SPORT INDUSTRY EXPERIENCE}

Bellarmine University, Louisville KY

2014-2018

Sport Information Intern/Web-Streaming Director

- Maintain and update Bellarmine Athletic Department website

- Create athletic style guide for appropriate Bellarmine University logo branding

- Create programs for upcoming events using Adobe Photoshop and Adobe InDesign

- Author two pre-game articles are sports for webpage use

- Operate live streaming program production truck for GLVC men's and women's home basketball, men's and women's soccer, volleyball and field hockey games, and NCAA basketball games 
- Manage Facebook (4.2K followers) and Twitter (5K followers) accounts, upload clips, and game summaries during and after live broadcasts

PGA of America, Valhalla Golf Club, Louisville, KY

Guest Service Representative

- Oversaw guest services for 10 corporations and over 100 clients

- Prepared and organized 6 hospitality tents each day for client usage

- Enforced event rules created by the PGA of America

- Welcomed and checked in clients to the hospitality village

Kentucky Derby, Churchill Downs, Louisville KY

Social Media Specialist

- Communicated with followers of the Churchill Downs Twitter account to enhance community outreach

- Managed sponsorship activation activity for Churchill Downs Twitter account $(65,000+$ followers $)$

- Promoted and enhanced image for 11 Taste of Kentucky Derby Sponsors

University of Louisville, Louisville KY

Facilities and Game Operations Volunteer Assistant

- Coordinated logistics for men's and women's soccer, basketball, and football home games

- Coordinated logistics for AAC Conference and NCAA tournament games

- Assisted with multi-million dollar athletic budget

- Supervised janitorial and security staff at athletic events

La Crosse Loggers, La Crosse, WI

2012-2013

Ticket Sales Coordinator

- Cold called over 400 former and potential customers with special ticket packages

- Interacted and managed all 1,000 season ticket holders

- Assisted with game day operations and promotions on field and in community

- Documented ticket sales and attendance for over 3,000 spectators each game day

- Trained and supervised 5 interns on ticket operations

\section{HONORS AND AWARDS}

University of Louisville CEHD Banner Bearer 2018

University of Louisville CEHD Outstanding Graduate 2018

University of Louisville CEHD Outstanding Graduate 2015

PROFESSIONAL AFFILIATIONS 
North American Society for the Sociology of Sport

Member

2016-Present

North American Society for Sport Management Member

2015-Present

Sport Marketing Association

Member

2015-Present 